Portland State University

PDXScholar

1976

\title{
Social problems and collaborative planning: toward a theory and model of social planning
}

Marjorie M. Ille

Portland State University

Follow this and additional works at: https://pdxscholar.library.pdx.edu/open_access_etds

Part of the Social Policy Commons, and the Urban Studies and Planning Commons Let us know how access to this document benefits you.

\section{Recommended Citation}

Ille, Marjorie M., "Social problems and collaborative planning: toward a theory and model of social planning" (1976). Dissertations and Theses. Paper 1686.

https://doi.org/10.15760/etd.1685

This Dissertation is brought to you for free and open access. It has been accepted for inclusion in Dissertations and Theses by an authorized administrator of PDXScholar. Please contact us if we can make this document more accessible: pdxscholar@pdx.edu. 
AN ABSTRACT OF THE DISSERTATION OF Marjorie M. Ille for the Doctor of Philosophy in Urban Studies presented December 8, 1976.

TITLE: Social Problems and Collaborative Planning: Toward a Theory and Model of Social Planning

APPROVED BY MEMBERS OF THE DISSERTATION COMMITTEE:

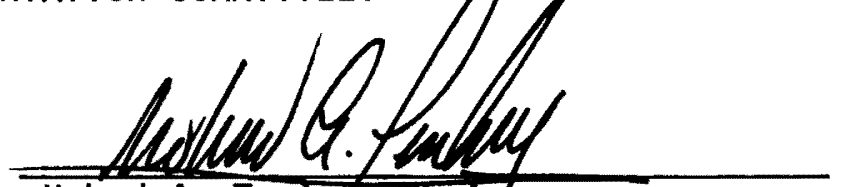

Nohad A. Toutan, Chairnan

teonare 10 can

Leonard D. Cain
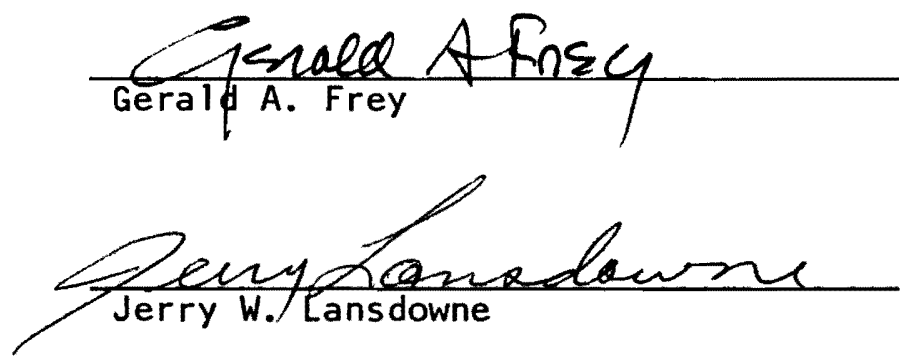

The concern of this dissertation is planning theory and practice; its purpose is to make planning more responsive to the problems of the city. The premise that the study is built on is that social planning must be in harmony with the nature of its subject matter, and that social problems is its subject matter. The supposition is that if we grasp the nature of social problems and build planning theory and practice on these insights, planning efforts will be more relevant and more effective. 
The approach is a theoretical one; social problems are the starting point. After urban problems--and poverty in particular--are examined from an historical perspective, a social systems framework is presented to clarify how problems are generated and maintained as well as to explain how responses to problems are shaped. The inquiry into the nature of social problems then draws upon sociological theory. This theoretical literature is found to focus on either the objective elements of social problems or on the subjective, that is, the process by which persons come to judge whether a condition is a social problem. Structural aspects of problems are not an important concern of the theorists.

However, in this study a problem is considered as social only when its causes lie outside of individuals--when the sources or origins can be found in existing structural or institutional arrangements. Problems are conceptualized as having two dimensions: objective and subjective ones.

Social problems--specifically, their objective and subjective dimensions--are related to social planning. It is contended that planning must deal with the objective elements of social problems, including structural aspects, as well as with the subjective dimensions. Or, in other words, social planning must (1) treat the structural causes of problems and also (2) address itself to the values, beliefs, definitions, etc. that obstruct social change.

In addition to this theoretical linkage of social problems and social planning, the dissertation situates planning in the context of a general theory of social reality. Drawing upon the work of Berger and 
Luckmann (1966), planning is conceptualized as a process in which reality is socially constructed. These theoretical concepts--the objective and subjective dimensions of social problems as the object of social planning and social planning as the social construction of reality-provide the basis for the model which is developed.

Three components of the model are treated. First, characteristics of the process are discussed, and it is contended that the social planning process must be "task-oriented," "experimental," "cybernetic," dialogic, and collaborative. Second, roles and phases in the process are discussed and illustrated. Consistent with the theoretical framework in which knowledge is considered as socially distributed, citizen, planner, and decision maker have roles in each of the planning phases. Since no one has a complete view of social reality, each is seen as having a distinct contribution to make in the task of defining the problem and its solution. Thus, resolving social problems requires that citizen, planner, and decision maker collaborate and learn from one another. The planner's role is elaborated as the third aspect of the model. By planner is meant an interdisciplinary team whose role encompasses two main functions: (1) technical tasks that have traditionally belonged to the planner, and (2) interactional tasks. Although other planning theorists have outlined interactional tasks for the planner, his role in the collaborative model is "to promote mutual learning through dialog." This role, similar to that of a process consultant, is considered unique to the collaborative planning model.

Although components of the model resemble those of other models, taken together, the characteristics of the planning process, planning 
phases, and planning roles differ from any other model. And importantly, the planning model grows out of a theoretical analysis of social problems as well as a broad theoretical framework.

The model is normative in nature, and although it is not tested empirically, it is evaluated at a theoretical level. The collaborative model and seven other planning models are assessed in terms of whether they are responsive to the nature of social problems. It is contended that the collaborative model is the only one that is responsive to the nature of social problems.

This dissertation--its theoretical concepts and conceptual model-is seen as a contribution to an emerging planning paradigm--one that holds the promise that we can learn to deal effectively with the problems that confront our cities. 


\section{SOCIAL PROBLEMS AND COLLABORATIVE PLANNING:}

TOWARD A THEORY AND MODEL OF SOCIAL PLANNING

by

MARJORIE M. ILLE

A dissertation submitted to the Faculty of Urban Studies in partial fulfillment of the requirements for the degree of

DOCTOR OF PHILOSOPHY

Portland State University

1976 
TO THE OFFICE OF GRADUATE STUDIES AND RESEARCH:

The members of the Committee approve the dissertation of Marjorie M. 11le presented December 8, 1976.
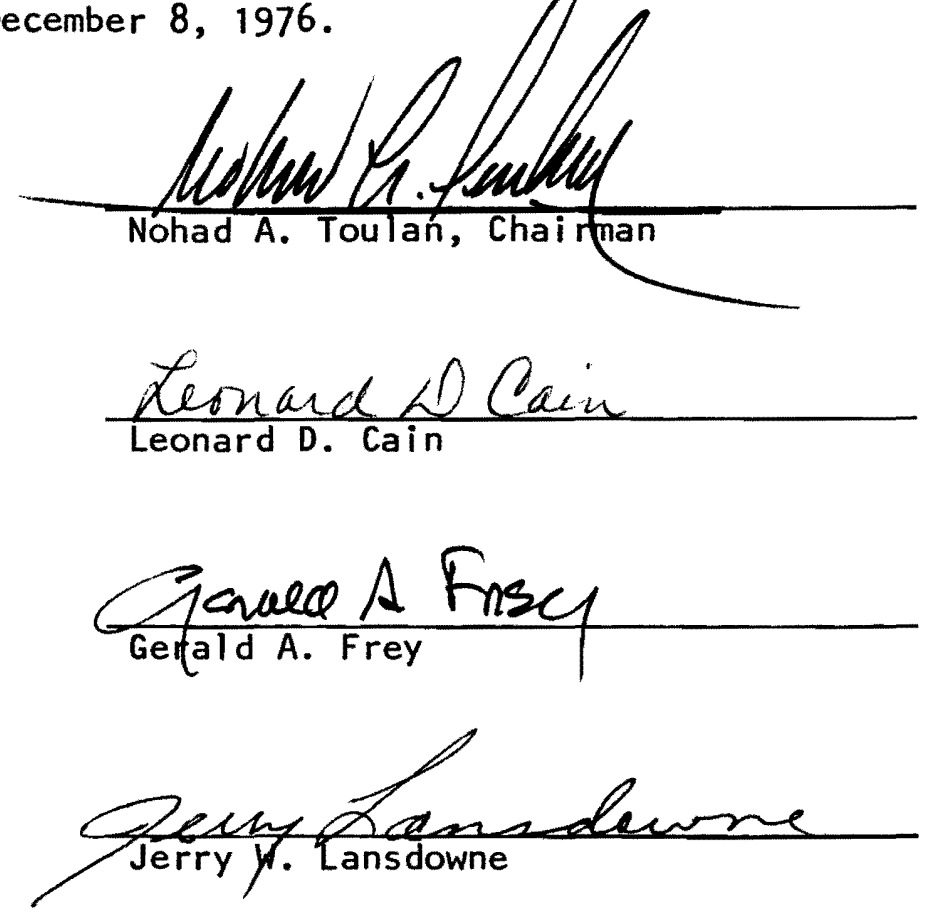

APPROVED:

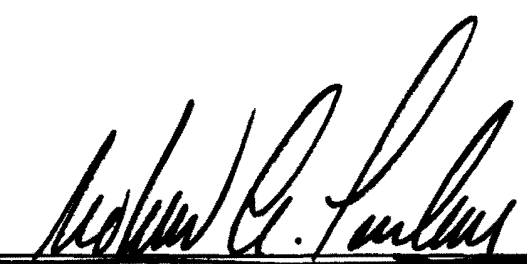

Nohad A. Toulan, Director, Urbañ fudies Graduate Program

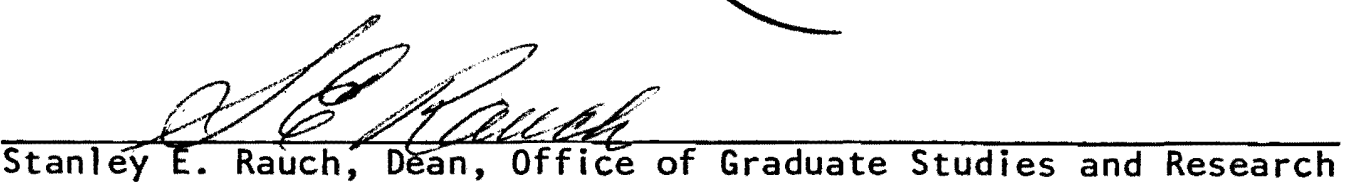

December 8, 1976 
TABLE OF CONTENTS

PAGE

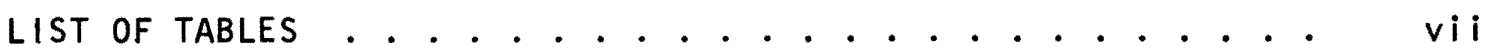

LIST OF FIGURES ....................... . . . . . . . . . . . . . . . . .

CHAPTER

1 SOCIAL PROBLEMS AND COLLABORATIVE PLANNING: TOWARD

A THEORY AND MODEL OF SOCIAL PLANNING. . . . . . 1

Introduction ............... . . 1

The Urban Crisis and Planning. . . . . . . 1

The Meaning of Planning: Essential Components . 4

Future-oriented

A Search for Effective Means

Action-oriented

The Meaning of Social Planning ........

A Review of the Literature

The Meaning of Social Planning: An Assessment and Proposal

The Purpose of This Dissertation .......

Major Premise and Approach

Outline of Chapters

II SOCIAL PROBLEMS IN HISTORICAL PERSPECTIVE . . . . . 34

The City and Social Problems ......... 34

Contemporary Urban Problems

Nineteenth Century Roots: Industrialization and Urbanization

Responses to Social Problems: An Historical

Perspective . . . . . . . . . . . . . 
Early Responses to Poverty The Nationalization of Reform Role of the Government: Laissez Faire vs. Intervention

The War on Poverty

From Model Cities to Revenue Sharing

Responses to Social Problems: An Analysis...

Explanations for the Persistence of Poverty Factors Causing Poverty and Shaping Responses to Poverty

Implications for Social Planning

The City and Social Problems: Past and Future.

111 SOCIAL PROBLEMS: A THEORETICAL ASSESSMENT. . . . . . 75

Sociological Theory and Social Problems. . . . 76

Definitions

Sociological Approaches

Theory of Social Problems: A Criticism

Social Practice: Definitions of Problems and

"Solutions".............. . . 84

The Relation between Definitions and "Solutions"

The Importance of Definitions

Social Problems and Social Planning. . . . . .

Social Problems and "Social" Causes:

A Definition

Implications for Social Planning

The Definitional Process and Citizen Participa-

tion. . . . . . . . . . . .

The Literature of Citizen Participation

Citizen Participation: A Planning Dilemma?

The Definitional Process: Planner and

Citizen Together

Conclusion . . . . . . . . . . . . . . 
IV TOWARD A THEORY AND MODEL OF SOCIAL PLANNING - 1 .

Theoretical Assumptions . . . . . . . . 114

The Nature of Social Reality

The Nature of the Human Person

The Nature of Social Interaction

Planning Theory . . . . . . . . . . .

Social Problems As the Object of Social Planning...............

Social Planning and the Construction of Reality.............. 126

Conclusion. . . . . . . . . . . . . 132

$\checkmark$ TOWARD A THEORY AND MODEL OF SOCIAL PLANNING - 11 . .

Additional Assumptions: Envi ronment and

knowledge. . . . . . . . . . . . . .

The Environment of Planning

Knowledge

Toward a Social Planning Model: Process

Characteristics.

A "Task-oriented" Process

An "Experimental" Process

A "Cybernetic" Process

A Dialogic Process

A Collaborative Process

The Social Planning Process: Phases and

Roles. . . . . . . . . . . . .

Phases

Roles

Roles and Phases Illustrated

The Role of the Planner in the Collaborative Mode 1. . . . . . . . . . .

A Review of Planning Roles

A Collaborative Role: An Elaboration

Conclusion. . . . . . . . . . . . . . 
VI COLLABORATIVE SOCIAL PLANNING: AN ASSESSMENT AND POSSIBILITIES. . . . . . . . . . . . . . 175

Improving the Policy/Planning Process. . . . . 175

Contemporary Approaches

Collaborative Social Planning: Approach and Theory

Collaborative Social Planning: The Model Evaluated

Normative Theories and Models

Challenges Facing Collaborative Social

Planning. . . . . . . . . . . . .

Individual Changes

Structural Changes

Knowledge and Skills

The Possibility of Collaborative Social Planning

Toward a New Planning Paradigm . . . . . . .

The Notion of Paradigm

The Paradigm Problem in Planning

A Revolution in Planning: An Emerging

Paradigm

Conclusion . . . . . . . . . . . . .

Collaborative Social Planning: Toward a New Paradigm

Collaborative Social Planning and the Urban Planner

REFERENCES ......................... 


\section{LIST OF TABLES}

TABLE

PAGE

1 Explanations of Poverty Prevalent in the Nineteenth Century .................. 85

11 War on Poverty.................. 91

III Contributions to Planning ............ 149

IV Some Conceptualizations of the Phases of Planning and Problem Solving . . . . . . . . . . . .

$\checkmark$ Role of the Social Planner in the Collaborative Model of Social Planning .............. . .

VI Models Evaluated: Dimensions of Social Problems as Targets of Planning . . . . . . . . . .

VII Models Evaluated on the Basis of Criteria for Effectiveness in Resolving Social Problems . . . . . .

VIII Interpersonal Skills and Knowledge Needed by Planners

IX Comparison Between the "Old" and "New" Planners ... 
1 The Social System and Social Problems. . . . . . 71

2 The Cycle of Poverty............... 90

3 Consequences of Defining a Problem in Terms of the Individual when the Cause Is Structural. .... 94

4 Social Planning Conceptualized as Confronting the Systemic Causes of Social Problems.......

5 Social Planning Conceptualized as Confronting the Objective and Subjective Dimensions of Social Problems . . . . . . . . . . . . . .

6. Social Planning and the Construction of Reality. . .

7 Planning as a Collaborative Process: Roles for Citizens, Planning Team, and Decision Makers..

8 Roles and Phases in the Collaborative Social

Planning Process . . . . . . . . . . . . 
CHAPTER I

\section{INTRODUCTION}

\section{THE URBAN CRISIS AND PLANNING}

"If we observe a society faced with a problem--poverty, riots, unsafe cars--and formulating a program to deal with it, we can be sure that nine times out of ten the problem will not be solved. If we look again, ten or twenty years later, we shall find that the problem may have been trimmed, redefined, or redistributed, but only infrequently will it have been treated to anyone's satisfaction. . . In short, the capacity of societies to treat their own problems and to change themselves seems rather limited" (Etzioni, 1970, p. 222).

Although the contention that our capacity to treat problems is $1 \mathrm{im-}$ ited is open to debate, the other assertion--that societies rarely solve their problems--is less likely to be disputed. Few persons today would claim that the urban problems that concerned us in the 1960 's have been satisfactorily solved. Cities are still plagued with problems: concentrations of the poor--especially minority poor, deteriorating and abandoned housing units, crime and unsafe streets, large numbers of unemployed persons, possible financial collapse, and so on. Housing programs, poverty programs, Model Cities, and other programs of the sixties have not effectively dealt with the city's problems. But does this warrant the conclusion that our capacity to treat our problems is limited? 
We believe that it does not. This dissertation is premised on the opposite belief: that we do have the capacity to treat urban problems, to change both ourselves and our institutions, and thus make our cities more livable for all. While we do agree that our treatment of urban problems has indeed been ineffective--that our theory and practice have been inadequate in the face of the problems that confront us, we also contend that planning theory and practice can be made more relevant to the problems of the city.

In maintaining that planning can be made more effective, the assumption is that the planner has an important role to play in the task of confronting urban problems--not merely as a technician, drawing on specialized knowledge and skills, but also as a person committed to attaking urban problems so that more persons may share more fully in life in "the good city."

Although some may disagree with casting the planner in the role of committed person--and particularly in the role of one who is committed to creating "the good city," it is impossible for the social scientist

${ }^{1}$ For those interested in a philosophical and moral treatment of urban poverty, Haworth's (1968) is an excellent one. He raises the question, "Why fight poverty?"--a question that is closely related to "Why fight urban problems?" His answers fall into three moral categories: goodness, justice, and prudence--all of which are seen, as aspects of the effort to create a good city. When poverty exists in a city, Haworth charges, it fails at being a "good city." His conception of "the good city" is a structural one--a satisfactory life style is related to traits of urban institutions. In summary, a good city is "a community in which the participants are enabled to develop themselves as human beings in consequence of its richness, openness, person-centeredness, voluntariness, flexibility, and controllability" (p. 38).

Haworth also discusses "the just city," as well as prudential reasons for dealing with urban poverty. 
or planner not to take a value stance. ${ }^{2}$ A similar perspective is expressed by Dror (1968) who addresses the question of knowledge, moral commitment, and social change. He states:

Insofar as knowledge that is relevant to human action becomes available, it is our moral duty, as well as our best bet, to use it as much as possible, with due humility but without giving in to the conservative biases so deeply rooted in most individuals and social institutions. . . . The choice we face is either to try to change the public-policymaking system in the light of what we know and thus increase our chances of realizing our bas ic values more fully and of dealing better with the problems faced by society, or to leave the shaping of the future to the short-sighted (though not blind) forces of spontaneous historical evolution ( $p$. 301).

In expressing his conviction that we have a duty to change our policy system so that we can better handle societal problems, Dror sets forth the choice facing us: either work to improve our ability to plan for change, or let the future more or less shape itself. In this dissertation we have opted for the first choice and will search for better ways of responding to our problems--aiming specifically to improve our ability to plan.

If change is to occur, if problems are to be handled more effectively, the planner must be devoted to making planning theory and prac-

2 Although planner John Dyckman (1966, p. 74) argues for a positive, value-free social science, he recognizes that "radical social planners" on the one hand are calling for redistribution of power, and on the other hand that "administrative social planners" are aligned with powerful interests. To protect citizens against the biases, condescension, and arbitrariness of social planners Dyckman calls for the articulation of public goals ( $p .75$ ). Other planners consider it impossible to be "valuefree." The advocate planners definitely have sided with the powerless. See Davidoff (1965) for a treatment of this perspective.

The impossibility of a value-free stance is widely recognized today among sociologists. Becker (1967) discusses the issue in terms of "whose side are we on?". The position set forth in this dissertation closely resembles Gouldner's $(1962,1968)$. 
tice more responsive and relevant to the needs and problems of the urban dweller. This is the challenge that this dissertation addresses.

The first step will be to review the planning literature in the attempt to identify key components of the planning process. The literature will also be reviewed for the insights it offers about the nature of social planning, and after assessing that literature, we will argue that there is a need to reconceptualize social planning. Finally, we will discuss how this dissertation approaches the task of improving our capacity to treat urban problems.

11. THE MEANING OF PLANNING: ESSENTIAL COMPONENTS

Since a basic premise of this dissertation is that present methods of decision making are inadequate in the face of complex problems, it must be clarified why it is assumed that improving planning theory and practice will enhance our ability to cope with urban problems. Therefore, the planning literature will be surveyed--with the focus on the meaning of planning. Three elements will be identified as essential to planning. They are: a future-orientation, a search for effective means, and an action-orientation. These elements, it is maintained, distinguish planning from other forms of decision making.

\section{Future-oriented}

Planning has been defined as "a process where because of faith in the ability to influence the future, one uses foresight to achieve predetermined goals" (Bunzel, quoted by Kahn, 1969, p. 13).

Another writer tells us that 
to plan is to gather our knowledge of our collective resources and to exploit our capabilities for change, thus modifying ourselves in order to meet more adequately the needs of the present and the future (Duhl, 1963, p. 302).

Both these definitions express a belief in our capacity to effect change and both focus on planning as future-oriented. In the first definition goal formulation seems to be placed outside the planning process--goals are predetermined. Planning is seen as directed toward the achievement of goals. The second definition also seems to assume the prior existence of goals. In other conceptualizations of planning--and in this dissertation--goal formulation is problematic and considered integral to the planning process. ${ }^{3}$

Because planning is future-oriented, that is, because it aims at effecting stated goals, improving our ability to plan will enable us to bring about a future in which problems are more effectively ameliorated-if not resolved.

\section{Search for Effective Means}

The two definitions cited above imply that planning is concerned with developing the means that will create change--that will reach the established goals. This aspect of planning will be our focus as we consider other definitions of planning.

Robinson (1972) too views planning as a process of determining goals, but he also considers designing means to achieve these goals es-

${ }^{3}$ Harris (1967) too recognizes the identification of goals as an essential part of the planning process, yet also as a task that lies outside the realm of science. He maintains that planning draws on both "science" and "humanism" for its knowledge and tools. His article sets forth what he sees as the limits of both. 
sential to planning. According to him:

Planning--whether it is for the development of a city as a whole, or the programming of its components (say, education or housing)--may be defined as the process of determining goals and designing courses of action by which these goals may be achieved (p. 33).

This definition then deals specifically with mearis-ends relationships. Gans (1970) proposes a similar definition, but specifies more precisely that planning is concerned with effective means. For him planning is

a method and process of decision-making that proposes or identifies goals (or ends) and determines effective policies (or means)--those which can be shown analytically to achieve the goals while minimizing undesirable financial, social, and other consequences ( $p, 223$ ).

Effective means, according to this definition, are those that can be shown analytically to be effective. Gans, however, does not point out that determining what consequences are desirable and which are undesirable--and for whom--takes the planner and/or decision maker into the realm of value judgments.

Planning is an intrinsically normative process, for both the specific goals to be pursued and the specific actions to be taken are selected within a value framework. Because of this, analysis cannot be purely objective or scientific, but is intimately connected with values or subjective beliefs. The notion of the analytical ("scientific") as well as the normative nature of planning is concisely expressed in Kahn's (1969, p. 17) definition of planning as "policy choice and programming in the light of facts, projections, and application of values."

That values enter into the task of analyzing alternatives is recognized by Webber. (1963) who explicitly incorporates value implications in- 
to his definition. In his view planning is

that process of making rational decisions about future goals and future courses of action which relies upon explicit tracings of the repercussions and of the value implications associated with alternative courses of actions, and in turn, requires explicit evaluation and choice among the alternative matching goal-action sets ( $p .320)$.

This definition also associates rational decisions with planning-a concept that has evoked a good deal of controversy. A rational decision, according to Banfield (1959), is one made in the following manner:

1. The decision-maker lists all the opportunities for action open to him;

2. He identifies all the consequences which would follow from the adoption of each of the possible actions; and

3. He selects the action which would be followed by the preferred set of consequences $(p, 140)$.

It is evident that decision makers in most cases cannot make a perfectly rational choice, $i$. e., in terms of Banfield's criteria. Banfield himself admits that "no choice can ever be perfectly rational" (p. 140). His "rational decision" is an ideal type and his model of rational planning is a normative one. ${ }^{4}$ They must be considered as such.

It is our contention that planning does not require "rational" decisions, but rather involves a search for effective means. This necessi-

${ }^{4}$ Banfield (1959) explains and defends the rational model as a normative one. Several others have written on the limits of rationality and/ or have criticized rational models. Friedmann (1967) uses the term "bounded rationality" to indicate the limits that circumstances place on rational decisions. He discusses environmental conditions, or the social context of planning, as "obstacles" to rational planning. March and Simon (1958) also discuss the "cognitive limits of rationality." Lindblom (1959) attacks the rational-comprehensive model, thus providing the basis for his incremental model. Dror (1968) too offers a criticism of the "pure rationality" model (pp. 132-41) and the "economically rational" model (pp. 141-42). 
tates a consideration of alternative courses of action, the identification of the consequences of each alternative, and an evaluation of each alternative in the light of the relevant ends (goals). The planner is confronted by limitations in each of the three steps identified by Banfield--and the more complex the situation, the more serious are the constraints. The planner is continually challenged to overcome these limitations and find effective courses of action. However, it is the search for effective means--not the effective means--that is an essential component of planning. Because planning searches for effective means, it holds the promise that it can treat the problems confronting us.

\section{Action-oriented}

In the definitions of planning cited above planning seems to cease once a course of action has been designed (Robinson) or when it has been finally selected (Gans, Webber, Kahn). We will now examine the role that implementation--or action--has in planning.

Lending support to the view that planning is only concerned with the design of means to reach goals is the distinction that is made between policy analysis, planning, community organization, and administration. These boundaries are delineated by Rein (1970) in the following way:

Policy analysis--accounting for the development of public pol$i c y$ and explicating the choices and assumptions underlying present or anticipated programs, wi thout necessarily attempting to alter the direction of policy or make specific and detailed choices...

Planning--converting value choices into concrete programs and plans for action by choosing among alternative patterns and levels of allocating resources to reach some predefined goal. Some have tried to combine these activities when they discuss policy planning. 
Community organization deals with the process of change either by drawing together diverse interests to facilitate reaching agreement on social objectives, or by organizing groups who are inarticulate and excluded from the decision process.. .

Administration implements choices already made, but in the process of identification may shape the direction of policy, setting it upon a new or only slightly altered course ( $p$. 5).

Similar distinctions are discussed by Gans (1974) in a paper in which he explores the possibilities of integrating three social work specialities: social policy, social planning, and community organization. Theoretically, according to Gans, these specialties can be considered as follows:

Social policy--as a goal-setting specialty aiming to correct the injustices of the market;

Social planning--as a programming specialty which stresses ra$t$ ional methods for the conception of the means or programs to achieve the goals set by social policy; and

Community organization--as an implementing speciality of organizational and political skills to realize these programs (p. 19).

The boundary distinctions drawn by both Gans and Rein relegate planning to a very narrow function. However, in this dissertation no distinction is made between planning and policy analysis. In the analysis of alternatives it is essential to explicate both values and underlying assumptions if one is to evaluate them. Neither will the theoretical distinction Gans makes between social planning and social policy be used-for, as we have already indicated, goal formulation is considered integral to the concept of planning.

Both Gans and Rein distinguish between planning and implementation. This distinction is theoretically justifiable as well as empirically valid, i. e., the administrator's role and the community organizer's role do differ from the planner's. However, implementation is integral to the 
concept of planning that is being presented here.

Planning is premised on a belief that human activity can influence the future. The assumption is that people engage in planning in an attempt to achieve goals. Planning is a purposeful activity.

This view is similar to that of Davidoff and Reiner (1962). Planning as they define it is "a process for determining appropriate future action through a sequence of choice" (p. 11). For them "determining" is more than identifying and selecting appropriate courses of action--it is assuring the action as well. They argue that "effectuation" is a planning concern, and that action is the outcome of planning efforts.

Friedmann (1969) has also fused action with planning. In his model plan formulation and plan implementation are not just merged, but are indistinguishable. His "action-planning" model includes "deliberation and choice as pervasive, on-going activities, but these are not to be identified as distinctive phases prior to action: they are inseparably a part of it" (312).

Considering action as an inseparable part of planning is essential to the concept of planning used in this dissertation. "Action" has a vital role to play in determining the effectiveness of our efforts to deal with problems. In our discussion of "the search for effective means" as a necessary element of planning, we did not consider how it is determined that one alternative will be more effective in achieving a goal than another--or even if it will be effective. The evaluation of means in the light of ends has given rise to the assumption that planning should lead to the maximization of the attainment of relevant ends (Meyerson and Banfield, 1955, p. 314). This "maximizing" model has been highly criti- 
cized, of course. A "satisficing" model, "a successive, limited comparisons" or incremental model (Lindblom, 1959, 1965), and an optimal model (Dror, 1968) have been developed and each proposed as more realistic than the maximizing model.

Our point, however, is not to discuss or evaluate these various models $;^{5}$ rather it is to indicate how it can be determined whether a means is effective. We propose that it is not analysis and evaluation that verify whether a particular course of action will be or is effective. "Action" is the test of whether means are effective, i. e., whether they lead in the direction of goal achievement. The effectiveness of the means can only be judged by practice. Do the means effect change? Do they lead toward goal achievement? Planning then is concerned with implementation--with action.

In summary, it has been maintained that planning is characterized by three elements: (1) a future-orientation--a concern with future goals; (2) a search for effective means--a concern with devising ways to achieve goals; and (3) an action-orientation--a concern with the actual realization of the goals. Because planning is a process characterized by these three components, it is a process that must be used and improved if urban problems are to be solved--if "the good city" is to be realized.

${ }^{5}$ Simon (1957, Chapters $\left.10,14,16\right)$ discusses the model of sat isficing man. March and Simon (1958) further develop this model. Altschuler (1965, pp. 300-02, footnote 2) discusses the models of maximizing man and satisficing man. Dror (1968, pp. 147-49) also considers Simon and March's satisficing model. 
III. THE MEANING OF SOCIAL PLANNING

A future-orientation, a search for effective means, and an actionorientation have been identified as characterizing the planning approach and also have been used to distinguish planning from other forms of decision making and problem solving. The planning approach itself "is largely neutral wi th respect to subject matter. . . Essentially the same processes may be applied in deciding how to deploy a military force, in guiding the activities of a corporation, in determining which social services are to be provided, or in deciding about the city's physical structure" (Webber, 1962, p. 320).

Although the planning approach is "largely neutral" with respect to subject matter, we will now attempt to distinguish social planning from other forms of planning. To accomplish this we will explore how definitions, boundaries, and goals of social planning have been treated in the planning literature. These meanings will be assessed, and another conceptualization of social planning--one used in this dissertation-will be proposed.

\section{A Review of the Literature}

Definitions. In reviewing the literature dealing with social planning one finds that the ways of conceptualizing social planning are almost as numerous as the theorists who do so. A recent book by Ecklein and Lauffer (1972) dealing with social planning illustrates this very well. The authors set forth nine ways that social planning has been defined.

1. A way of concerting community influence towards achievement of a common goal. 
2. A process that gives effect to the wishes of the community.

3. A rational method of problem solving.

4. A process in which policy, determined by a separate political process, is translated into a set of operational orders for the execution of that policy.

5. A systematic ordering of the near future; a designing of the future.

6. Rational, goal-directed behavior, seeking the optimum adaptation of means and ends as guided by a limiting set of social values.

7. A process whereby the planner feeds more information into the decision-making system.

8. Program development based on a process of goal selection and the progressive overcoming of resistance to goal attainment.

9. A means of directing social change through some form of coordinated program in order to further social well-being by attacking social and community problems (pp. 212-13, numerals added).

The first eight "definitions" are inadequate in that they do not distinguish social planning from other forms of planning. ${ }^{6}$ The last definition comes closest to identifying social planning, yet it needs further explanation if it is to enhance our understanding of the concept. Little seems to be gained by listing these "definitions"--other than to indicate "fuzziness" in the conceptualization of social planning.

Ecklein and Lauffer do not themselves define social planning; instead they describe and discuss the kinds of social planning that are presently practiced. Their approach is not unusual, for few who write about social planning attempt precise definitions. Neither do the writers even use the same terms in their conceptualizations, thus leading to the proliferation and confusion of concepts. Various authors deal with

"Many of these "definitions" do not even define planning, let alone social planning. For example, the second definition seems to describe the electoral process better than the planning process. 
social planning and: its domain (Kahn, 1969; Gil, 1973), types (Gans, 1968; Brooks, 1970), functional assignments (Dyckman, 1970), goals (Fitch, 1967), objectives (Perloff, 1962), substantive areas (Brooks, 1970), core (Perloff, 1965), scope (Perloff, 1965; Brooks, 1970), terrain (Rein, 1971), boundaries (Boulding, 1967; Rein, 1970).

Not only is there a lack of precise agreement among various theorists on the meanings and usage of these concepts, but even in reading just one person's writings one can experience this conceptual confusion. In one article Gans (1958b) states that social planning includes two kinds of planning: societal planning and social programming. He explains:

Societal planning is concerned with broad goal determination for the society and with evaluation of programs on a broad level. - . The term social in social programming should be defined loosely, and the scope... should be broad... so that programs can be developed for those societal goals which are not handled by economists, land-use planners, or architectdesigners. . ( $p .85)$.

Gans then distinguishes between social planning and that done by economists, land-use planners, and architect-designers--making it quite clear that this second type of social planning deals with noneconomic and nonphysical phenomena. But in two subsequent articles Gans denounces dichotomizing physical and social planning $(1963,1968$ a). He views the dichotomy as meaningless (1962, p. 245) and as theoretically unjustifiable (1968a, pp. 72-73). He asserts that "no goal can be defined so narrowly that it is only physical or only social" (1962, p. 245). He proposes "a synthesis of the so-called social and physical planning approaches" (1968a, p. 75). Then there would be only planning: "an approach which agrees upon the best goals and then finds the best 
methods to achieve them" (1963, p. 245). Social planning is used by Gans in two contradictory or seemingly contradictory senses.

In consulting the index of a book containing Gans' essays (1968, p. 393) for a definition of social planning, the reader is referred to Gans' description of what he terms planning for "guided mobility." Programs for guided mobility "seek to aid low-income people to change their fortunes and their ways of living, they are attempts to guide them toward the social and economic mobility that more fortunate people have achieved on their own" (1962, pp. 232-33). In this very article to which we are referred for a definition of social planning, we find Gans urging that the terms, physical planning and social planning, be eliminated.

What accounts for this seeming discrepancy of meaning in the writings of just one man? The answer perhaps lies in a consideration of the various audiences that were addressed.

"Memorandum on Social Planning" was originally prepared in 1958 for the Social Planning Division (and its Social Planning Unit) in the Puerto Rico Planning Board. Gans was attempting to be of practical assistance to an already established planning board. Al though reluctant to describe goals as either economic or social, he did use the term "social" as an administrative category that would include noneconomic and nonphysical programs (p. 85).

The 1963 paper was given to a conference of the American Institute of Planners and the 1968a article first appeared in the Encyclopedia of the Social Sciences. Both articles are concerned with city planning and "a new planning concept which places greater emphasis on economic and social methods of improving community life" (1963, p. 231). Gans was 
critical of the tendency of city planning agencies to append social planning to physical planning, preferring instead a goal-oriented approach to planning. If city planning was to truly improve cities, then planning to do away with urban poverty and deprivation, i.e., programs for guided mobility, must be given a higher priority, according to Gans. Not only does the audience being addressed seem to influence the conceptualization of social planning, but the theorist's own field also affects the meaning that is given social planning. Mayer (1972) considers the meanings of social planning as used in four fields: social work, delinquency prevention, community mental health, and city planning (pp. 7-19). We will not duplicate his efforts here, but his review of the literature from these various fields is instructive: no common agreement exists as to what constitutes social planning.

In trying to find a meaning for social planning that transcends particular fields of specialization, Dyckman (1966) provides a useful starting point. He specifies three operational meanings of social planning:

1. At the societal planning level, social planning means the selection of the social goals of the nation or state, and the setting of targets for their achievement. It requires a ranking of these goals, an assessment of the cost (in terms of other objectives) of achieving them, and judgments of the feasibility of such programs.

2. Social planning, in a closely related meaning, involves the application of social values and action criteria to the assessment of programs undertaken in the pursuit of economic or political goals. Thus, it can mean the testing of the consequences--in terms of intergroup or interpersonal relations--of everything from broad economic development programs to specific redevelopment projects.

3. Social planning can mean specifically 'social' programming arising from the broad social goals of the community. The 
traditional welfare activities of public and private agencies have been the principal focus of such planning in the United States (pp. 67-68).

In a more recent article Dyckman (1970) restricts social planning

to two meanings:

Social planning is either planning for social services or planning, whether economic or physical, which is sensitive to the social outcomes of its plans and which places differential value on these outcomes ( $p .27)$.

Expressing the same concept, but in different terms, Dyckman (1970) says:

American planning that qualifies for designation 'social' is either that kind of planning, whatever its perspective, that deals with social services, or is planning for environmental or economic goals that takes into account the social consequences of its effectuation ( $p, 27)$.

"Societal planning" is used by Dyckman to apply to "planning that seeks to directly restructure the society so as to alter its social relationships" (1970, p. 27). He acknowledges that very little "societal planning" exists in American society.

A conceptualization similar to Dyckman's, but not as clearly articulated as we will see, is found in the writings of Perloff $(1963,1965$, 1968). In his earliest article dealing with social planning Perloff (1963) offers no definition, but in expressing his personal concern about social and human resources problems, he seems to view social planning as planning for human services. But Perloff goes beyond the traditional notion of planning for human services, focusing on five social objectives for metropolitan regions--some of which deal with elements other than social services. He proposes a framework for social planning that includes the regional economy and social structure, and further contends that it is necessary to integrate social planning with physical planning activities. 
Perloff in a later article (1965) sets forth three organizational tasks that must be accomplished in order to cope with metropolitan social problems. First, he says, there must be coordinated planning for welfare by both governmental and voluntary agencies. Second, social planning must involve economic forces "so that local attacks on problems of unemployment, underemployment, poverty, economic discrimination, and the like, can be carried out in a planned and coordinated fashion" (p. 298). And lastly, social and physical planning must be joined. Social planning, according to Perloff, must be joined with economic and physical planning. Social planning, he declares, must include "all pertinent socio-economic and human-behavior considerations" (1965, p. 298). Social planning then would provide the human resources counterpart to physical city planning" (p. 299). This statement should not be taken to mean that social planning is restricted to the typical social welfare planning, for later in the article Perloff declares the need for an extensive redefinition of the scope of planning. He contends that "a broad view which includes aspects of economic, social, physical, political, cultural, and psychological concern is more appropriate than a view which deals with narrowly conceived 'health and welfare' problems'" (p. 299).

This distinction between a broad view and a more narrowly conceived one ${ }^{7}$ moves Perloff close to Dyckmann's conceptualization of

7 Another way to distinguish a "narrow" view from a "broad" view is to consider who is the target of planning. Fitch's (1967, p. 329) concern is with the "narrow" consideration of social planning which "refers to policies and programs to raise the cultural and economic levels of certain population groups, mainly those who are not self-supporting." The broader view includes "all planning which aims to promote the general welfare, as contrasted to the interests of small groups" (p. 329). 
social planning.

The current meanings given to social planning have been thoroughly explored by Alfred Kahn, a professor of social work, who devotes an entire chapter of his book, The Theory and Practice of Social Planning (1969), to that task. ${ }^{8}$ Although he discusses various approaches to a definition, he himself does not offer a definition of social planning. He maintains that:

This is an early moment in the history of social planning, and any system of classification will soon be outdated. Nonetheless, the listing of circumstances occasioning social planning, reconsidered in the light of the elements of the definition which has been presented, does permit the creation of a working typology (pp. 18-19).

Kahn then proceeds to present in some detail the meanings that social planning has. According to him social planning at present can be:

Planning within an agency or organization in social welfare. (This is properly seen as administrative planning.) . .

Planning for a concert of services on a community level. (This is sectorial or categorical planning on the local level.) . . . Planning to introduce (or correlate) social components into housing projects, or into local, city-wide, or regional housing and renewal activities. (This is the social in relation to physical planning.). . .

Problem-oriented or social-trend oriented planning. This may also be seen as planning for the interrelationships among or restructuring of intervention systems, usually with reference to a broad national, state, or regional problem. . .

Planning the social aspects of fiscal and monetary policy or other public programs not primarily defined as 'social'. . .

Planning the social aspects of balanced development. This phraseology best suits United Nations usage. Others may prefer to talk of relating social concerns to economic planning or of social aspects of economic planning (pp. 19-20.

\footnotetext{
${ }^{8}$ See Chapter 1, "What 1: Social Planning?", for that extended discussion.
} 
Although Kahn admits that this classification of the forms of social planning will soon be outdated, his classification of current usages is quite comprehensive. This application of the term "social planning" to a variety of situations indicates the breadth of its meaning. Its present usage in so many circumstances greatly complicates attempts to specify a more precise meaning for social planning--and one that will be acceptable to those involved.

Boundaries. Closely related to definitions of social planning is the issue of boundaries. In seeking to answer the question, "What is social policy?", Rein observes that the definition of social policy is not settled (1970, p. 6), but rather than attempting to formulate a formal definition, he instead explores the question of boundaries. Our examination of three boundaries--between social policy and the academic disciplines, between social policy and public policy, and between social policy and social work--is based on Rein's analysis.

In the consideration of what separates social policy from the academic disciplines, such as economics, political science, and sociology, Rein discusses two views. One holds that because social policy draws upon the major social sciences for its body of knowledge, has minimal theory, and lacks unique methods, it is a "field" and not a "discipline."10

9 As was previously indicated, no distinction is made in this dissertation between social planning and social policy. The literature that deals with social policy will be considered as applicable to social planning.

${ }^{10}$ By social policy as a field is meant "the development of collective action for social welfare in which scholars drawn from various disciplines try to clarify problems" (David V. Donnison, quoted by Rein, 1970 , p. 8). 
The other view is in disagreement-holding that because social policy is developing its own theory and methodology, it should be regarded as a discipline separate from the other social sciences. At this time no consensus exists on this boundary question.

The relationship between social policy and public policy is a second boundary issue. Rein expresses why he believes this boundary is an important one: "If we fail to establish the boundary between public and social policy, then the field of inquiry will be as broad as human wisdom and social experience itself" (p. 13).

Boulding (1967) has attempted to delimit social policy from one aspect of public policy--the economic. He notes that "economists study primarily that segment of the social system that is dominated by exchange" ( $p .5)$. He suggests that "perhaps, therefore, we can identify the 'grant' or unilateral transfer. . as the distinguishing mark of the social just as exchange or bilateral transfer is a mark of the economic $c^{\prime \prime}(p .7)$. This distinction by Boulding permits a consideration of social policy as "intervention outside of the market system" (Rein, 1970, p. 13). Yet Rein points out that this concept too has been challenged, for in practice the market is a mechanism that is used to supply some social services.

Neither does regarding social policy as responsive to human need and public policy as having other immediate aims contribute to our understanding of either (Rein, p. 15). Thus, Rein holds that there is no satisfactory distinction between social policy and public policy.

The third boundary issue examined by Rein is that between social work and social'policy. This leads him to a brief review of the mean- 
ings of social work, personal social services, ${ }^{11}$ and social welfare. After defining social work Rein observes: "As the theme of protection is stressed social work not only moves toward advocacy, but it presses into the broader areas of policy, planning, social reform, and social engineering" (1970, p. 16).

Thus, as the definition of social work is expanded, it becomes impossible to make a clear-cut delineation between social work and social policy. The exploration of this third boundary issue leads Rein to assert that "the broader the definition, the fuzzier become the boundaries" (p. 18). Although Rein fails to find a suitable distinction between social work and social policy, he does narrow social welfare policy to three possible meanings:

all social services including those distributed in the market; or only the public and private transfer systems; or policies, broader than social services, which include those economic and physical development policies directed at social welfare objectives (pp. 17-18).

Rein's designation of these different activities of social welfare policy closely resembles the meanings Dyckman proposes for social planning. 12

This consideration of boundaries has offered us a different perspective on social planning, but we are forced to concur with Rein's conclusion that substantial difficulties exist in delimiting the bound-

${ }^{11}$ See Rein (1970, pp. 3-4) for a discussion of what he terms "the stubborn ambiguity" in the meaning of social services. tions.

${ }^{12}$ Refer to pp. $16-17$ of this dissertation for Dyckman's defini- 
aries of social policy. This consideration of boundaries has not led to a more precise meaning for social planning.

Objectives. In an effort to understand social planning, we have examined definitions and boundaries. Now we will consider what have been proposed as the goals or objectives of social planning. Both concrete and abstract goals will be considered.

Fitch (1967) is one planner who has specified concrete goals for social planning. Included in what he terms "achievement" goals are the following:

1. Education, including training and retraining of adults.

2. Income maintenance programs for those who are economically stranded through personal incapacity or from social malfunctioning such as unemployment.

3. Social services and counseling for those who need outside personal assistance and counseling.

4. Medical services, both general and preventive, and specific remedial services.

5. The apparatus of law enforcement, penology, parole, etc. directed at the prevention of delinquency and rehabilitation of those who tend to get into trouble by committing various offenses.

6. Housing . . a minimum essential ingredient of human resource development. . .

7. Employment. . has been considered to be a major concern of economic planning, but there is no point in talking about social planning without considering employment. . . .

8. Measures to combat discrimination and segregation . .

9. The whole set of other aspiration, achievement and performance goals . . . directed at improving the environment, better to meet the physical and spiritual needs of the entire population. . (pp. 338-39, emphasis added).

Concrete objectives for social planning are also dealt with by

Perloff. He sets forth five social objectives for metropolitan regions in his 1963 article. In an article (1965) that he considers an exten- 
sion and development of this earlier one Perloff specifies six areas that social planning needs to be concerned with:

1. Jobs and incomes of families...

2. Financial support to those who cannot become economically self-supporting..

3. Emotional support for individuals and family groups who need it.

4. A high level of social services, particularly education and health...

5. Decent housing and a satisfying physical environment for all families...

6. Elimination of racial discrimination . . (p. 299 , emphasis

Although these six areas are not expressed in the language of objectives, they closely resemble Perloff's earlier formulation of objectives, and more easily permit a comparison with Fitch's goals. One finds that Fitch and Perloff are in close agreement--the only difference consists in Fitch's including "the apparatus of law enforcement . . ." as a goal.

Another way to approach the matter of objectives is to treat them in a more abstract manner. Fitch (1967) does this when he proposes two "aspiration goals" for social planning: (1) the elimination of poverty and its causes and (2) the elimination of the long-standing evil of racial discrimination (p. 337).

These two goals are included in the social objectives proposed by a British sociologist, Peter Townsend:

1. The achievement of social equality or justice,

2. The redistribution of wealth,

3. The adjustment of income to meet the needs of dependency, equality for women,

4. Equality for people of different race or religion and so on (quoted by Gil, 1973, p. 7). 
While there is close agreement on goals between Fitch and Townsend, Fitch states the goals negatively, that is, in terms of eliminating poverty and discrimination; Townsend expresses them positively--emphasizing equality and redistribution. Both expressions support Rein's declaration: "A compelling case can be made to define social policy as planning for social externalities, redistribution, and the equitable distribution of social benefits, especially social services (1970, p. 5).

In this brief review of the goals/objectives of social planning we have seen them expressed both in concrete and in more abstract terms. The concrete objectives, as formulated by Fitch and by Perloff, might easily be placed in Dyckman's categories of social planning: either as a form of the social services or relating in some way to environmental or economic goals. The abstract expressions--Fitch's aspiration goals, Townsend's objectives, and Rein's expression regarding social policy-resist this kind of categorization.

However, can a common thread be found in these varied expressions of goals/objectives? Redistribution, according to Titmuss (1968), another British social policy theorist, provides that commonality. His analysis of the categories of social policy led him to the conclusion that redistribution underlies all social policy. He contends that all categories of social policy are

concerned with changing the individual and family pattern of current and future claims on resources set by the market, set by the possession of accumulated past rights, and set by the al locations made by Government to provide for national defense and other non-market sectors. . ( (p. 192).

Redistribution is also seen by Rein (1971) as the principal objective of social policy. "The primary subject matter of social policy," 
he declares, is "egalitarianism--a concern with the problems involved in the more equitable distribution of social goods" (p. 297).

Thus, egalitarianism or redistribution seem to be the ultimate purpose of social policy. This assertation, of course, is a controversial one. Many may reject it as a goal of social planning, or may reject social planning because this is its goal, and even those who accept it may well question the possibility of achieving much significant redistribution. But our purpose is not to argue for any particular goal or objective: rather we have examined this issue to illuminate the nature of social planning. Looking at goals-objectives of social planning has provided us with another perspective in our search to find a meaning for social planning.

The Meaning of Social Planning: An Assessment and Reconceptualization

In the preceding pages the nature of social planning has been examined from three "perspectives:" definitions, boundaries, and objectives. This review indicates that there are few attempts at formal definitions of social planning or social policy, and that boundaries are not clearly delimited either.

Definitions, boundaries, and objectives ultimately converge on the subject matter of social planning. Brooks (1970), after reviewing the literature of social planning, asserts that "the 'social' in social planning refers, of course, to the nature of the substantive areas involved"' (p. 4). We have seen that consensus does seem to exist that social planning is concerned with the social services and with certain specific areas, such as education, medical services, housing, and manpower development (Perloff, 1965; Fitch, 1967; Kahn, 1969; Brooks, 1970). 
The subject matter of social planning is regarded by many theorists as anything that touches the broad questions of equity and justice. Thus, "it is not the social services alone, but the social purposes and consequences of agricultural, economic, manpower, fiscal, physical development, and social welfare policies that form the subject matter of social policy" (Rein, 1970, p. 4, emphasis added).

Conceptualizing social planning either as referring to the nature of its substantive areas, i.e., social services or specific areas, or in the broader sense as any planning that touches the question of equity and justice, does accurately reflect current usage. However, it is our contention that these notions of social planning are inadequate for three reasons. First, understanding the "social" in social planning as referring to the nature of substantive areas--the subject matter involved--is not a precise meaning. In this usage if one is planning a service for people--be it education, health, housing, etc.--it can be called social planning. Why not be more exact and refer to social service planning, or educational planning, housing planning, manpower planning, etc.?

Second, when the term social planning is used broadly to include planning that takes social consequences into account, social planning becomes identified with any form of planning. All forms of planning should be sensitive to social outcomes and their differential impact, but that seems little reason to justify calling it social planning.

Third, when considering the kinds of problems facing modern urban society, both conceptions--social planning as referring to the nature of the substantive areas and as that planning that takes social consequences 
into account--are inadequate.

For these reasons current usages of social planning are held to be inadequate ones. Social planning needs to be understood in another sense. In this dissertation planning will be considered as "social" onIy when problems are conceptualized in structural terms and when the alternatives that are formulated deal with these structural aspects.

If social planning is conceptualized in these terms, planning for the unemployed, or for community mental health, or for the relocation of low-income persons, etc. will not necessarily constitute social planning. If planning focuses on the individual as the unit of analysis and/or the object of change, it is not social planning. The reconceptualization of social planning that has just been proposed is based on the belief that "the source of social problems lies somewhere in the social order, the organized set of relationships which exist among individuals engaged in a system of interaction" (Mayer, 1971, p. 132).

Since it is contended that the source of problems is structural, other concepts of social planning are held to be inadequate precisely because they do not require that the causes of the problem be confronted. Planning needs to deal with the organized sets of relationships that are involved, and when it does, it is social planning.

${ }^{13}$ Social structure is defined as "the complex array of roles and statuses that define the behavior of individuals and their relations with one another." The term can also refer to "any patterned regularity of behavior or interaction" (Chinoy, 1968, pp. 68-69).

In Chapter 11 of this dissertation structure is discussed as one component of the social system. 
IV. THE PURPOSE OF THIS DISSERTATION

\section{Major Premise and Approach}

We have stated that our purpose is to make planning more responsive to the problems of our cities. In the early 1960's several articles appeared that had the same goal--their authors focused on how to make urban planning more responsive to social goals and social problems. It was recognized that urban planners should be concerned not only with the physical environment of the city, but also that they had a responsibility for social goals as well (Webber, 1963; Frieden, 1965). Others saw linking physical or urban planning with social planning as the necessary task (Gans, 1963; Perloff, 1965).

Although the concern of this dissertation also is attempting to make planning more responsive to the problems of the city, we will not search for a "more comprehensive approach" to improving urban conditions

as some have done (Frieden and Morris, 1968), nor advocate that "the city planning" and "social planning" and/or economic planning approaches be coordinated as others have advocated (Frieden and Morris, 1968; Perloff, 1968). Our approach to improving planning will begin with an examination of the nature of social problems, and then we will consider the implications this has on planning to resolve these problems.

This approach to planning theory differs significantly from most current approaches. Many who attempt to make planning more effective begin by accepting the existent political and social context. For example, Kahn (1969) accepts the reality that planning is limited by the existent political process (pp. vii-ix, 58-59, 339). It is within this framework, then, that he grapples with ways to make planning more rele- 
vant and responsive to social needs. Kahn endeavors to enhance the rationality of the planning process by taking political variables--that both constrain and facilitate planning--into account. A very realistic approach to social planning theory and practice--and one that is useful to planners.

However, the starting point of this dissertation is very different. It is not: How can we improve social planning within a given social and political context? Rather our starting point is: Looking at social problems, what must be done to resolve them? What kind of planning theory and model are needed if social problems are to be resolved.

The first approach is recognized as a valid one. It is our belief and contention that the second is also a valid and potentially fruitful one.

This approach to planning theory differs from contemporary approaches in yet another way. In analyzing current planning theories it is possible to distinguish between those that are concerned with procedure or the planning process itself and those theories that deal with the subject matter of planning (Hightower, 1969). However, it appears essential that a theory of social planning involve both process and subject matter. Our contention is that the subject matter of social planning must be examined before a procedural model can be developed. Thus, this is how theoretical concepts and a social planning model will be developed in this dissertation.

The specific contribution of this dissertation lies in its relating the nature of social problems to planning theory and practice. The premise we will build on is that social planning must be in harmony with 
the nature of its subject matter--and that its subject matter is social problems. The supposition is that if we grasp the nature of social problems and build planning theory and practice on these insights, our planning efforts will be more relevant and more effective.

Therefore, our approach is a theoretical--and normative--one. Social problems are the starting point. After an historical and theoretical analysis of social problems, we consider what implications their nature has on social planning, and the theoretical concepts and a model are developed.

The theoretical concepts, then, grow out of a consideration of social problems, and the model is consistent with these concepts. The development of the components of the model did not occur in a vacuum. A vast literature on planning and policy is available, and thus, the concepts and models of numerous theorists have been studied--with elements borrowed or reconceptualized. Components of the model do resemble other models, however, in their entirety--characteristics of the planning process, planning phases, and planning roles--differ from any other model. And, importantly, the model is related to theoretical concepts which are in turn related to a theoretical analysis of social problems.

The model is normative in nature; it is not tested empirically. In assessing the model we will evaluate it at a theoretical level. Because our contention is that in order to be effective, a social planning model must grow out of a consideration of the content of planning and be responsive to the nature of that content, the model will be evaluated on that basis.

We will now consider in more detail how we propose to develop these theoretical concepts and model. 
Outline of the Chapters

Since we intend to link social planning with social problems, we will first delve into the rature of social problems. Two chapters will be devoted to this exploration. Some of the historical responses that have been made to problems of poverty will be discussed in Chapter 11 . A social systems framework is presented in order to clarify how problems are generated and maintained as well as to explain how responses to these problems are shaped.

Chapter 111 draws upon sociological theory for insight into the nature of social problems. They are conceptualized as having two dimensions: objective and subjective--both of which must be taken into account in social planning. Definitions of problems are also related to the solutions that are offered for problems.

The next two chapters, IV and $V$, focus on social planning. In Chapter IV social planning is placed in a framework of social theory and is discussed as the social construction of reality. Social planning is specifically related to social problems--with evidence from the examination into the nature of social problems supporting two propositions:

1. If social problems are to be dealt with effectively, social planning must treat the structural causes of these problems.

2. If social problems are to be dealt with effectively, social planning must address itself to the values, beliefs, definitions, etc. that obstruct social change.

Chapter $V$ deals with components of the planning model. It is argued that the planning process must be a "task-oriented," "experimental," "cybernetic," dialogic, and collaborative one if social problems are to be 
resolved. Roles and phases of the model, which is identified as a collaborative one, are discussed and illustrated. The planner's role is outlined in some detail.

In the last chapter our approach and conceptual model are assessed along with other approaches to improving the policy/planning process and several planning models. It is contended that the collaborative model developed in this dissertation is the only one that is responsive to the nature of social problems. This dissertation--its theoretical concepts and conceptual model--is seen as a contribution to an emerging planning paradigm--one that holds the promise that we can learn to deal effectively with the problems that confront our cities. 


\section{CHAPTER II}

\section{SOCIAL PROBLEMS: AN HISTORICAL PERSPECTIVE}

\section{THE CITY AND SOCIAL PROBLEMS}

\section{Contemporary Urban Problems}

"We are citizens of the richest and most fortunate nation in the history of the world. . . [Yet] there are millions of Americans--one fifth of our people--who have not shared in the abundance which has been granted to most of us, and on whom the gates of opportunity have been closed" (Johnson, 1964, in Will and Vatter, pp. 9-10).

In this speech President Johnson recognized the problems of inadequate education, broken homes, a hostile and squalid environment, racial injustice, crime, delinquency, disease, hunger, and the hopelessness and despair of those living in these circumstances. And so, "a national war on poverty" was declared in March, 1964.

Only three years later violence erupted in twenty-three American cities. In appointing a commission to investigate these "civil disorders," Johnson identified the conditions that breed despair and violence: "ignorance, discrimination, slums, poverty, disease, not enough jobs." He again declared that "we should attack these conditions" (Report of The National Advisory Commission on Civil Disorders, 1968, p. xv). Today in the 1970 's these still remain serious urban problems. As one pages through history, poverty and its attendant conditions are ever-present--affecting both city dwellers and peasantry. A review 
of two thousand years of thought about urban life reveals an ever-present distrust of the city and a concomitant admiration of agrarian life (Erickson, 1967). Writers from earliest times have left negative images of cities--cities are viewed as centers of great evils, crime, and squalor. Anti-urbanism ${ }^{1}$ and a superficial acquaintance with history--with poverty and the city--may give rise to the view that today's problems are similar to those of the past, and therefore, in some way are inevitably associated with urban life.

In many ways the problems of contemporary cities, and especially the conditions of its poorest residents, are similar to those that have always plagued the city. Yet the problems of contemporary cities in the United States are also different: they are rooted in the nineteenth century--in industrialization and its consequences.

The historical roots of contemporary urban problems will be examined in this chapter. When seen in this context, contemporary problems do not appear to be necessarily endemic to urban life. And it is our assumption that these problems are therefore amenable to resolution. Because poverty is intimately related to these problems, we will focus on it--using poverty, urban problems, and social problems as interchange-

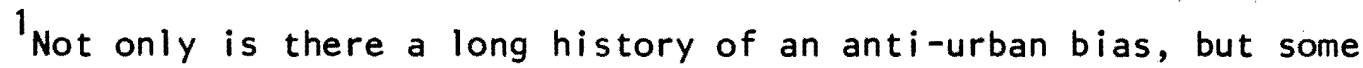
urban experts contend that ant $i$-urbanism, as an ideology, has prevented us from constructively coping with the problems of the city. For example, see Hadden et al., 1967, pp. 118-24.

Anti-urbanism is not the only ideology that prevents us from dealing adequately with urban problems. Racism is also a bias that is an important factor explaining the neglect of the city. The concentration of large numbers of blacks in center cities and the flight of the white to the suburb must also be considered. For a discussion see the reports of The National Advisory Commission on Civil Disorders (1968, 1969). 
able terms. Our emphasis will be on the responses that have been made to problems; then we will seek to understand some of the factors that have shaped these responses. Finally, as a help in clarifying both the causes of problems and responses to them, a social systems model will be presented. This will serve as a basis for the theoretical concepts and planning model that will be developed in later chapters.

Nineteenth Century Roots: Industrialization and Urbanization

A noted historian, Richard Hofstadter (1955), has observed: "The United States was born in the country and has moved to the city" (p. 23). Hofstadter then proceeds to develop his thesis that American life--our ideas, values, and institutions--has been shaped in large part by our agrarian experience. Our concern in this section, however, is not with our agrarian beginnings, but rather with what prompted "the movement to the city."

Two hundred years ago at the birth of the nation, its citizens lived primarily in rural areas and were a nation of farmers. Today eighty per cent of the population live in urban areas. Americans have indeed moved to the city. Many factors explain this movement, but our focus will be on industrialization as the primary force behind urbanization, and as the factor that distinguishes contemporary urban problems in the United States from those of other periods of history.

Industrialization--and the factory system--had taken root in America at the end of the eighteenth century. By 1830 manufacturing was flourishing in the East, although industry was not yet concentrated in the factory system. At this time also only about seven per cent of the nation's population lived in cities of over 8000 (Hofstadter, 1948, pp. 
56-57). Manufacturing continued to grow. New inventions led to the expansion and spread of the factory system. Growth stimulated the demand for cheap labor. Immigrants responded to the opportunities for employment in industry and in canal and railroad construction, as well as to the plentiful farm land that was available. In some places of the country the immigrant was welcomed, yet as early as 1819 immigration was cited as the principal cause of pauperism in New York City, and it was feared that the city would be overwhelmed by the hordes of newcomers (Bremner, 1956, p. 8).

The Know-Nothing Party and Nativist movement in the 1840's and $1850^{\prime} s$ were reactions to the influx of foreigners. ${ }^{2}$ Immigrants were perceived as flooding the labor market--driving wages down, displacing native citizens from jobs or forcing them to accept work at subsistence wages. In 1837 the new mayor of New York City expressed fear at the possibility that the immigrants might generate "a plague by collecting in crowds within small tenements and foul hovels." He saw them "filling every part of our once happy land with squalid poverty and profligacy" (quoted by Bremner, 1956, P. 8).

Others expressed a more sympathetic view. "The mournful and disgusting condition" of the thousands of the "laboring population" who

${ }^{2}$ The Know Nothing Party first came into existence in New York City. It successfully elected James Harper as mayor in 1844. As a national party it existed for only a few years in the early 1850's. The party's slogan: "Americans must rule America!"

The Nativist Movement (1820-50) grew out of the bitter opposition to immigrants. Morrison and Commager maintain that "for the most part, however, the hatred of immigrants was economic in motive. They competed with mechanics who were trying to protect their standard of living by labor unions. Natives refused to work with newcomers, who were then forced into manual labor. . ." (1957, Vol. 1, p. 502). 
lived in New York City's slums in the 1840's aroused the concern of Dr. John H. Griscom, a pioneer sanitary reformer. In Boston William Ellery Channing denounced the practice of "letting cellars and rooms which cannot be ventilated, which want the benefits of light, free air, and pure water, and the means of removing filth!" (Bremner, 1956, p. 5). The poor in other cities lived in similar conditions.

The economic panics of 1819 and 1837 , leaving large numbers unemployed with no source of livelihood and affecting the lives of many others, reduced numerous Americans to levels of degradation previously unknown in this country. By 1860 industrial and urban growth had given birth to problems of poverty--"novel in kind and alarming in size" (Bremner, p. 4). Yet the United States was predominantly a rural society with eighty per cent of its population living on farms.

The explosive growth of industry and cities in the years following the Civil War extended and intensified poverty and problems of the cities and their residents. Between 1860 and 1910 the country's population increased almost sevenfold. Immigrants continued to pour in. By 1910 over thirteen million inhabitants were foreign-born--one-seventh of the total population. ${ }^{3}$ The expansion of industry was a major force behind

3 Between 1860 and 1910 the rural population grew from 25,226,000 to $49,973,000$ while the urban grew from $6,216,000$ to $41,998,000$. The most rapid growth occurred in cities of 100,000 or more (Hofstadter, 1955, p. 174). In 1907 immigration reached a peak with 1,285,000 immigrants entering the country. A notable shift in the sources of immigration had occurred over time: from northwestern Europe to the peasantry of southern and eastern Europe (Hofstadter, 1955, p. 177).

See Wilensky and Lebeaux (1958, pp. 49-55) for a concise account of the relationship between industrial growth and immigration and for an explanation of how the immigrant emerged as "a social problem." 
population growth, and specifically, behind urban growth. Industrial production increased phenomenally: the production of bituminous coal increased five times, crude petroleum twelve times, steel ingots and castings over one hundred forty times in the thirty years between 1870 and 1900 (Hofstadter, 1963, pp. 1-2).

The latter half of the nineteenth century was a time of immense industrial and urban growth (and immigration). More significantly, it was a period of transition: the United States was in the process of being transformed from a rural society into an urban one. A nation based on an agrarian economy with a comparatively wide diffusion of property and power was evolving into one based on an industrial economy with weal th and power concentrated in the hands of few persons. 4

In this period of transition, the 1890 's stand out as "the watershed of American history," for it was during this decade, according to historian Henry Steele Commager (1970), that

a full-throated recognition [came] of the crowding problems of agriculture, urban life, slums, trusts, business and political corruption, race prejudice, and the maldistribution of wealth, and with it, convulsive efforts to adapt a federal political system to a centralized economy, and a laissez-faire philosophy to a program of social dernocracy (p. 46).

These problems, though more widely recognized in the $1890^{\prime}$ s, did

${ }^{4}$ For a further discussion of this shift in the distribution of wealth, status, and power that occurred after the Civil War, refer to Hofstadter (1955, pp. 135-36) and to Dye and Zeigler (1971, pp. 71-79). Hofstadter relates "the status revolution" to the Progressive Movement. He develops the thesis that many in the middle class became Progressives "not because of economic deprivation but primarily because they were victims of an upheaval in status" (p. 135). See Chapter 4, "The Status Revolution and Progressive Leaders," for the development of this thesis. 
not emerge then, ${ }^{5}$ but have existed in an incipient form since the very beginning of industrialization in this country. It was during the $1880^{\prime}$ 's and $1890^{\prime}$ 's that growing numbers of Americans--farmers, workers, small businessmen and others of the middle class--began to become cognizant of their existence. And as shall be discussed later, not only were problems recognized, but a major reform movement grew out of this recognition.

In summary, at the turn of the century every large city in the United States had its slums where workers lived in crowded and squalid tenements in equally squalid neighborhoods. 6 Problems of housing, sanitation, disease, and other problems of the urban poor were intimately connected with inadequate wages, unsafe and unsanitary working conditions (that produced high accident rates and occupational diseases), and frequent unemployment. These conditions of the laborer--men, women, and children--are an integral part of nineteenth century industrialization with its tremendous productivity and generation of wealth. Today's urban problems must be seen in this historical context.

${ }^{5}$ After some historical research the student who is seeking to understand today's urban problems may conclude that these conditions are rooted in the second half of the nineteenth century. Two examples will illustrate why this inaccurate conclusion might be made. In their book which analyzes the impact of industrialization on social welfare services in the United States Wilensky and Lebeaux (1959) begin with the problems emerging in the decades following the Civil War. (See Chapter 3, "The Early Impact of Industrialization on Society.") Also after reading Hofstadter, the Pulitzer Prize-winning historian of the Progressive Era, the student might perhaps infer that urban problems arose in the United States in the latter half of the nineteenth century. See both his The Age of Reform and The Progressive Movement: 1900-1915.

${ }^{6}$ As late as 1910 the 10,000 persons living in the Hungarian settlement in Buffalo, New York, did not have a single bathtub (Powell, 1968, p. 431). 
11. RESPONSES TO SOCIAL PROBLEMS: AN HISTORICAL PERSPECTIVE

In our search to understand contemporary urban problems we will again take an historical approach as we consider both private and governmental responses that have been made to problems of urban poverty. No attempt will be made at either a comprehensive or a strictly chronological study. Responses to specific problems, such as housing, sanitation, public health, child welfare, labor problems, etc. will not be considered in any detail. Our consideration will be selective--focusing on key organizational responses in the nineteenth century, the reform movement that culminated in 1915, the War on Poverty of the 1960's, and current federal programs. The New Deal will be touched briefly as we examine the development of the federal government's role in coping with urban problems.

\section{Early Responses to Poverty}

Public Responsibility. Long before the Industrial Revolution occurred in the United States, methods had been devised to provide for needy colonists. In the $1600^{\prime}$ 's colonial assemblies accepted the principle that the smallest unit of government had the responsibility to care for those who were unable to care for themselves. ${ }^{7}$ The response of the colonists to the problem of poverty was influenced by British tradition and law, and especially by the Elizabethan Poor Law of $1601 .^{8}$ That law

7 For a discussion of social welfare in colonial America, see Trattner (1974, Chapter 2).

${ }^{8}$ For a further discussion of the Poor Law refer to Trattner (1974, Chapter 1), Polanyi (1957), and Pumphrey (1965, pp. 28-29). 
recognized the existence of various categories of the poor and provided accordingly: the aged and infirm (the "impotent" or helpless) were to be cared for (provided with "relief"), orphans apprenticed, and work was to be provided for the able-bodied. Family responsibility as well as private charity were recognized, but when these proved incapable of meeting need, responsibility was placed at the lowest level of government--the town or the parish.

After independence was gained, laws modeled after the British Poor Law were enacted. "As new states drew on the experience of older ones, the Poor Law was transmitted, with a minimum of change, across the continent. Modifications did not change the essential nature of the law until well into the twentieth century" (Pumphrey, 1965, p. 26).

Responsibility for the needy gradually began to expand beyond the local community. 9 As early as 1701 Massachusetts colony recognized that meeting the needs of the poor was sometimes beyond the ability of the town and the colony assumed the responsibility of reimbursing towns when they provided for nonresidents. At the end of the eighteenth century the state of New York provided relief for persons who had been removed from their homes during the Revolutionary War and also granted funds to cities to assist the needy. In 1824 New York transferred responsibility for public assistance from towns to the county. Specialized facilities for the deaf, dumb, and mentally ill began to be established by the states. Although not assuming total responsibility states expanded

${ }^{9}$ One of the themes of the history of welfare in the United States that Pumphrey (1965) develops is the expansion of the geographic basis of welfare. Polanyi (1957, p. 95) discusses the same tendency in British social welfare policy. 
their role in providing for the needy.

Private Efforts. Throughout American history individuals and voluntary associations have responded to needy persons. ${ }^{10}$ After the Panic of 1837 a number of charitable societies were organized to meet the needs of those suffering from the depression. Soon thirty to forty societies existed in New York City, and the demands on them were great. In 1843 the Association for Improving the Condition of the Poor (A.I.C.P.) was founded. The A.I.C.P. was not just another charity agency, rather $i$ ts aim was to coordinate the work of the many existing agencies. "Friendly visitors" called upon the needy and provided aid--either referral to an appropriate agency or help from the A.I.C.P. itself. The association also worked to improve housing conditions, health, and child welfare. Housing surveys were conducted, model tenements built, and public sanitation and compulsory school attendance laws were promoted.

Charity Organization Societies (C.0.S.) founded a generation after the A.I.C.P. Sought to determine who were deserving of assistance and endeavored to provide more efficient service. The C.0.S. coordinated existing charitable organizations, sought to "encourage the investigation of appeals for assistance, prevent duplication of effort by different groups, discover imposters, and suppress mendicancy" (Bremner, 1956, p. 51). Volunteers investigated the poor, referring them to an agency if they were found "deserving." The ultimate goal of the visitors was to

${ }^{10}$ For a survey of voluntary charitable activity see Robert $H$. Bremner (1960) who deals with philanthropy from colonial times to the mid-twentieth century. He also shows how attempts to "do good" by furthering human welfare has sometimes conflicted with American beliefs of individualism and opportunity. 
stimulate the poor to become self-sufficient. The means: advice and example.

A different approach to urban problems of the nineteenth century was that of the settlement workers. ${ }^{11}$ In the 1880's settlement houses were established in New York City and Chicago. By 1900 about one hundred were in existence across the country. Young men and women, largely well-educated and middle- or upper-class, lived among the poor. Eager to assist individuals, they also worked to transform the environment of the slum neighborhood. Settlement houses originally provided a meeting place for neighborhood organizations, then in response to a variety of needs workers became involved in providing a broad range of services: playgrounds; kindergartens; classes in art, music, homemaking; clinics; and day nurseries. Investigations into poverty and its manifold dimensions led settlement residents into social reform--campaigning for public parks, playgrounds, better schools, public health services, better tenement laws, and other areas of advocacy.

\section{The Nationalization of Reform}

Throughout the nineteenth century countless individuals and groups labored to counteract the problems created or exacerbated by industrialization and urbanization. As problems increased in both scope and intensity, private organizations increased in number and size. In the attempt to make charitable efforts more efficient, new methods were developed and efforts to coordinate agencies continued. Social work gradu-

\section{${ }^{11}$ Davis (1967) explores the relationship between the settlement} workers and the reform movement of the Progressive Era. In his view the settlement movement was in the vanguard of reform. 
ally became a paid and professional activity. Cities continued to dispense relief and responded in some ways to problems of housing, sanitation, health, and other conditions. The role of the state too gradually expanded, with state supported institutions multiplying. But the federal government had rejected any permanent role in social welfare activities. $^{12}$ We will highlight the reform efforts from 1890-1915 that finally drew the federal government into responding to the problems of industrialization.

Populism. Interestingly, Populism, the first political movement to seriously attack the problems created by industrialization, originated--not in the city, but in the countryside. Subjected to unfavorable market and price conditions, farmers saw themselves as exploited by "the Plutocrats," "the money interests" (Hofstadter, 1955, p. 58). "The Populists . . ." according to Hofstadter, "were rebelling against the domination of the country by industrialists and finance capitalists". ( $p$. 93). The federal government was seen as the only force capable of confronting the problem, and thus the Populist Party demanded national reforms. Populism reached its peak in 1894 (Hofstadter, p. 100), but by then the demand for reform had spread from the farmers to the middle

${ }^{12}$ Trattner (1974, Chapter 5) traces the development of "scientific charity" in private, voluntary organizations and at the state level. He indicates that although the federal government had concerned itself with education in the Northwest Ordinance of 1787, on occasion had aided victims of fires, floods, and cyclones, and had also deeded public land to both private and public institutions, it had rejected a permanent role in social welfare. President Pierce reinforced this lack of involvement by vetoing an 1854 bill that would have given states ten million acres of federal land for mental hospitals. (Dorthea Dix was largely responsible for the passage of the legislation.) This view that the federal government should have no role in charity was to control federal-state relations in social welfare for fifty years. (Refer to Chapter 4 for this discussion.) 
class and to the two major parties.

Progressivism. During the $1890^{\prime}$ 's growing numbers of the urban middle class awakened to the evils that had accompanied the tremendous industrial and urban growth. Those who had worked to alleviate problems in the city were well acquainted with these evils, but many now began to view them in a new light. Davis (1967) notes the frustration of the settlement workers--feelings that were no doubt shared by other reformers :

For more than two decades they had campaigned for better housing laws, for shorter hours and safer working conditions, for parks and playgrounds, and for other reforms in the city. . . They had tried to correct the abuses they saw all around them; occasionally they had joined political reform movements, but al together they were disappointed with the results (p. 193).

What had been the results? In spite of the efforts of so many, cities at the turn of the century were "industrial wastelands--centers of vice and poverty, ugly, full of crowded slums, badly administered" (Hofstadter, 1963, p. 2). Efforts of urban reformers "had of ten been frustrated by unco-operative courts and politicians, and even when they - had managed to elect an official or pass a reform bill, they had remained dissatisfied and disturbed by the problems remaining" (Davis, 1967, p. 194).

Many had learned from experience that the power of voluntary associations, city government, and the state was inadequate to cope with the major problems engendered by industrialization and urbanization. It was seen as essential to carry reform to the national level. This turning to the federal government for assistance in attacking problems created by industrialization characterized both the Populist and Progressive Movements . 
While a diversity of social classes with a wide variety of issues embraced Progressivism, ${ }^{13}$ three broad goals can be identified: (1) "to reform the business order, to restore or maintain competition . . and to expand credit in the interest of the consumer, the farmer, and the small businessman;" (2) "to minimize the most outrageous and indefensible exploitation of the working population;"14 and (3) to institute political reforms that would restore government to the control of the common citizen and strengthen the democratic process (Hofstadter, 1955, p. 238) .

Accomplishments. Reformers battled political bosses at local and state levels, and in many cases succeeded in enacting various democratic reforms aimed at returning government to the people. Progress was also made in social reforms. Tenement laws were adopted that required higher standards for construction, decency, and safety. States passed legislation regulating the labor of women and children, enacted workmen's compensation, and assistance laws. 15

${ }^{13}$ The Progressive Movement is described by Hofstadter (1955, p. 131) as urban, middle class, and nationwide. "After 1900 Popul ism and Progressivism merge, although a close student may find in the Progressive era two broad strains of thought, one influenced chiefly by the Populist inheritance, the other mainly a product of urban life. Progressivism was characterized by a fresh, more intimate and sympathetic concern with urban problems--labor and social welfare, municipal reform, the interest of the consumer" ( $p .133)$.

14 While the second goal is based on the recognition that workers were exploited, reformers believed that there was nothing inherent in the system that caused class exploitation. The first goal clearly indicates that the economy itself was accepted--granted it was in need of reform that would widen economic opportunity.

${ }^{15}$ Refer to Bremner (1956, Chapter 12) for a discussion of tenement house reform and the crusade against child labor. He also traces efforts to regulate hours and conditions of women's work (Chapter 13). 
In some states legislation was directed at regulating railroads, public utilities, insurance companies, and other businesses, but many times problems were beyond the control of the state. Reformers then demanded action at the federal level. These efforts led to federal legislation regulating large corporations and railroads and were eventually successful in enacting tariff, banking, and credit reforms. 16

In large part the laws were ineffective in dealing with the problems, yet the basis and precedent were established for further reforms. The federal government had accepted "a wide and pervasive responsibility for the welfare of its citizens, and for the poor and powerless among them" (Hofstadter, 1963, p. 15).

In the following pages we will focus on the federal government's role, analyzing the conflicting views of intervention in a market economy.

Role of the Government: Laissez Faire vs. Intervention

The role that government should assume has been the subject of conflicting ideological views (Fine, 1956; Schottland, 1967). On the one hand, proponents of laissez faire and natural law have argued for a minimal role for government. On the other hand, others have argued that

${ }^{16}$ The Sherman Act (1890) and the Clayton Act (1914) were antitrust measures aimed at monopolistic practices of corporations. The Pure Food and Drug Act (1906) and the Meat Inspection Act (1907) were designed to protect the consumer. The Federal Trade Commission (1914) was established to prevent unfair trade practices. The Hepburn Act (1906) gave the Interstate Commerce Commission power to regulate railroads. Tariffs were revised downward by the Underwood Tariff (1913)-the first important tariff reform since the Civil War. Banking and credit practices were affected by the creation of the Federal Reserve System (1913). 
government has a responsibility to promote the welfare of its citizens, and thus must intervene and modify the free play of economic forces. We will focus on these conflicting views of intervention in a market economy, tracing the movement from nonintervention to a negative role for government, and finally to a positive one.

Nonintervention. The doctrine of laissez faire was a natural development of the eighteenth century with its belief in rationality and natural law. "Do not interfere," "leave the market alone," and all will work toward the good of society. These notions fit well with the concept of a mechanistic universe.

Although first advocated by the Physiocrats with respect to the export of grain, it was through Adam Smith (Wealth of Nations, 1776) that laissez faire was given theoretical justification. Smith's "whole economic philosophy stemmed from his unquestioning faith in the ability of the market to guide the system to its point of highest return" (Heilbroner, 1964, p. 53).

A self-regulating market implies that all goods, labor, land, and money are for sale on the market, and that the price of each (prices, wages, rent, and interest) must be left free to find its own natural level. Any interference with the market mechanism--so the theory went-would be at society's expense.

The emerging capitalist class found the theory of a free and unfettered market much to their liking and advantage. This theory which relegated government to the role of nonintervention was consistent also with the traditional American distrust of governmental power and the be- 
lief that the best government is one that governs least. 17

Intervention: A Negative Role for Government. Yet, according to Karl Polanyi (1957), in practice government cannot be relegated the role of strict nonintervention. The major thesis of Polanyi's book, The Great Transformation (1957), ${ }^{18}$ is that a self-regulating market is in actuality an impossibility, "a stark utopia." Accepting the concept produced a dilemma, for "inevitably, society took measures to protect itself, but whatever measures it took impaired the self-regulation of the market, disorganized industrial life, and thus endangered society in yet another way" (Polanyi, pp. 3-4).

Polanyi shows that continuous and increasing government intervention was necessary to protect "free markets" (Chapter 12). Although Polanyi uses British policy to support his thesis, his analysis applies to nineteenth century America as well. Americans believed in the competitive order and accepted the market system, yet Jeffersonians and Jacksonians--even before the Populists and the Progressives--believed that government had a role to play in maintaining competition, in policing the market.

From the 1880's to 1915 , which marked the end of the Progressive Era, the federal government was increasingly relied upon to regulate

17"The distrust of authority" is cited by Hofstadter (1955, pp. 228-29) as a "well-established trait in the national character."

18 In this book Polanyi analyzes the market economy of the nineteenth century and its social and political implications. The key to the political and economic institutions of that time, he maintains, lay in the laws governing the market economy $(1957, p .3)$. He offers an insightful analysis of these nineteenth century British institutions. 
large corporations and railroads. This intervention was at first a response to the needs of the entrepreneurial classes or those on the brink of entrepreneurship: "the farmers, small businessmen, professionals, and occasionally the upper caste of the artisans" (Hofstadter, 1955, p. 305). Laws were enacted that affected the meat packing industry, a Pure Food and Drug Act was passed, a national conservation policy adopted, tariffs lowered, the Federal Reserve System created, and the Federal Trade Commission established. Although the federal government was more frequently intervening in the market, the role it assumed was largely negative and preventive. 19

Intervention and the New Deal: A Positive Role for Government. With the advent of World War I the reform movement that had assigned a more active role to government halted and seemed to disappear in the prosperity of the twenties. ${ }^{20}$ But within a few years the depression gave birth to another period of reform: "the New Deal."

Hofstadter maintains that the New Deal differed from all other periods of reform in American history (1955, pp. 302-16). It was the only time when a leader of a reform party took office during a severe depres-

${ }^{19}$ Hofstadter (1948) discusses Wilson's "New Freedom" as "an attempt of the middle class, with agrarian and labor support, to arrest the exploitation of the community, the concentration of wealth, and the growing control of politics by insiders, and to restore, as far as possible, competitive opportunities in business" (p. 260). In embracing the progressive creed, Wilson admitted that he was not against big business, but against trusts; nor was he against free competition, but illicit competition ( $p .256$ ). Wilson, as other reformers, proposed "no fundamental alteration in the economic order. He . . aimed to preserve competition, individualism, enterprise, opportunity. . " (p. 259).

20 In his examination of the 1920's Hofstadter (1955, pp. 272-301) asserts that about the only new concern of the federal government was the regulation of the production and distribution of liquor. 
sion. 21 More significantly, other reform movements had dealt with "reforms of an essentially entrepreneurial sort and only marginally with social legislation" (p. 308). For the first time the federal government assumed responsibility for the condition of the labor market, for social security, unemployment insurance, wages and hours. Fiscal policy was used to stimulate the economy. A federal housing act was also approved authorizing public housing. Although the program was a small one, in Charles Abrams' view, it was politically revolutionary (1965, p. 4). In this particular exercise of the welfare power the federal government accepted a measure of responsibility for an urban problem, and also chose to deal directly with the city.

More significantly, the New Deal signaled the beginning of an era in which the federal government undertook a positive role in intervention: actively promoting the welfare of its citizens. ${ }^{22}$

\section{The War on Poverty}

We have considered nineteenth century responses to urban problems, have traced the role that government--and the federal government in particular--assumed through the 1930's. Now our focus turns to the Economic

${ }^{21}$ Progressivism flourished during a time of comparative prosperity, while the reforms of the New Deal, of course, were initiated during a severe depression. See Hofstadter (1963, pp. 6-7 and 1955, pp. 302-16) for a contrast between these two periods of reform.

${ }^{22}$ This view is consistent with Hofstadter's interpretation. Theodore Lowi (1969) also maintains that the principle of positive government was established by 1937. However, Lowi argues that we need to look at the purpose of the intervention: is it to maintain the status quo, or is it concerned with change, and if so, what degree of change? For that discussion see Chapter 3, "The New Public Philosophy: Interest Group Liberalism." 
Opportunity Act of 1964, more commonly known as the "War on Poverty." No attempt will be made to evaluate its programs, rather we will seek to answer why a "war" was declared, what it was, and how this response compares with previous responses to poverty.

Origins. Several writers have traced what they consider to be the origins of the War on Poverty. ${ }^{23}$ There is no need here for a comprehensive explanation, and indeed, the origins of the War on Poverty are not easy to explain (Levitan, 1969, p. 11). Thus, the remarks that follow seek only to place the legislation in its historical context.

With the advent of World War $I I$ and during the post-war period poverty was largely forgotten. Some social legislation was passed, but on the whole, the nation was indifferent to poverty or issues of reform. General prosperity characterized 1963 and 1964: the economy was expanding, incomes were rising (Levine, 1970, p. 45; Levitan, 1969, pp. 11-12). Yet an awareness was growing that not all Americans shared in the general economic weli-being. Statistical analyses revealed that the number of persons living in poverty was actually increasing, and that the incidence of poverty fell heavily on certain groups: racial minorities, the aged, and those living in certain areas of the country. Michael Harrington's book, The Other America (1963), and an article by Dwight MacDonald that appeared in The New Yorker in early 1963 brought the phenomenon of mass poverty before the public (Levitan, 1969, pp. 12-13).

It was during this period of increased consciousness of the plight

${ }^{23}$ The origins of the War on Poverty are discussed by Sundquist (1969), Donovan (1967), Moynihan (1969), Levitan (1969), and Levine (1970). 
of the poor that the Economic Opportunity Act--the federal government's response to poverty--was enacted. However, Piven and Cloward (1971) offer another explanation for its passage--arguing that the Economic Opportunity Act, as well as other social legislation of the Kennedy and Johnson administrations, ${ }^{24}$ was initiated primarily in an effort to strengthen their political base in the nation's cities. In 1960 ninety per cent of Northern blacks were concentrated in cities in the ten most populous Northern states. "To reach, placate, and integrate a turbulent black constituency, the national Democratic administrations in the 1960's -. . sponsored a variety of programs "to help blacks get more from local government" (Piven and Cloward (1971, p. 281).

Whether this was the political imperative, as Piven and Cloward cogently argue, is debatable. However, demographic facts as well as the growing civil rights movement no doubt made the Kennedy and the Johnson administrations more responsive to the issue of poverty (Levitan, 1969, pp. $14-15)$.

Goals and Programs. In President Johnson's Message on Poverty on March 3, 1964, he declared that "for the first time in our history it is possible to conquer poverty." He also spoke of opening "the gates of opportunity" for the one-fifth of the nation who was poor (Will and Vatter, 1970, pp. 9-11). Overcoming poverty and extending opportunity may

24 Besides the Economic Opportunity Act of 1964 the Juvenile Delinquency and Youth Offenses Control Act of 1961, the Community Mental Health Centers Act of 1963, and Title I of the Demonstration Cities and Metropolitan Development ACt of 1966 are included as part of the federal strategy in the cities. For an extended discussion of federal intervention in the cities see Piven and Cloward (1971, Chapter 9, "The Great Society and Relief: Federal Intervention'). 
be seen as the broad goals--and the stated goals--of the Economic Opportunity Act. 25

There are many ways that the programs can be classified or discussed. Again, many writers have done this. Also assuming that readers have some familiarity with these programs, we will not review the programs, but will only highlight three categories:

1. The manpower programs: Job Opportunities in the Business Sector (JOBS), Job Corps, and Neighborhood Youth Corps (NYC)--whose objective was to provide training to improve the ability of the worker to enter the labor market and increase his income;

2. Educational programs: Head Start, Follow Through, and Upward Bound--whose objective was compensatory education or equalizing educational opportunity; and

3. The Community Action Programs (CAP's). Title Il of the Economic Opportunity Act authorized any activity that would give promise of eliminating poverty. Community action programs might aim at "developing employment opportunities, improving human performance, motivation, and productivity, or bettering the conditions under which people live, learn, and work." The programs were to be "developed, conducted, and administered with the maximum feasible participation of residents of the area and members of the groups served." The CAP's could be under the auspices of either public or private nonprofit agencies (Clark and Hopkins, 1968, pp. 6-7).

${ }^{25}$ Levine (1970, Chapter 3) argues that the War on Poverty had two objectives: anti-poverty and equal opportunity. From his evaluation of its programs, he concludes that the stress was primarily on opportunity. 
Operating under these broad guidelines, CAP's led to a variety of programs: services, community organization, and community action. 26

Comparison with Earlier Responses. Although the Economic Opportunity Act has been considered only briefly, some comparisons can be made between it and earlier responses to poverty and urban problems.

Levitan expresses the belief that the 1964 legislation is rooted in the tradition of the Elizabethan Poor Law, as the title of his book, The Great Society's Poor Law (1969), indicates. After an evaluation of the implementation of the Economic Opportunity Act, Levitan concludes that society grudgingly provides help to the poor (p. 318 ). The goal of the act, Levitan maintains, "was not to ease the burdens of poverty by providing cash;" rather its goal was "to offer the poor the opportunity to lift themselves out of poverty" (p. 318 , emphasis added).

The War on Poverty is also rooted in the New Deal. Emergency Relief, the Works Progress Administration, the National Youth Administration, and the Civilian Conservation Corps "were earlier versions of the war or skirmishes against the prevailing poverty of the Depression years" (Clark and Hopkins, 1968, p. 3).

In the 1930's the federal government had responded to problems of poverty. Yet the poor of that time could not be distinguished by racial or other characteristics. The programs of the New Deal--especially social security and the legislation that regulated hours, wages, and work-

${ }^{26}$ Clark and Hopkins (1968) conclude from their analysis that the CAP's were overwhelmingly service-oriented. Their conclusion is supported by Hallman (1968) who found that thirty-two of the thirty-five CAP's he evaluated emphasized services. 
ing conditions--affected the vast majority of Americans. The poverty of the 1960's was different: it was highly concentrated in groups that were characterized by unequal opportunity. The War on Poverty, directed at these groups, especially at the large number of black Americans, differed then from earlier efforts (Levine, 1970, p. 33).

The Housing Act of 1937 had involved the federal government directly in the city. This role was expanded by the Housing Acts of 1949 and 1954. The federal government became concerned with slum clearance and urban renewal--assuming a responsibility for renewing the cities (Abrams, 1965, pp. $78-79)$.

With the Economic Opportunity Act, the federal government became further involved with the city and its problems. Al though the "war" was on poverty, both rural and urban, the cities were the primary battlefields. 27

According to Piven and Cloward (1971), the War on Poverty and other Great Society programs involved a unique administrative arrangement-a "direct relationship between the national government and the ghettoes, a relationship in which both state and local governments were undercut" (p. 261). The language of the legislation might refer to the "inner city," "slums," or the "urban core," but these were only euphemisms for the ghetto $(p, 260)$. In their view, as the New Deal circumvented the states, dealing directly with the cities, the Great Society--in offering

27 Piven and Cloward (1971) cite the "urban bias" of the Great Society's programs. To support this assertion they quote Levitan: "For the nation as a whole, CAP grants over the first four years averaged roughly $\$ 97$ per poor person. The comparable figure in the ten cities that received the largest grants was almost three times the national av-

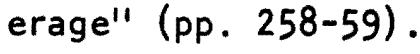


federal funds to the ghetto--was circumventing city government (p. 263). Donovan (1967) also acknowledges the existence of a new pattern of federal-local relationships, suggesting that "one of the most interesting aspects of the new legislation is its heavy reliance on local initiative." He states that the requirement of "maximum feasible participation" of the local residents and the poor may well be "the most significant social welfare innovation since the days of the New Deal" (p. 60).

Earlier the Housing Act of 1954 did require that cities show evidence of "citizen participation" in order to receive urban renewal funds. But "participation" in urban renewal resulted in city-wide advisory boards--not in the involvement of the poor or the residents of the area slated for clearance. A workbook from the Office of Economic Opportunity, the agency that administered the CAP's, stated that "one of the major problems of the poor is that they are not in a position to influence the policies, procedures, and objectives of the organizations responsible for their welfare"' (Donovan, 1967, p. 43). Institutions were considered unresponsive to the needs of the poor, and thus, social agencies, schools, health agencies, and city government became targets of reform. ${ }^{28}$ Most previous efforts to deal with poverty had the individual as a

${ }^{28}$ The forerunners of the community action programs were the Juvenile Delinquency and Youth Offenses Control Act of 1961 and the Grey Area Projects sponsored by the Ford Foundation. These were attempts to attack the causes of poverty through community action.

See Marris and Rein (1967) for a discussion of the origins of community action as an approach to social problems and also for a discussion of the evolution of community action under the Economic Opportunity Act.

Moynihan (1969) also discusses the President's Commission on Juvenile Delinquency (Chapter 3 ) and the Mobilization for Youth, a Ford Foundation project in New York City (Chapters 3 and 6). 
target of change. 29 Most of the poverty programs of the 1960 's--even most of the community action programs--ultimately did too. Yet CAP's involved the poor in varying degrees in planning and in administering programs. Some of the CAP's, recognizing the need for institutional change, were committed to the strategy of giving power to the poor and of stimulating their confrontation with "the establishment." The attempt to involve the poor does represent an important break with traditional social welfare activities (Clark and Hopkins, 1968, p. 7).

From Model Cities to Revenue Sharing 30

The programs of the War on Poverty were intended in various ways to extend opportunity to the poor. However, the physical environment of their neighborhoods and cities had not received much attention. The Model Cities program grew out of this concern. The task force that designed the original Model Cities legislation saw the possibility of incorporating the social concerns of the War on Poverty with programs dealing with the physical environment of the city.

The purpose of the Model Cities program was two-fold: first, to provide "assistance to enable cities. . to plan, develop, and carry out programs to rebuild or revitalize large slum and blighted areas," and secondly, "to expand and improve public programs and services available to the people who live in such areas" (Frieden and Kaplan, 1975, p. 53).

${ }^{29}$ This point will be developed in Chapter 111 , Section 11.

${ }^{30}$ This discussion of Model Cities and Revenue Sharing is based primarily on Frieden and Kaplan's analysis (1975). 
An underlying purpose was "to reform the federal grant-in-aid system by making it more responsive to local priorities, more flexible, and more subject to control by local elected officials" (Frieden and Kaplan, 1975 , p. 232). The concentration of funds in poverty areas of selected cities and the improved coordination of federal aid were key concepts.

The Demonstration Cities and Metropolitan Act of 1966--the Model Cities legislation--included phrases such as "coordination of federal assistance," "prompt response to local initiative," and "maximum flexibility in programming," but according to Frieden and Kaplan, "they were clearly devoid of real operational content. . . In effect, they reflected more the expressed hopes and desires of the program's supporters than the specific marching orders of Congress or the White House" (p. 67).

In practice, the Model Cities program became another grant-in-aid to the cities, not the unifier of all other federal aid programs to the city as some had envisioned. Improvements were made in poverty neighborhoods, but in the face of the need the changes can hardly be considered significant ones.

What is the current response of the federal government to the city and its problems? Briefly let us consider two aspects: income and aid to cities.

1. Income Provision. Attempts of the Nixon Administration to enact a farnily assistance plan failed. Partial reforms have been made in welfare legislation and in social security. Cash and in-kind benefits have been expanded: medical care payments, food stamps, student aid, child care, and housing subsidies. However, the income received by numerous Americans--especially by racial minorities, households headed by 
women, and the elderly--continues to place them below the poverty leve1. 31

2. Revenue Sharing: General and Special. Since 1972 cities have received federal revenue funds with virtually no strings attached. Cities may also apply for special categorical grants. Manpower is one such, and community development, included in the Housing and Community Development Act of 1974, is a second. Community development is primarily concerned with the physical aspects of the city: water and sewer projects, urban renewal, urban beautification and open space, historic preservation, housing rehabilitation, etc. Model Cities is also included.

How does revenue sharing respond to the needs of the urban poor? A 1973 study of cities with populations over 50,000 found that the patterns of spending of revenue sharing allocations is similar to that of cities' normal budgetary decisions. "Cities reported spending only 1.6 percent of their new funds for social services for the poor and aged, and only 1.1 percent for health services" (Frieden and Kaplan, 1975, p. 246). This is a slightly smaller proportion for health and welfare needs than in the normal city budget.

Population, overcrowded housing, and the extent of poverty are considered in the allocation of funds for community development. However, the law does not require that efforts be concentrated to improve the living conditions of low- and moderate-income groups.

${ }^{31}$ The number of persons in 1975 officially classified by the federal government as living in poverty was nearly $26,000,000--a 10.7$ per cent increase over 1974. 
Frieden and Kaplan maintain that the performance standards for participation in community development decisions reflect a more limited conception of resident participation than that of the Model Cities program. They fear that the participation of poor residents will be weakened, and that participation may ultimately revert to the limited form that characterized the early urban renewal program (pp. 252-53). 32

The "politics of neglect," the title of Frieden and Kaplan's book, aptly characterizes the responses of the federal government in the 1970's to the needs of the urban poor and the crisis facing the city.

\section{I. RESPONSES TO SOCIAL PROBLEMS: AN ANALYSIS}

In the previous section our concern was with responses that have been made to social problems. Numerous individuals and groups, as well as various levels of government have responded to a variety of problems: housing, health, crime and delinquency, child welfare, etc. Our focus, however, was necessarily limited and was primarily on urban poverty. We have seen that over the years the federal government has assumed a more active role in promoting the social welfare of all citizens, as well as in accepting more responsibility for the poor.

In spite of all these efforts, poverty and its related conditions continue to exist. President Johnson expressed the belief that it is possible to conquer poverty. Why then does poverty persist? Several

${ }^{32}$ An alternate conclusion is drawn by Cole (1975). While admitting the need for additional research, he maintains that "the most objective conclusion appears to be that revenue sharing has not and will not lead to the demise of municipal citizen participation opportunities, al though the form they will take in the future may be altered" (pp. 73-74). 
different answers to this question will be summarized and the theoretical debate on this issue will be briefly discussed. A social systems model that explains both the causes of problems and factors shaping responses to problems will be presented. Finally, the implications this has for social planning will be considered.

\section{Explanations for the Persistence of Poverty}

Numerous explanations have been offered for the persistence of poverty. They can be placed in two broad categories: those that assign responsibility to the poor themselves and those that consider the social structure as generating and maintaining poverty. The first two theories that will be summarized blame the poor; the others focus on some aspect of the social structure as the dominant factor.

The Individual As Responsible. There seems little need to clarify this view point. Popular throughout history, many still accept it as the chief explanation for poverty. According to a 1969 survey of attitudes toward poverty and anti-poverty programs, fifty-six per cent of white Americans support the view that individual failings are primarily responsible for poverty (Reissman, 1973, p. 69)..$^{33}$

If policy decisions are influenced by public opinion, this belief is an important factor in explaining "the politics of neglect."

33 In a study by Rytina et al. (1970) respondents were asked, "Why are poor people poor?" Sixty-two per cent of the rich expressed the belief that poverty is the result of personal attributes, while only seventeen per cent of poor blacks agreed with this. The study also examined beliefs about the American opportunity structure. The data tends to confirm the hypothesis that "the support of an ideology is strongest among those who profit most from the system which the ideology explains and defends, the rich in this case" (p. 715). 
The Lower Class As Self-perpetuating. "The culture of poverty" (Lewis, 1966), "lower-class culture" (Miller, 1958), "the disreputable poor" (Matza, 1966) are similar versions of a concept of poverty in which a special set of values, norms, and behavioral traits--non-conforming with middle class standards--are ascribed to the poor.

This notion of poverty was prevalent in the social science literature in the 1960's. Marris and Rein (1967) as well as Moynihan (1969) cite the key assumptions of this concept as underlying the original planning of the community action programs.

If social policy is based on this concept, as many of the War on Poverty programs were, ultimately it must focus on individual deficiencies as the cause of poverty. For although the social structure or societal conditions ${ }^{34}$ may have originally given rise to lower class culture, once it comes into existence it is viewed as self-perpetuating. "By the time slum children are six or seven they have usually absorbed the basic attitudes and values of their subculture. Thereafter they are psychologically unready to take full advantage of changing conditions or improving opportunities that may develop in their lifetime" (Lewis, 1966, p. 21).

34 Oscar Lewis (1966) "suspects" that "the culture of poverty flourishes and is endemic to the free-enterprise, pre-welfare-state stage of capitalism" ( $p .24)$. He is also "inclined to believe the culture of poverty does not exist in socialist countries" (p. 23).

Among the factors cited by Lewis as preconditions for the culture of poverty are: "a cash economy, with wage labor and production for profit and with a persistently high rate of unemployment and underemployment, at low wages, for unskilled labor" (p. 21). Lewis also observes: "The dominant class asserts a set of values that prizes thrift and the accumulation of wealth and property, stresses the possibility of upward mobility and explains low economic status as the result of individual personal inadequacy and inferiority" (p. 21). 
Thus, according to this perspective, social institutions play no major role as a present cause of poverty. In fact, if the poor are incapable of taking full advantage of opportunities, the ability of social institutions to eradicate poverty is questionable. ${ }^{35}$ In this view, the persistence of class poverty seems inevitable.

The Political System. In two separate studies--one of five urban programs of the 1960's (Piven, 1971) and another of federal efforts to solve five contemporary social problems (Jones, 1971)--the writers arrive at similar conclusions: the federal government (the political system) is incapable of solving social problems. Why? Because programs designed to cope with problems are ultimately shaped by politics.

Both Piven and Jones posit the existence of a pluralistic political system in which government representatives are responsive to competing interest groups. "In the process of gaining enough adherents for a program to eradicate a social problem," the program must necessarily become so diluted and diverted "that it is either irrelevant to the problem or incapable of solving it" (Jones, 1971, p. 585).

The assumption is that to maintain itself, the political system

35 Banfield (1970) blames the lower class for crime, poverty, educational and racial problems. Programs aimed at solving these problems are bound to fail, Banfield asserts, because the lower class is unable to respond. Little can be done for these problems, although time and economic growth may eventually alleviate them. According to Banfield, no urban crisis exists, and he warns that by treating a spurious crisis as if it were real, we may unwittingly make it so (p. 22). Efforts to "solve problems" of the city are only likely to make them worse.

In a later work Banfield (1974) reaffirms his basic thesis that the nature of the lower class makes real change impossible, and he again warns against governmental programs designed to solve problems. 
must appeal to its middle class constituencies. 36 "It is not feasible for government to attempt to change fundamental inequities within the economic, social, and political structures" (Jones, p. 586). Therefore, social programs will continue to deal with symptoms of problems. And problems necessarily persist.

A Power Elite. 37 The proposition that the poor remain poor because the middle class does not support a change in the status quo has just been set forth. The assumption is that political power lies in the middle class--that public policy is reflective of their interests.

Elitist theory holds a contrary proposition: public policy is a reflection of the interests and values of elites. Who are the elites? They are those who occupy key positions in economic, political, or military institutions. They are drawn primarily from the upper socio-economic classes. There is considerable circulation of elites. They move freely between positions in corporations, government, the military and in some of the other influential institutions.

Although elites disagree on some issues, these are relatively un-

${ }^{36}$ Walinsky (1964) argues that "the middle-class majority does not want to improve significantly the lot of the poor, or--a further step-that the middle-class actively desires to keep the poor where they are" (p. 160). The middle-class, according to Walinsky, wishes to "keep the poor in their place" in order to preserve their own status.

37"The power elite" position set forth here is based on $C$. Wright Mills' book (1959). A book edited by Domhoff and Ballard (1968) contains articles reviewing and criticizing Mills as well as Mills' reply. An explanation of American politics from an elitist perspective is offered by Dye and Zeigler (1971). Chapter I explains the meaning of elitist theory, while Chapter 13 sets forth some propositions.

Mills (1959) and Domhoff (1970) deal with a national elite, while Hunter (1953) deals with a local elite, developing the thesis that power in Atlanta was concentrated in elites. 
important. They share basic values and are committed to the preservation of the existing social system. Masses are influenced--even manipulated-by elites, rather than elites being influenced by the masses.

Since elites control decision making, it is unlikely that any substantial changes will be made that would alter existing relations. Public policy reflects the general conservatism of the elites. Inequality and power seem destined to persist.

The Economic System. In C. Wright Mills' (1959) version of the power elite, power is lodged in positions in economic, political, and military institutions. More specifically, it is wielded by those who occupy the key institutional positions. Conceptualizing a tripartite power-base, Mills held that the institutions, although related and interdependent, remain separate spheres.

A radical critique, 38 influenced by Marx, faults Mills for not explicitly stating what forms the basis for the consensus existing among the elites and for not specifying what unites the three separate institutional hierarchies.

In this view the three institutions do not share equally in power-the economic sphere dominates the other spheres. Real power resides in those who control the economic order. Power is class-based, not position-based, and resides in the upper class of business owners and corporate managers.

${ }^{38}$ The explanation of this perspective is based on three articles contained in the Domhoff and Ballard collection (1968). See Part 11: "Radical Critics of The Power Elite" and the articles by Lynd, Sweezy, and Aptheker.

See also Domhoff's discussion of The Power Elite and its critics, pp. $251-78$. 
Public policy decisions reflect their interests which are primarily economic: the continuance of the economic system with private enterprise and the protection of private property. The working class has shared in the fruits of economic growth and some concessions have been made in order to reduce tension. But decisions ultimately serve to perpetuate the system in which property and income are distributed unequal$1 y .39$ No radical redistribution of wealth or income is likely to occur. Thus, the economic system will continue to generate inequality and poverty.

\section{Factors Causing Poverty and Shaping Responses to Poverty}

Debate over Key Factors. Some of the prevalent theories that are offered to explain the existence and persistence of poverty in the United States have been reviewed. Factors that have been considered as causes include: the poor person as an individual, lower class culture, the political system, the middle class, the power elite, and the economic system.

In addition to these competing explanations, an attempt to pin-

${ }^{39}$ According to this perspective whether economic, political, or social unrest becomes revolutionary is largely dependent upon how the elite handle the situation. Dye and Ziegler's (1971, Chapter 12) treatment of the Civil Rights Movement is typical of this perspective. They conclude that "if elitist democracy in America is to survive the present racial crisis, those who rule must use their influence as opinion leaders of the white masses to foster attitudes more conducive to social change and racial equality" ( $p$. 319). If the white elite is able to "enact and effectively administer programs that more equitably distribute rewards and opportunities throughout all segments of society... ., it will thereby reduce the tension. . . and reduce the revolutionary potential of a deprived minority" (p. 319).

Thus, this perspective admits that change occurs, but it is considered minimal--only enough to placate the dissatisfied. The system remains basically the same--with the elite firmly in control. 
point key factors is further complicated by a disagreement over the relative importance of elements in the social structure. An analytical distinction can be made between the factual or institutional level of social structure and the normative or ideological level, that is, values, beliefs, norms, etc.

In analyzing causes of and responses to poverty one is faced with the question of how much weight to assign to the values of individualism and competition, the work ethic, beliefs in opportunity and equality, etc. It must also be determined whether to explain causes and policy primarily at the institutional level--the political system, economic system, and/or social organization. Some hold that we should look primarily to the normative and ideological, for it supports or reinforces the factual level, while others maintain the opposite.

A similar disagreement arises when some theorists distinguish between infrastructure and superstructure--with the infrastructure conceptualized as giving rise to the superstructure. Marx contended that the economic system--the means of production (technology and organization) and the relations of production--determines the superstructure. Marx included in the superstructure all non-economic institutions, as well as the cultural and symbolic systems. Others besides Marx have used this concept, but differ on what comprises the infrastructure: is it the economic system, community, technology, dernographic factors, or combinations of these? ${ }^{40}$

${ }^{40} \mathrm{~A}$ demographic-ecological framework has frequently been used by American sociologists to explain the urban way of life. Powell (1968), using another framework, argues that the key to the city is the economic institutions: first the market, then the corporation. He uses Buffalo, New York, from 1810-1910 as a case study to support his thesis. 
The theoretical debate over the causes of poverty continues. 41 Competing theories about the relative importance of normative and institutional aspects of the social structure also continue to be offered. Supporting evidence is fragmentary, and thus, definitive answers to end the debate are unavailable.

A Social Systems Perspective. Although agreement on the causes of poverty is lacking, in order to develop policy and programs to cope with poverty and its attendant problems--to develop a social planning model, some theoretical perspective must be accepted. In this dissertation a "single cause" approach is rejected. Economic and technological factors are acknowledged as definitely significant. Yet norms, values, and ideology are so intertwined with technology and institutions that they may not only reinforce the existing patterns, but may even determine which are to survive. 42

A framework developed by Donald A. Schon (1971)--one which we will adopt--permits a consideration of several factors. The social system is conceptualized as consisting of structure, technology, and theory. Structure includes the institutionalized relationships between persons,

${ }^{41}$ This debate is closely related to explanations of social change. For a concise summary and critique of sociological theories of social change see Cohen (1968, Chapter 7).

42 In attempting to explain what determines social class Warner and his colleagues (1949) advanced a similar view. They assert: "It cannot be denied that economic and technological factors are important in the determination of class and status orders. We must not lose sight of the fact, however, that the social system, with its beliefs, values, and rules, which governs human behavior may well determine what kind of technology and what kind of economic institutions will survive or thrive in any given tribe or nation" (p. 21). Cohen (1968, p. 198) too concurs with this view. 
between institutions, in institutions, and in organizations. Theory refers to norms, values, and ideology--what some refer to as the symbolic system. Technology refers to those tools and techniques used by members of the social system. These three components interact with one another and are interdependent. Two key assumptions about these system components are: "They have evolved in relation to one another and they are built on one another. Hence, one cannot be changed wi thout inducing change in the others" (Schon, p. 36).

This conceptualization of the social system and how problems and responses fit into this framework is illustrated by the following dlagram.

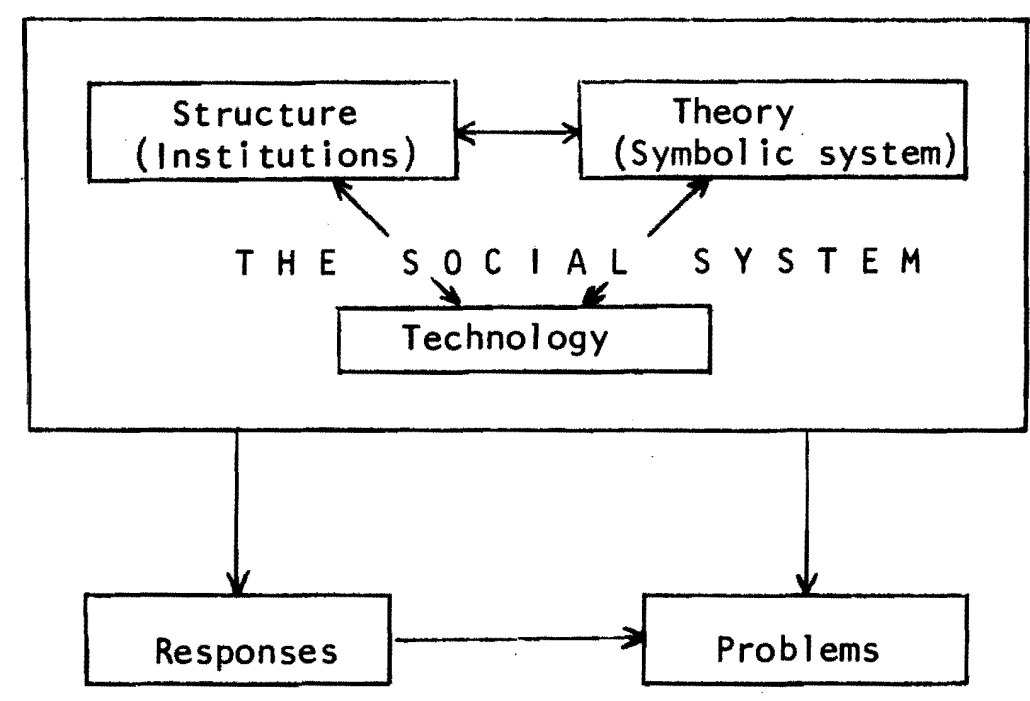

Figure 1. The social system and social problems.

Problems are generated and maintained by the social system, with technology, theory, and structure interacting as causes. But responses to problems are also shaped by the social system. Technology may be capable of eliminating poverty, but institutions may fail to respond to 
that possibility, and individualistic values may conflict with and override altruistic or humanitarian ones. It is the interaction of these components that determines the response that is made to problems. ${ }^{43}$

Implications for Social Planning

The adoption of a systems framework permits us to focus on "structure" as the cause of problems, and at the same time to consider "theory" as a key factor in the generation and perpetuation of social problems. Several theorists contend that responses to problems have been geared more to the maintenance of the social system--the status quo--than they have been to the causes of problems. For example, Schattschneider (1960) has advanced the thesis that the political system develops "a mobilization of bias"--"a set of predominant values, beliefs, rituals, and institutional procedures ('rules of the game') that operate systemically and consistently to the benefit of certain persons and groups at the expense of others" (Bachrach and Baratz, 1970, p. 43). 44

The concept of "bias" and its "mobilization" was applied by Schattschneider only to the political system, but the mobilization of bias is a concept that can be extended to the social system itself. "Theory"

${ }^{43}$ In stating that these components "determine" policy, no claim is made that this is a deterministic process, that is, that if we can identify essential variables, a response can be predicted. What we do mean is that the social system--theory, technology, and structure--provides a framework within which the response is made. The meaning will be clarified in Chapter IV when the nature of the human person and social interaction are discussed.

${ }^{44}$ For Schnattschneider's (1960) discussion of the mobilization of bias see Chapter 2, "The Scope and Bias of the Pressure System." It should be added that he clearly identifies the bias as a "business or upper-class bias." 
and "structure" interact, or "bias is mobilized," so that social systems are characterized by dynamic conservatism, that is, "their boundaries and patterns of internal relationships resist change" (Schon, 1971, p. 32).

This conservatism or bias affects responses that are made to problems. It must be considered in planning social change. Our proposition is that social planning must focus on both "structure" and on "theory" if social problems are to be resolved. Both are causally related to social problems. Thus, they can be used not only to explain the persistence of problems, but can also be considered sources of change--as targets of intervention.

We will return to this conceptualization of social problems in Chapter IV when we develop more fully the link between social problems and social planning.

\section{THE CITY AND SOCIAL PROBLEMS: PAST AND FUTURE}

This chapter has focused on social problems, especially the problem of poverty. We have seen that today's problems of poverty are rooted in the nineteenth century. Associated with industrialization and urbanization, poverty differs from that existing prior to the industrial revolution.

We also traced some responses--both private and governmental--that have been made to the problems of poverty. Our purpose was to provide an understanding of how problems have been confronted historically. This historical account provides the basis for the analysis that will be undertaken in the next chapter when the relation between problem definition 
and solution is explored.

Since efforts at various levels of government and by many persoris and groups over the years have failed to eliminate problems of poverty, we outlined some explanations for their persistence. A social systems perspective has been proposed as a framework for conceptualizing both the causes of problems and the factors that shape responses to problems. This framework will be used when social planning is conceptualized in Chapter IV.

In summary, three questions have been addressed in this chapter: First, what are the historical roots of today's social problems? Secondly, how have we coped with these problems? And lastly, why do problems persist?

A fourth question seems to follow: Will we continue to respond half-heartedly to problems? Or in other words, will problems persist? This question, however, will not be considered. Instead we will raise another: How might social problems be confronted? We have already begun to answer that question with the contention that social planning must focus on changing elements in the social system--specifically, structure and theory.

To enrich and complement the insights that have been gained, the next chapter will probe more deeply into the nature of problems. We will analyze them from a sociological perspective. Only after social problems have been explored can we develop a model of social planning that offers the possibility of successfuly confronting these problems. 
CHAPTER III

\section{SOCIAL PROBLEMS: A THEORETICAL ASSESSMENT}

This chapter continues the exploration into the nature of social problems that was begun in the previous chapter. Operating on the premise that in order to be effective, social planning must grow out of a consideration of its content and be responsive to the nature of that content, we must examine social problems further, for they are the content of social planning.

While the last chapter considered social problems primarily from an historical perspective, our approach now is in a more theoretical vein. The chapter is divided into four sections. The first draws upon sociological literature for theoretical insights into social problems. The second part analyzes social practice--assessing the relation between the definition of a problem and its solution. The implications that this theoretical approach to social problems has for social planning is the concern of the third section. The last part considers in more detail the ramifications on citizen participation. Our investigation into the nature of social problems leads to the contention that the participation of citizens is essential in social planning. This provides a theoretical basis for the inclusion of citizens in the social planning process. 


\section{SOCIOLOGICAL THEORY AND SOCIAL PROBLEMS}

In turning to the sociological literature that deals with social problems we will consider how sociologists define social problems. Then we will investigate how sociological theorists treat social problems. Two distinct approaches--what we identify as the subjective and the objective-will be reviewed. Finally, we will criticize these approaches for what they neglect, that is, social structure.

\section{Definitions of Social Problems}

'Whenever people begin to say, 'Isn't it awful! Why don't they do something about it?,' we have a social problem" (Horton and Leslie, 1970, p. 3). Although this is by no means a formal definition of social problems, the ingredients for such a definition are present.

Most definitions of social problems focus on two elements: an objective element and a subjective or definitional one. A social problem is seen as referring to an objective--an actual--condition (the "it" that's considered "awful"). But to say "Isn't it awful!" also implies that some social standard or norm is used as a criterion to judge "it," the objective condition, as "awful." Thus, definitions of social problems also contain a subjective dimension that refers both to the judgment that a discrepancy exists--the definition that there is a problem ("people begin to say...."), and to the basis of or the norm for the judgment ("it's awful"). Implicit also is a belief that action can be taken to change the situation.

The following are representative of definitions found in sociological literature: 
Social problems [are] the substantial, unwanted discrepancies between what is in a society and what a functionally significant collectivity within that society seriously (rather than in fantasy) desires to be in it (Merton, 1966, p. 799).

A social problem is a condition which is defined by a considerable number of persons as a deviation from some social norm which they cherish (Fuller and Myers, 194lb, p. 320).

A social problem is a condition affecting a significant number of people in ways considered undesirable, about which it is felt something can be done through collective social action (Horton and Leslie, 1970, p. 4).

All three of these definitions refer to an objective element--a condition that exists. All refer in some way to a norm. Although only the second definition refers explicitly to the definitional process, the others imply that someone must define or judge a condition as a discrepancy, a deviation, or as undesirable.

Those who look to sociologists for assistance in understanding social problems are assured that "sociologists usually consider a social problem to be an alleged situation which is incompatible with the values of a significant number of people who agree that action is necessary to alter the situation" (Rubington and Weinberg, 1971, pp. 5-6).

Our discussion thus far seems to indicate that substantial agreement exists among sociologists as to what constitutes a social problem. However, in delving deeper into the sociological literature on social problems, instead of finding clarity and basic agreement among theorists, one finds substantial cleavage and disagreement. A discussion of four articles that appeared in recent issues of Social Problems will illustrate this cleavage. 


\section{Sociological Approaches}

Although Rubington and Weinberg $(1971,1973)$ have identified and analyzed five sociological perspectives on social problems: social pathology, social disorganization, value conflict, deviant behavior, and labelling; we will classify current theories according to whether their emphasis is on: (1) the subjective, evaluative, or definitional dimension of social problems, or (2) the objective elements of social problems. Two articles by Kitsuse and Spector $(1973,1975)$ and two by Manis (1974a, 1974b) will be discussed as illustrative of these two approaches. The implications that these two approaches have for social planning will be examined later.

Kitsuse and Spector: The Definitional Process. Kitsuse and Spector (1973) examine two approaches to the study of social problems: the functionalist approach and the value-conflict approach. They find that the functionalist tradition, as exemplified by Merton, focuses on objective conditions. Although Merton (1966) acknowledges that sociologists need to consider who is evaluating a condition as a social problem, he does not limit social problems to those identified as such by the people being studied. Merton holds that "social problems are not only subjective states of mind; they are also, and equally, objective states of affairs" (p. 788).

Merton distinguishes between manifest social problems--"1those objective social conditions identified by problem-definers as at odds with the values of the society," and latent social problems--those "conditions that are also at odds with values of the society but are not generally recognized as being so"' (p. 788). 
In making this distinction, Merton, according to Kitsuse and Spector, emphasizes the objective over the subjective. They criticize him for making the sociologist the ultimate judge of whether a social problem exists and challenge the basis for such a judgment.

Waller (1936) and Fuller and Meyers (1941a, 1941b) recognized that value-judgments play a key role in explaining the subjective elements of social problems and were among the first to consider them a formal cause of the condition which is considered undesirable. Kitsuse and Spector criticize the value-conflict position for not following this unique insight, for not moving "to the position that objective conditions are not necessary" (p. 413). According to them, the distinctive task of the sociology of social problems is to explain 'the 'subjective elements' of social problems--the process by which some groups successfully define a condition as a problem within their society" (p. 418).

It is in the light of this assertion that Kitsuse and Spector (1975) explore the relationship between labelling theory and the valueconflict approach to social problems. Both perspectives consider social problems "as products of social processes in which members of a group, community, or society perceive, interpret, evaluate, and treat behavior, persons and conditions as problems" (pp. 584-85). Once again valueconflict theorists are criticized for concentrating on objective conditions and for abandoning the study of social definitions.

Labelling theorists focus on the definitional process that labels behavior as deviant or a condition as a social problem. Howard Becker's work exemplifies the best of this approach, yet he too is concerned about the role of objective conditions. He asks: "Can people define 
any condition that does not exist--an illusion--as a social problem?" (quoted by Kitsuse and Spector, 1975, p. 589). Becker concludes that objective conditions must be included in a conception of social problems and that their existence must be verifiable.

Kitsuse and Spector, however, object to Becker's "balanced view," to his sacrificing "the integrity of the definitional process." They charge that "this reduces the definition from a social construction of reality, an accomplishment of members of the society, to a mere mechanical reaction to exterior forces" (p. 589).

In their view a ''social problem' is not a quality that inheres in social conditions; rather, it is an emergent product of definitional processes in which people perceive, define, and assert conditions to be social problems" (p. 586). Kitsuse and Spector maintain that sociologists who study social problems must focus on definitional processes, examining how persons perceive and define certain conditions as social problems, and how they organize to solve or ameliorate them. The distinctive subject matter of the sociology of social problems is not objective conditions nor how these conditions are generated by the social structure, but rather the definitional processes and the processes by which problems come to be acted upon (pp. 586, 593).

Manis: Objective Conditions. Manis (1974a, 1974b), taking a position contrary to Kitsuse and Spector, maintains that the leading sociological perspectives have essentially similar conceptions of social problems. In this assertion he includes Merton with Kitsuse and Spector. What unites these apparently disparate perspectives, according to Manis, 
is that they define social problems in the light of popular values' (1974a, p. $307 ; 1974 b$, p. 2). Manis criticizes these perspectives for failing to focus on those objective conditions that are detrimental to the well-being of society. Social conditions "become epiphenomena rather than the central focus of analysis" (1974b, p. 3).

Sociologists, according to Manis, must face the task of distinguishing between spurious and genuine (objective) social problems and between trivial and serious ones. Manis agrees that value-criteria are essential in the identification and appraisal of social problems. He argues, however, that society's values are not adequate criteria for a scientific inquiry into social problems. In place of societal or popular values, Manis proposes that the knowledge and values of science be used to identify social problems and to assess their seriousness. ${ }^{2}$ Manis does not ignore the role that beliefs and values play in the public's perceptions of social problems nor the importance of explaining social behavior. What Manis does emphasize is that the task of a sociology of social problems is to focus on social problems as objective conditions .

l'Interestingly, Kitsuse and Spector criticize Merton for focusing on objective conditions, while Manis faults Merton for not giving enough attention to objective conditions.

${ }^{2}$ Manis devotes an article (1974a) to arguing that scientific values would provide more useful and transcultural criteria for defining social problems than "the voice of the people." In a follow-up article (1974b) Manis admits that "specifying and applying the values of science will be a difficult task" ( $p$. 7), but he urges that this be done. He also outlines a "scientific" approach to determining the seriousness of social problems. (By seriousness Manis means the primacy, the magnitude, and the severity of social problems. For the further development of these concepts refer to his article.) 
Theory of Social Problems: A Criticism

Two distinct approaches to the study of social problems have been presented. While the discussion of the four articles and their divergent views has offered insights into various sociological perspectives, an important dimension is missing. No attention was given to the structural aspects of social problems. For that perspective we will consider C. Wright Mills" analysis (1943) of what he termed "the professional ideology of social pathologists."

After reviewing sociology texts written during the period 19091941, Mills found that social problems were typically defined "in terms of deviation from norms" (pp. 531-32). His primary criticism was that sociologists of social problems had no structural viewpoint. They tended "to slip past structure to focus on isolated situations... . There is a tendency for problems to be considered as problems of individuals, and . . sequences of situations were not seen as linked into structures" (p. 534).

Does Mills' criticism of over thirty years ago apply today? First, let us look at the definitional approach to social problems in the light of this criticism. Kitsuse and Spector are quite explicit about their position, admitting that they do not consider the question of "how conditions are generated by the social structure" or "how institutional arrangements produce certain social conditions" to be the proper subject matter of the sociology of social problems $(1975$, pp. 586, 593). Mills' criticism, they would argue, is not a valid one. They would also deny that they focus on isolated situations or that they consider problems to be those of individuals. Kitsuse and Spector would not find this charge 
relevant, for their focus is on the definitional process and on the persons who are involved in that process. The fact that public definitions have no structural linkages or that they focus on individuals, Kitsuse and Spector would answer, is not their concern nor the concern of the sociology of social problems.

In a discussion of the seriousness of social problems Manis (1974b) indicates that it is important to identify and treat primary social problems--those that cause, either directly or indirectly, other social problems, and hence have important consequences on society. This concern wi th causal relations might lead to structural considerations, but Manis is not explicit about this.

Mills' criticism of sociologists of an earlier time does seem to apply to sociologists of social problems today. This failure to conceptualize social problems structurally has important implications for social practice. Mills points out what he saw as the consequences of not attending to the structural dimensions of social problems: These theoretical perspectives reinforce the approach of social workers and other professionals who see problems as a series of "cases." In terms of dealing with problems, this conception of "social" problems does not lend itself to collective action ( $p$. 531). Neither does it "make it easy to reform the status quo" $(p, 537)$.

Two theoretical perspectives on social problems--one stressing the definitional dimension; the other focusing on the objective elements of social problems--have been discussed and criticized for their neglect of the structural elements of social problems. No further assessment or criticism of these perspectives will be offered, for our purpose is lim- 
ited to gleaning insight into social problems. Later in the chapter we will consider the implications these perspectives may have for social planning.

For further insight into the nature of social problems we turn now from sociological theory to social practice.

\section{SOCIAL PRACTICE: DEFINITIONS AND "SOLUTIONS"}

Some of the responses that have been made to social problems were considered in the previous chapter, and now will be subject to further analysis. We will focus on how a problem is defined and examine the relationship that exists between a definition and a "solution." Problem definition will be seen as an essential factor in determining what solution will be offered for the problem. This assessment will give rise to the contention that if social problems are to be resolved, they must be defined in structural terms.

The Relation between between Definitions and "Solutions"

Nineteenth Century. Individualistic explanations of poverty prevailed throughout most of the nineteenth century. Poverty was seen to be the problem of an individual. It was believed that if a person worked hard and was thrifty, he would succeed. And so the logic went, if a person were poor, the fault was personal--he had failed. By the opening of the twentieth century another explanation was gaining acceptance: the economic system itself generated and maintained poverty and its attendant problems.

Table I presents different views of poverty that were prevalent in the nineteenth century. The first two have a similar definition of pov- 


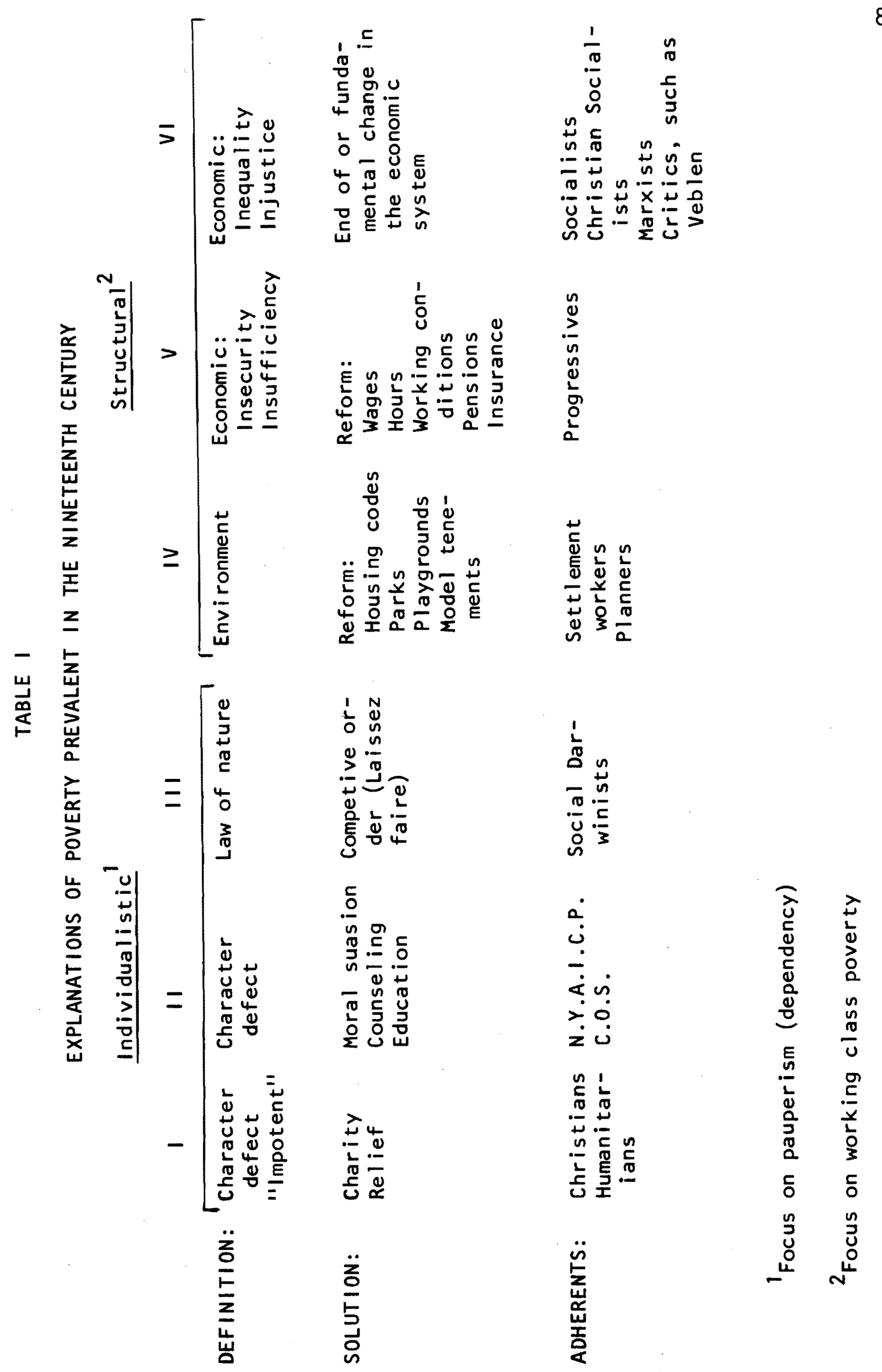


erty--it was seen to result from some personal deficiency, ${ }^{3}$ whether it be intemperance, indolence, or lack of thrift. This definition, however, prompted two different responses. One group was impelled to provide charity or relief, with the focus more on the obligation of the giver than on the needs of the recipient or on his worthiness or unworthiness. The second group, represented by the New York Association for the Improvement of the Poor and the Charity Organization Societies focused on the poor with the suspicion that they really didn't mind their degradation. 4 These humanitarians feared that persons might remain in a state of pauperism, so in giving relief they sought to avoid fostering dependency. They held what was the dominant view throughout the century--that "public assistance should be granted, not only sparingly, but grudgingly; it should be.. . dispensed only in ways that would discourage people from seeking it" (Bremner, 1956, p. 47). Individual counseling and attempts to improve the character of the poor were seen as the chief means of combatting poverty.

A third individualistic interpretation of poverty derived from evolutionary theory. The application of Darwinism to society suggested that through competition and the "struggle for existence" the weak would perish while the strong would survive. Competition was a law of nature

3 A distinction was made between the "deserving" poor or the "impotent," that is, the aged, the ill, orphans, etc., and those who were "undeserving."

4 In a discussion of attitudes toward the poor Kenneth Clark and Jeannette Hopkins (1968, pp. 19-20) characterize those in the first group as the "Good Samaritan-Lady Bountiful Tradition" and those in the second group as in the "Puritan-Horatio Alger Tradition." 
and any interference to protect the "unfit" would slow the evolutionary process, impeding society's improvement. According to William Graham Sumner, the leading American exponent of Social Darwinism, the answer lay in cultivating economic virtues: "Let every man be sober, industrious, prudent, and wise, and bring up his children to be so likewise, and poverty will be abolished in a few generations" (quoted by Hofstadter, 1955a, p. 61).

These individualistic interpretations were more in harmony with the conditions of the early nineteenth century than they were with the United States of the latter half. Opportunities abounded, land was available, labor was scarce, towns were growing rapidly. "There was substantial truth in the assumption that willingness to work brought material well-being, while failure implied some personal defect in the sufferer" (Bremner, 1956, p. 17).

However, built into the thriving industrial economy were depressions which recurred with regularity after 1819. Hard work and thrift did not guarantee economic security. As more and more workers experienced involuntary unemployment, structural explanations for poverty gradually gained adherents.

Before mid-century many reformers began to consider environment as an important factor in urban problems. If housing and the neighborhood environment could be improved, they belleved, many urban problems would be solved. Settlement residents embraced this fourth explanation of poverty and sought not only to assist individuals, but worked to transform the neighborhood--hoping to eventually create a new urban environment. By the late 1890's many of the visitors of the Charity Organization 
Societies, settlement residents, and other reformers were formulating a broader view of poverty, defining it in terms of insecurity and insufficiency (Bremner, 1956, pp. 124-25). The individual was now viewed as a victim of economic forces over which he had little or no control. Unemployment and low wages were considered as the primary causes of poverty. Reformers proposed legislation to establish minimum wages and maximum hours, to protect the worker against unemployment, accidents, illness, old age, and to prohibit child labor. 5

Although critical of the economic system, the majority of these reformers had faith in the ability of legislation to correct abuses of the system. More radical critics, however, maintained that inequality and injustice were inherent in the capitalist system itself, and therefore demanded more fundamental changes. Marxists, of course, advocated the overthrow of capitalism, but they had little influence in the United States at this time. A religious critique of capitalism was also advanced. $^{6}$ Capitalism was indicted as anti-Christian--for its exaltation of selfishness, competition, and profit; for placing more value on goods than on persons; for stunting the moral growth of persons and for corrupting their spirit. Others criticized the economic system, but of-

${ }^{5}$ For a discussion of the role of social workers in these reform efforts see Part 111 of Robert H. Bremner's From the Depths (1956).

Walter Rauschenbusch was the most well-known of those who preached the "Social Gospel." As a replacement for the capitalist system, he proposed communism--not Marxist, but resembling that of the early Christian community. 
fered no solutions. 7

Although a broad range of definitions and solutions were offered in the nineteenth century, the focus was primarily on the individual. That view prevailed until the depression of the 1930's changed the focus--poverty was seen as associated with the economic system and was defined in terms of insufficiency and insecurity. Solutions, such as unemployment insurance, social security, and eventually a minimum wage, were adopted that were to cover--not remedy--the deficiencies of the economic system.

After the Great Depression--through the 1940's and 1950's--poverty was largely forgotten by mainstream Americans. Finally in the 1960's poverty was again brought into our consciousness. We will examine poverty programs of that period and the assumptions that underlie them. Although definitions of poverty in the 1960's may appear more sophisticated and programs are "new" and diverse, we shall see that a great deal of similarity exists between the definitions and solutions that predominated in both the nineteenth century and the 1960's.

Programs of the 1960 's. The conception of "the poverty cycle" underlies the poverty programs of the $1960^{\prime} s$. In this view poverty exists for a number of reasons:

Inadequate education, low or non-existent income, limited job opportunities, dilapidated and overcrowded housing, poor physical and mental health, an inclination towards delinquency and crime--these and many other characteristics of poverty both

${ }^{7}$ Thorstein Veblen was one such critic. His perceptive critique of the pecuniary economy which subordinated production to profit can be found in his The Theory of the Leisure Class (1962). Veblen, however, proposed no alternate system. 
cause and are caused by each other, interacting in a manner which renders it virtually impossible for the disadvantaged child, adult or family to break out of the "cycle of poverty" (quoted by Marris and Rein, 1967, p. 38).

This conceptualization of the "cycle of poverty" is illustrated by the diagram of Rist (1972, p. 44):

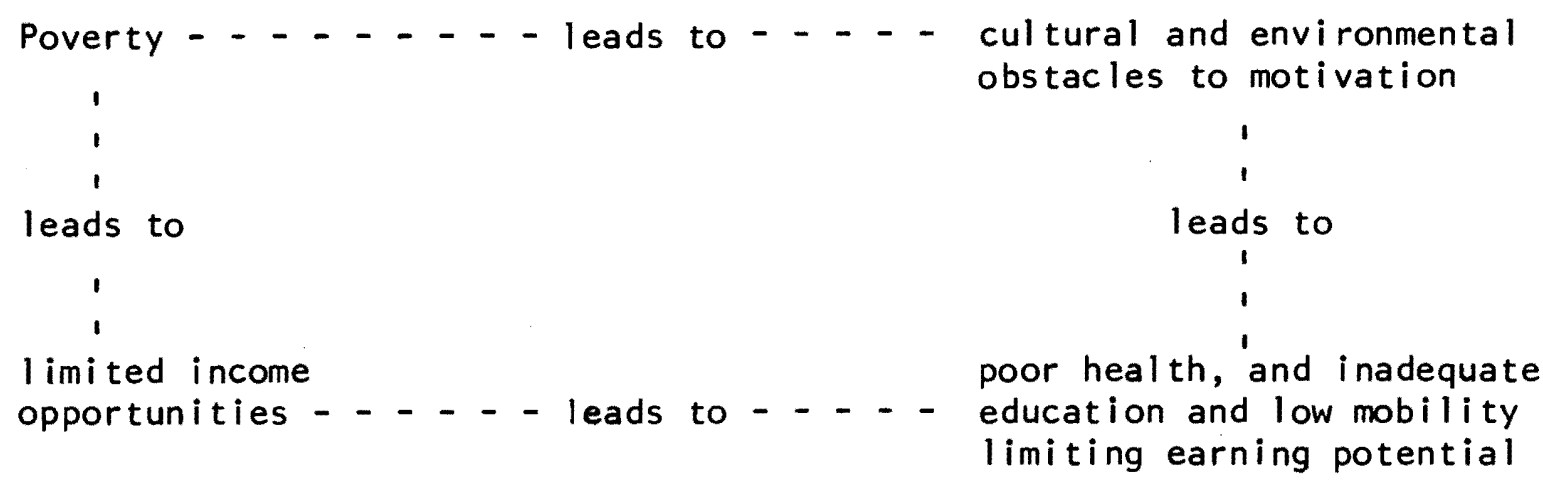

Figure 2. The cycle of poverty.

The causes of poverty are seen as circular and interrelated. Poverty is self-perpetuating. Attacking the problem of poverty demands a comprehensive approach, but as Marris and Rein point out, it also permits a flexible strategy. "Intervention at any point may be effective" (Marris and Rein, 1967, p. 39).

Looking at actual programs sponsored under the Economic Opportunity Act, three different definitions of poverty can be identified. Table $\|$ relates these definitions to the "solutions" that were offered by the War on Poverty programs. Explanations for poverty ranged from the poor person to institutions to the powerlessness of the poor. However, an examination of the Community Action Programs (CAP's) reveals what the focus of the "War on Poverty" was.

In an analysis of thirty-five CAP's Hallman (1968) found that onehalf assumed that the cause of poverty lay in the nature of the poor them- 
TABLE I

WAR ON POVERTY: DEFINITIONS AND SOLUTIONS

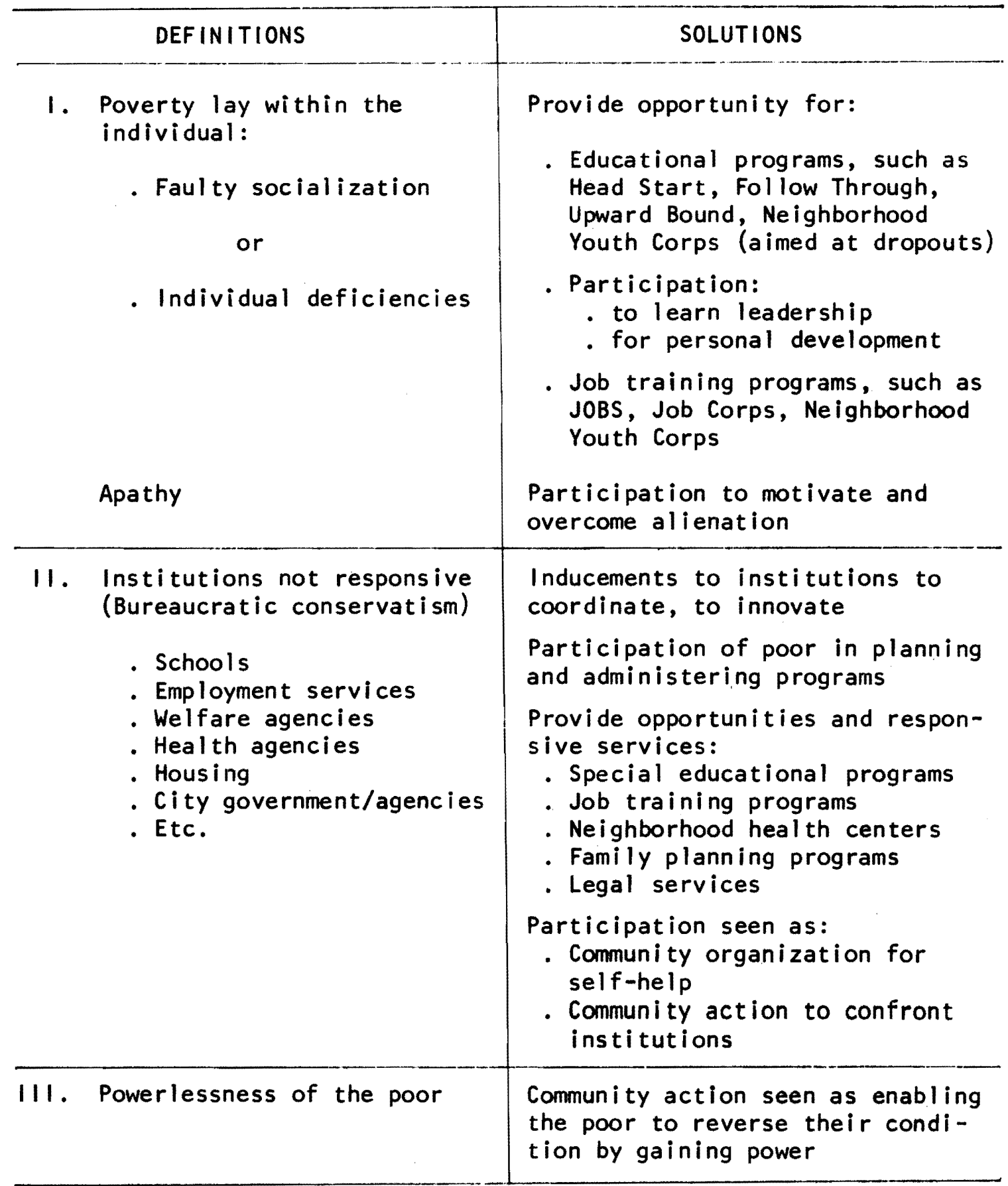


selves. The other half too placed responsibility on the individual, but in addition maintained that society and its institutions had also failed. However, service programs predominated in nearly all CAP's with the services aimed at individuals rather than families or groups (p. 287). In only three communities did the strategy of giving power to the people predominate; confrontation and conflict were deliberately chosen as strategies to produce institutional change (p. 289).

Al though modern programs dealing with poverty may be more diverse and sophisticated, the dominant definition of poverty in the 1960's differed little from the one that predominated in the nineteenth century: the individual is held responsible for his condition. And thus, the dominant strategy has been directed toward changing the individual rather than reforming or changing the system.

\section{The Importance of Definitions}

From the foregoing discussion it should be obvious that a strategy that is devised to cope with a problem is closely related to how the problem is defined.

If poverty is defined in terms of individual deficiencies, the strategy of manpower training may be appropriate to that definition. But although a strategy is appropriate to the definition of the problem, it may be totally ineffective in attacking the problem.

If "full employment" is defined so as to permit a five per cent unemployment rate, then unemployment is built into the economic system, that is, it is structural. Although the strategy of training individuals may benefit some, it cannot effectively solve the problem of those 
five per cent whose unemployment is structurally generated. 8

Figure 3 illustrates the consequences of not adequately defining a problem.

When the causes of poor housing, unemployment, low income, etc. are rooted in the structure of economic and social relations, problems cannot be remedied by trying to motivate or educate individual persons. A definition that fails to deal with the causes of a problem leads to a strategy that is ineffective in coping with the problem--and it may even exacerbate or add new dimensions to the original problem.

An example of a strategy that not only is ineffective in treating a problem, but has also created a new one is public housing policy. Housing policies have not been directed at practices, e.g., taxation policies, federal home loan policies, credit policies of lending institutions, real estate practices, that contribute to the "housing problem." As a consequence, substandard housing still exists and the housing stock continues to deteriorate. Moreover, the housing problem now has a new dimension.

This new dimension--the consequence of public housing policy--has been aptly described by the National Commission on Urban Problems: "In most cities of the country, high-rise public housing units clearly indi-

${ }^{8}$ The Work Incentive Program (WIN) provides a good example of this kind of strategy. WIN was devised to provide job training for the poor in order to reduce overall welfare costs. Hill (1974) maintains that the program was based on four assumptions about the structure of the labor market which can be seriously questioned. Yet the Department of Labor failed to refer to the structure of the labor market. Consequently responsibility for program failure has been assigned to administrative problems and the deficiencies of the trainees--not to the structure of or conditions in the labor market. 


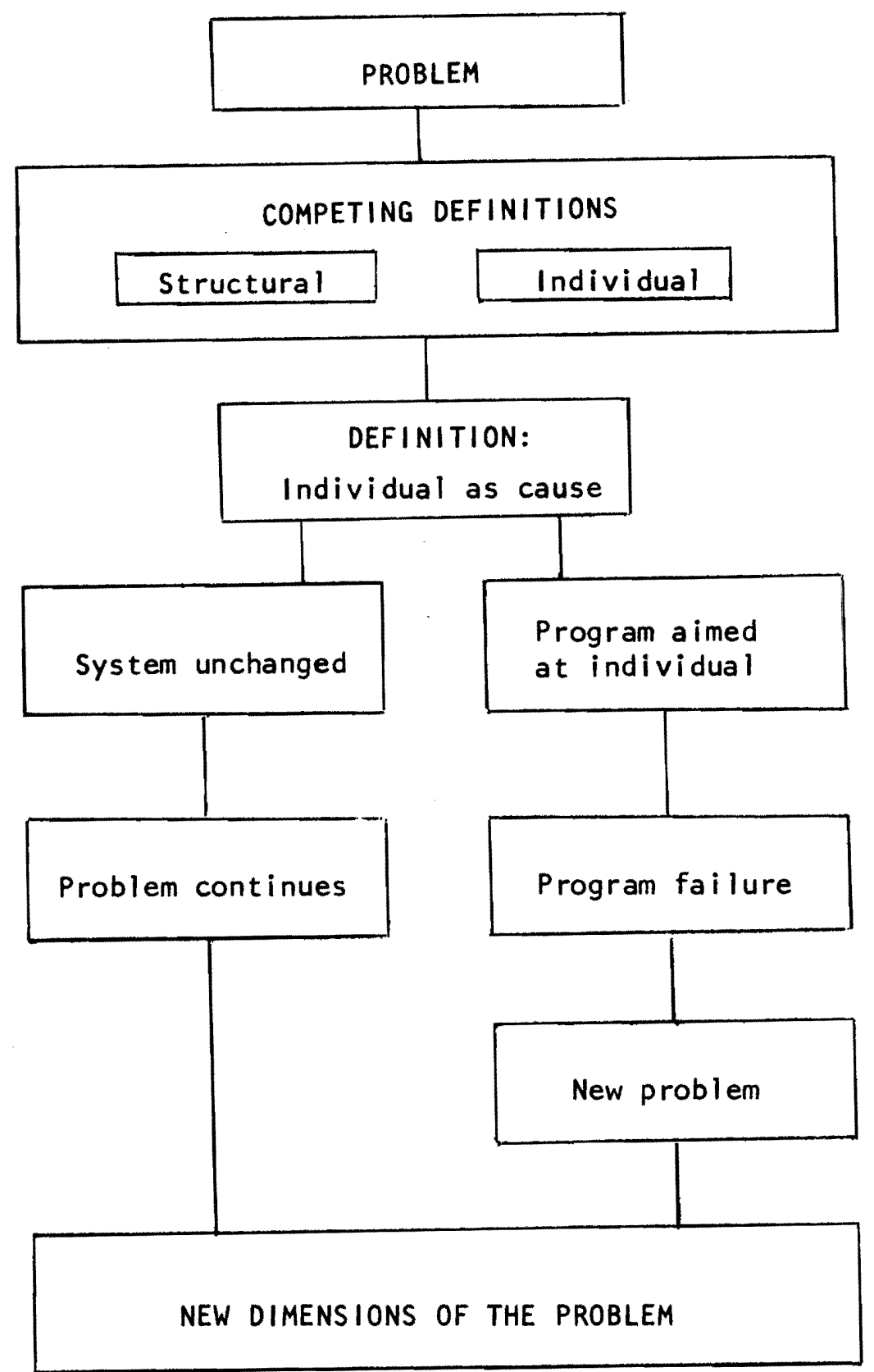

Figure 3. Consequences of defining a problem in terms of the individual when the cause is structural. 
cate what they are--large congregations of the poor. They stand out in many communities like so many sore thumbs" $(1969$, p. 123). Thus, a policy proposed as "a solution" for the shortage of low-cost, decent housing units did add low-cost units to the market. But their highly standardized design, their high density, their design as "island," reinforces "the charity stigma" attached to subsidized housing. "Each project proclaims, visually, that it serves the "lowest income group"' (Wurster, 1966, p. 247). Public housing has added a new dimension to the "housing problem."

Our review of how problems of poverty have been handled leads to the conclusion that not only have efforts been limited, but they have been misdirected. The predominant definition of poverty has focused on the individual as the cause. Correspondingly programs have been geared to the individual. Efforts have been misdirected in that they ultimately end with the treatment of symptoms--not causes.

It is a basic contention of this dissertation that urban problems will never be solved unless they are conceptualized structurally. This does not imply, of course, that this conceptualization will automatically lead to implementation, and thus "solution." However, definition is a key determinant of the kind of program that can be offered as a "solution." If problems are to be resolved, social planning must address itself to the causes of social problems--that means defining problems in structural terms and choosing "solutions" that deal with structural relations. 


\section{SOCIAL PROBLEMS AND SOCIAL PLANNING}

The analysis of definitions and solutions that has just been completed has emphasized the importance of dealing with problems structurally. Earlier in the chapter it was noted that the sociological literature fails to define social problems in structural terms. Sociological theorists do not conceptualize social problems structurally. In this section social problems will be defined in structural terms. Then the implications for social planning that can be drawn from our theoretical investigation into the nature of social problems will be considered.

\section{Social Problems and "Social" Causes: A Definition}

"If you take the words 'social problems' and try to isolate them, it is obvious that these two words should represent 'social' in contrast to something else" (Horowitz, 1968, p. 87). What we have seen, however, in reviewing current definitions, is that any condition that is incompatible with the values of a considerable number of persons is a social problem. Manis would use the values of science as a standard, while Kitsuse and Spector recognize any condition identified as a social problem as one--by definition.

Using these conceptions of social problems, one has difficulty in specifying what is not a social problem. The meaning that is being proposed for social problems does distinguish between problems and social problems. A problem is said to exist when there is a discrepancy between actual conditions and a social standard or norm. However, a problem is social only when its causes lie outside of individuals--when the sources or origins can be found in existing structural or institutional arrange- 
ments. Social planning then is concerned with social problems which are related to and generated by social, economic, and political institutions. Individual behavior itself, though important, is not the prime consideration.

Merton (1966, p. 783) claims that "no satisfactory case has been made for confining the scope of social problems" to only those that are social in origin. We are suggesting that two reasons justify our doing so. First, this approach avoids reductionism, that is, reducing the problem to a single cause or to one of individuals. The contention is that social problems should be considered as social facts which need to be explained by other social facts. 9 The second reason is that this approach to social problems has important connections with social planning. For unless problems are conceptualized structurally, strategies will not be adopted that deal with causes. And we have argued, if problems are to be resolved, they must be dealt with structurally. Reserving the term social problem only for those problems whose source is social (structural) has important implications for efforts aimed at alleviating problems. These reasons seem a sufficient justification for confining social problems to those whose origin is social.

\section{Implications for Social Planning}

It is not the task of the social planner to reconcile the conflicting theoretical views of social problems nor to work toward the development of a "full-fledged theory of social problems." That task remains

${ }^{9}$ Durkheim in his classic study, Suicide, argued that suicide, seemingly a very personal matter, was a "social fact." He offered explanations for suicide in terms of other social facts. 
the domain of the sociologist. While it would be helpful to the planner if adequate theory existed, the current theoretical debate does offer the planner important insights that should be incorporated into planning theory and practice. We will now consider what the social planner can gain by taking into account both the objective and subjective dimensions of social problems.

Objective Dimensions of Problems. While social theorists may debate whether objective conditions are essential elements of a social problem, the planner is necessarily concerned with objective conditions and with methods of changing them. Planners typically have approached problems as objective conditions, as technical issues. Analysis and proposals aimed to alleviate or eliminate problems have also been considered technical matters (Rein, 1969, pp. 238-40). Social planners seem well aware of the complexity and interrelatedness of social problems and the need for better information and data systems, tools of analysis, theory, etc. 10

The analysis of problem solving efforts of the nineteenth century and of the 1960's explored the relation between problem definition and the strategy adopted. Our contention is that social problems need to be defined in structural terms and alternatives must be devised to deal with these structural aspects. The development of more sophisticated theory, methods of analysis, and planning tools must be directed toward the structural dimension of problems, for if this technology supports programs that are primarily aimed at individuals, social problems will

10 For further discussion refer to Rittel and Webber (1973), Perloff (1965), and Manis (1974b). 
continue to exist. Structural relations must be considered an important element in the objective make-up of social problems and as a target of the planner's intervention.

Subjective Dimensions of Problems. Planners ordinarily have focused on objective conditions and have been concerned with basing their plans on a thorough, objective appraisal of the existing conditions and with improving the rationality of the process. When an objective analysis has little influence on what is done with the problem, the planner may decry the vested interests, the conflicting objectives, and the politics that are involved. Yet the fact that groups offer competing definitions of problems should not be viewed as obstructing the planning process--impeding its rationality and the planner's expertise.

The review of theoretical approaches to social problems suggests that we not only consider social problems as pertaining to objective conditions, but also take into account their subjective or definitional aspects. Blumer (1971) believes that there is "a clear need to study the process by which a society comes to see, to define, and to handle their social problems" (p. 301). While Blumer charges that sociologists who study social problems "notoriously" ignore this process, it is also true that planners as well have paid scant attention to the definitional process.

When social problems are viewed as the product of a process of collective definition, others besides planners are seen to have a role in identifying, defining, and handling social problems. Problems--definitions and solutions--are recognized as not just the domain of the expert. Problems are not merely objective conditions that can be solved 
by an objective analysis and the design of effective means.

Attending to the subjective dimension of problems means that the planner must recognize the role that others play in the process of collective definition. The interaction between citizens and between citizens and planner is considered essential in determining the fate of the problem. When the planner acknowledges this dimension of social problems, he will realize the need to study the process of collective definition and to understand it. Then he must determine what role he can play--with others--to bring about better methods of dealing with social problems.

The planning literature currently refers to this interaction between citizens and between planner and citizens as "citizen participation" in the planning process. It is our contention that viewing social problems as the product of a process of collective definition provides us with a different and fruitful perspective on citizen input in the planning process. In the next section we will focus on citizen participation--considering in more detail the implications that our examination of social problems has on it.

\section{THE DEFINITIONAL PROCESS AND CITIZEN PARTICIPATION}

An extensive examination of citizen participation will not be undertaken in this dissertation. However, some brief comments will be made about the literature that exists on the subject and about some experiences with citizen participation in federal programs. Because some contend that citizen participation presents a dilemma for the planner, that view will be discussed. In considering whether citizen participa- 
tion is a planning dilemma, we will show that if the subjective or definitional aspect of social problems is taken into account, citizen participation not only is not a dilemma, but is essential in coping with social problems. Focusing on the nature of social problems forces us to reconsider citizen participation--providing us with a theoretical basis for its inclusion in the planning model presented in this dissertation.

\section{The Literature of Citizen Participation}

A rather extensive literature dealing with citizen participation does exist. That literature provides us with theoretical and normative perspectives as well as empirical studies of citizen participation. It is not the domain of any one of the social sciences, but has drawn contributions from sociologists, political scientists, psychologists, lawyers, planners, and community organizers. Evidence from the literature, however, "is contradictory, inconclusive, particularistic, and overly qualified by the dictates of time, place, and circumstance" (Spiegel and Mittenthal, 1968, pp. 3-4).

Because of insufficient evidence, generalizations about the value of citizen participation are difficult to draw--that is, ones that will not be challenged. "Anyone can draw just about whatever meanings his predilections desire," Spiegel and Mittenthal assert, for the approach to citizen participation is suffused "with normative judgments, value-laden preconceptions, lack of objective criteria and standards of measurement, and a host of differentiated perspectives" (p. 4).

Although accurate generalizations about citizen participation are difficult to formulate and no unifying theory exists, the planner needs 
to be familiar with the literature and must also be aware of its limitations. It does not serve our purpose here to review the literature or to directly assess or evaluate "the many faces of citizen participation."11 It is pertinent, however, that we examine whether citizen participation is an obstacle in planning to solve problems. Some contend that the demand for participatory denocracy interferes with the professional expertise that is needed to cope with complex problems. Thus, we will face the issue of whether citizen participation is a dilemma confronting planners.

Citizen Participation: A Planning Dilemma?

In answering this question we will briefly review citizen participation in federal programs, assess that experience, and then consider two articles in which citizen participation is treated as creating a planning di lemma.

Experiences with Citizen Participation. A review of the experiences of citizen participation in urban renewal activities, community action programs, and in Model Cities provides evidence that controversy and struggle have characterized the relations between professionals, officials, and citizens in some cities.

From his analysis of citizen involvement in three federal programs, Mogulof (1969) contends that involvement of citizens has moved from the concept of coalition to that of adversary. He concludes:

The movement from the public-private coalitions of the Delinquency Program, to the expansion of the coalition in the CAP to include neighborhood leaders, and now to "adversary"

${ }^{11}$ This is the title of Spiegel and Mittenthal's article (1968). 
relationships between government and the black neighborhood in the Model Cities Program, appears to be a central theme of the history of these programs (1969, p. 231, emphasis added).

In some cities more harmonious relations have existed between citizens and planning agencies and the city government. Cooptation ${ }^{12}$ has been a prevalent method used by planning agencies to gain support for planning endeavors (Burke, 1968, p. 291). Dahl (1961) labels citizen participation in the urban redevelopment process in New Haven a "democratic ritual." According to Dahl, "citizen participation gave legitimacy and acceptability to the decisions of the leaders, created a corps of loyal auxiliaries who helped to engender public support for the program and to forestall disputes" (p. 133).

A study of citizen participation procedures led Arnstein (1969) to distinguish eight levels of citizen participation. Most citizen participation activities were classified as either "non-participation" or as "tokenism." Whether citizen participation has been characterized by more or less harmonious or conflictual relations, Arnstein concludes that citizens, when they have "participated," have ordinarily been excluded from real power.

Mogulof and Arnstein both worked for the Model Cities Administration, both examined citizen participation in federal programs, and their articles appeared in the July, 1969, Journal of the American Institute of Planners. Yet the two view citizen participation quite differently. As has been indicated, Mogulof saw citizen involvement moving toward an ad-

${ }^{12}$ Cooptation is defined as "the process of absorbing new elements into the leadership or policy-determining structure of an organization as a means of averting threats to its stability and existence" (Selznick, 1949, p. 13). 
versary relationship. From the perspective of change Mogulof foresaw that "very probably . . neighborhood councils or congresses [will] emerge as quasi-governmental units for their areas in the Model Cities Program with jurisdiction gradually spreading to non-Model Cities expenditures" (p. 321).

Arnstein maintained that most CAP's were characterized by "the empty ritual of participation" with no redistribution of power occuring to the poor. She foresaw the likelihood of this being repeated in most of the Model Cities programs (pp. 216-17).

Mogulof was optimistic about the likelihood that federal programs would enable the poor to exercise more control over resource allocating mechanisms, while Arnstein was generally pessimistic about the possibilities for change.

Analyzing Model Cities programs six years after Mogulof and Arnstein, Frieden and Kaplan (1975) offer the following assessment of citizen participation:

The Model Cities Program . . . was intended to create agreement and partnership between residents and city government. Even though the participating residents did not always share this view, the nature of the program itself pushed them increasingly toward a cooperative stance with local government after the initial ground rules had been established. Organizing the poor was never a major purpose of the program as HUD administered it $(p .83)$.

Assessing current federal requirements for participation Frieden and Kaplan maintain that the "performance criteria on the role of poverty area residents in community development decisions and operations are weak and diffuse" (p. 252). Although the Department of Housing and Urban Development has set administrative rules for citizen participation, Frieden and Kaplan suggest that "the performance standards can be met by 
superficial citizen involvement" (p. 253). Their analysis and projections tend to support Arnstein's contention that citizen participation as exemplified in federal programs ultimately maintains the status quo.

It appears that after years of experience with citizen participation it can be viewed from two divergent perspectives: that of citizens, especially the poor--as a means of gaining citizen power; or the perspective of the planning agency/city government--as a means of social control.

Planners ordinarily do not consider citizens "a means to achieve better planning goals nor are they seen as partners in assisting an organization in achieving its goals; rather they are viewed as potential elements of obstruction or frustration..." (Burke, 1968, p. 291). The citizen is seen primarily as advisory or as a target of "educational" efforts. The aim is to use citizen participation in order to lend legitimacy to official decisions.

HUD's current rules for citizen participation lend themselves to the social control perspective, for as Frieden and Kaplan (1975) have suggested, these requirements can be met by superficial citizen involvement. However, it is doubtful whether citizens will be satisfied with minimal involvement. The tension between citizen participation as a method of gaining citizen power and as a means of social control still exists.

"The Dilemma" Examined. We will now explore the basis for this tension, or what some have referred to as "a planning dilemma," and try to determine whether this dilemma can be resolved. In doing so, we will draw upon articles by Burke (1968) and Rein (1969). 
Burke (1968) contends that the participation of citizens in community planning presents a basic dilemma. The basis for the dilemma, according to Burke, is the demand for both participatory democracy and professional expertise in decision making. He seeks to resolve the dilemma by identifying five strategies of citizen participation, enunciating their assumptions and the conditions necessary for the effectiveness of each strategy.

The resolution of the dilemma is effected, Burke suggests, by choosing a strategy of citizen participation that fits the role and resources of a particular organization. He believes that organizations themselves can resolve the dilemma.

Planning agencies must be more precise about what they mean by citizen participation, how they intend to implement it, what agency resources will be used to organize and involve citizens, and what voice citizens will have in planning decisions (Burke, 1968 , p. 294).

While Burke has provided an insightful analysis of various forms and functions of citizen participation, his reliance on the planning agency does not provide a satisfactory resolution for what he defines as a basic conflict between citizen participation and professional expertise. Since his solution is to adapt citizen participation to each organizational environment, cooptation or an educational/therapeutic strategy may well be the one the agency decides "fits." Burke's proposal for the resolution of the dilemma is too heavily weighted on the side of the planning agency, and thus oriented toward the status quo and social control.

Rein (1969) approaches "the dilemma" from another direction--he explores the problem of the legitimation of social innovation. He asks, 
"How is the need for innovative intervention justified and support for it secured?" (p. 233).

Four different sources of authority are identified by Rein as legitimating the intervention of city planners. He calls these the authorities of expertise, bureaucratic position, consumer preferences, and professional values. After reviewing each of these as a source of legitimation, Rein examines three strategies planners draw upon and how each contributes to the legitimation of reform.

The strategy of elite consensus acknowledges the reality of institutionalized power. Legitimation for change and reform depends upon the endorsement of those representing established institutions and powerful interests. But the pursuit of this strategy is likely to conflict with the purpose of reform and will ultimately impede innovation.

Rational analysis is another way of legitimating planned change. As we have al ready indicated, this has tended to be the approach that planners have favored. The fundamental dilemma of rational planning, according to Rein, is the conflicting requirements of rationality and feasibility (p. 239). A rational solution is not necessarily politically relevant, thus the strategy of rational analysis, or professional expertise, may conflict with the other strategies of legitimation.

The third strategy discussed by Rein is that of citizen participation. After reviewing the difficulties of this strategy, he concludes that confrontation "with established institutions not only is likely to create conflict, but also may fail to generate any constructive accommodation that can lead to real reform" (p. 242).

Each strategy then has an inherent dilemma that stands in the way of social change. Can these dilemmas be resolved? Rein concludes that 
they cannot, for they are "inherent in the nature of American social life" (p. 242). Pursuing all three strategies simultaneously ultimately leads to conflict. The best that can be done, according to Rein, is to pursue all the strategies in the same and in different organizations, stressing one and then another (p. 242).

Rein warns: "It is futile to search for paradigms and prescriptions that will clear the whole problem out of the way and ultimately demonstrate that the strategies are indeed consistent and mutually reinforcing, not fundamentally in conflict" (p. 242).

Contrary to Rein's admonition of futility, we contend that it is both necessary and possible to formulate a new conceptualization of the planning process in which planner and citizen play complementary roles. It is actually misleading, as Seaver (1966) points out, to speak of "a dilemma of citizen participation."13 A dilemma exists when one is faced with a choice between unsatisfactory or unpleasant alternatives. But there can be no choice between citizen participation and the planner's expertise. It is not possible, nor is it desirable to exclude either. What then can be done to resolve the difficulties?

The Definitional Process: Planner and Citizen Together

Aleshire (1970) argues that the relationship between planning and citizen participation must be improved. He presents two possible approaches: in "the planning model," citizen participation is made a part of the planning process; and in "the citizen participation model," plan-

${ }^{13}$ Seaver (1966) rejects the notion that citizen participation is a dilemma facing planners, and redefines the problem as being one of determining the degree citizens should participate in the planning process. 
ning becomes part of that process. Aleshire's basic point is that citizen participation and planning have a complementary relationship and that it is essential to harness "the power of citizen participation to the potential of planning" ( $p$. 393).

Although Aleshire's suggestions for improving planning and participation are appropriate, little is gained by distinguishing between citizen participation and planning. It is more useful to consider the citizen and planner as having complementary roles in one process, whether it is called a planning process, a decision making process, or a problem solving process. Thus, the necessary task is not to join planning and citizen participation--which is Aleshire's argument. Rather the task facing us is to unite planner and citizen in one process, capitalizing on the unique contributions of both.

This view is not one that is widely accepted, for in the planning literature, problem solving is ordinarily regarded as the domain of the expert, requiring scientific analysis and a high degree of objectivity. Indeed, planning when conceived as a comprehensive, rational, efficient process seems jeopardized by the involvement of nonprofessionals in the process. (And hence, the planning dilemma.)

However, we are proposing a reconceptualization of social planning-one that flows from the nature of social problems. The review of theoretical approaches to social problems enables us to consider social problems not just as objective conditions, but also to take into account the subjective aspects of social problems. If we accept this analysis of social problems, then social planning must deal with both the objective and subjective aspects of social problems. And that entails a role for 
both "expert"--to deal with the analysis of objective conditions and evaluation of alternatives, and for citizen--acknowledging his role in the definitional process. While it might be easier and more efficient if the planner had control over definitions and solutions, the planner does not exercise that prerogative, thus he needs to attend to the definitional process in which others participate.

Very little is known about that process, however, five stages have been identified by Blumer (1971):

1. The emergence of a social problem. "A social problem does not exist for a society unless it is recognized by that society to exist" (pp. 301-02). This recognition of social problems is a highly selective process--one that needs study so we can understand how it works.

2. The legitimation of the problem. "After gaining initial recognition, a social problem must acquire social endoresement if it is to be taken seriously and move forward in its career" (p. 303). Again little is known about the factors that are involved.

3. The mobilization of action with regard to the problem. In this stage those who wish change come in conflict with those who oppose it. As a consequence, some problems survive, others fade away. "How the problem comes to be defined, how it is bent in response to awakened sentiment, how it is depicted to protect vested interests, and how it reflects the play of strategic position and power--all are appropriate questions that suggest the importance of the process of mobilization for action" (p. 304).

4. The formation of an official plan of action. The official plan "is almost always a product of bargaining, in which diverse views 
and interests are accommodated. . - What emerges may be a far cry from how the problem was viewed in the earlier stage of its career" (p. 304).

5. The transformation of the official plan in its empirical implementation. "Invariably to some degree, frequently to a large degree, the plan as put into practice is modified, twisted and reshaped, and takes on unforeseen accretions" (p. 304). Blumer adds, "I scarcely know of any facet of the general area of social problems that is more important, less understood, and less studied than that of the unforeseen and unintended restructuring of the area of a social problem that arises from the implementation of an official plan of treatment" (p. 305). Blumer's model of the definitional process reflects present reality. If planners acknowledge the importance of collective definitions with regard to social problems, they will study this process in order to understand it. Recognizing that each stage of the collective process is a crucial one in determining the fate of the problem, they will seek to incorporate the stages identified by Blumer into the planning process.

Citizens, politicians, and bureaucrats are involved in the process of collective definition. Citizens cannot be relegated to only the stage of goal formulation, or politicians to the formal decision stage, or administrators to the implementation stage. Studying the process of collective definition should make this clear to the planner.

Participation of citizens in the planning process can be seen in a different light, for with this perspective on social problems the planner will not consider different interests, definitions, goals, val- 
ues, etc. as obstacles to be overcome. They will rather be viewed as natural conditions of a pluralistic, heterogeneous society. The planner's task is to find ways of incorporating citizens and groups into the social planning process in order to facilitate the exchange between planners and citizens and between citizens themselves, and also to capitalize on the unique contribution of each in helping to define and resolve social problems.

Focusing on the definitional aspect of social problems leads us to the conclusion that the participation of citizens--rather than posing a dilemma--is essential to the planning process.

\section{v. CONCLUSION}

At the beginning of the chapter it was stated that a social planning model must be responsive to the nature of its content. Since social problems are the content of social planning, we examined the nature of social problems by looking at both sociological theory and social practice, i.e., analyzing how problems have been dealt with historically.

Solutions have been related to definitions, and it has been argued that social problems must be defined in structural terms--with social planning addressing itself to structural causes. From sociological theory we have seen that the process of collective definition plays an important role in determining the fate of a social problem. From this perspective, citizen participation is no longer regarded as a dilemma, nor is one concerned about the degree citizens should participate--the participation of all that have interests in the problem and 
in all stages of the planning process becomes an important concern.

The next chapter will elaborate the theoretical framework that underlies our conceptualization of social planning and should both clarify and support the contention that no inherent conflict exists between citizen and planner joining together to deal with social problems. 
CHAPTER IV

TOWARD A THEORY AND MODEL OF SOCIAL PLANNING - I

Some theoretical concepts and a model of social planning will be presented in this chapter and the next. We will focus first on theory, intending to accomplish two objectives. One is to relate what has been learned from our examination of social problems to social planning. The second is to place social planning--theoretical concepts and the model--in a broader theoretical framework. Before endeavoring to do either we will set forth some underlying theoretical assumptions and will also give some brief attention to the present state of planning theory.

\section{THEORETICAL ASSUMPTIONS}

While a consideration of theoretical assumptions may appear to be a digression, it is necessary for these are basic premises underpinning the concepts of social planning that will be developed in these two chapters. These premises deal with the nature of society, man, and social interaction. Because they are drawn from sociological theory, they may be unfamiliar to many planners. Although drawing heavily on those theorists known as symbolic interactionists, ${ }^{1}$ there is no inten-

1Refer to Herbert G. Blumer's essays which are found in his book, Symbolic Interactionism: Perspective and Method (1969); George H. Mead (1934); Arnold M. Rose (1962); and articles in a reader edited by Jerome G. Manis and Bernard N. Meltzer (1967). 
tion to represent any specific theorist or group of theorists. Our approach is eclectic--and although there will be come overlap in the discussion, there is consistency in our assumptions about social reality, man, and social interaction.

The Nature of Social Reality

Berger and Luckmann (1966) provide an insightful analysis of the social construction of reality. Developing three major propositions about the nature of social reality, they present society as a human product, as objective reality, and as subjective reality. Each proposition will be discussed briefly, and is accepted as a basis for the social planning theory and model presented in this dissertation.

1. Society is a human product ( $p p .47-128$ ). Men acting together produce the human environment. Languages, customs, institutions with their roles and norms, etc. are man made. Any given social order, in both its origins and its continued existence, is a product of human activity.

2. Society is an objective reality (pp. 58-61). Once in existence institutions are experienced as objectively real, as existing over and beyond the individual. Institutions come to be perceived by individuals as external and coercive facts. ${ }^{2}$

Berger and Luckmann also discuss the question of reification ( $p p$. 88-92). Reification occurs when man no longer realizes that social re-

2 Emile Durkheim recognized that "social things are actualized only through men; they are a product of human activity" $(1964, p .17)$. Yet Durkheim came to focus on the objective reality of social facts, neglecting man, the producer. Durkheim stressed man's experience of social facts as existing outside of him and as exerting coercion over him (p. 3$)$. 
ality is the product of human activity--in fact man, the producer of the social world, is considered its product. The authors point out: "It is important to keep in mind that the objectivity of the institutional world, however massive it may appear to the individual, is a humanly produced, constructed objectivity" (p. 60).

3. Man is a social product (pp. 128-83). Each individual is born into a particular society with the society predefining "that fundamental symbolic apparatus with which we grasp the world, order our experiences and interpret our own existence" (Berger, 1963, p. 117). Thus, the individual experiences and internalizes the social world as an objective reality, making society subjective reality for him. This occurs through the process of socialization which is defined by Berger and Luckmann as "the comprehensive and consistent induction of an individual into the objective world of a society or a sector of it" (p. 130).

Yet the symmetry between objective and subjective reality is never complete, that is, socialization is never completed. Although every society develops procedures of reality-maintenance to safeguard itself-it still remains possible for a person's subjective reality to be transformed.

\section{The Nature of the Human Person}

The three propositions that have been discussed above deal with the nature of social reality. Man, as an integral part of that reality, entered into that discussion. Now, however, we will focus specifically on the nature of man--considering how the social sciences have typically viewed man, and then will set forth the view of man that the theoretical concepts and model of social planning presented in this dissertation is 
based on.

The model of man espoused by mainstream contemporary sociologists has been an "oversocialized conception" (Wrong, 1961). According to this view the individual internalizes social norms and then behaves in accordance with them. Society imposes external constraints on the individual by sanctioning behavior, but constraint also "become internal, psychological, and self-imposed as well"' (Wrong, p. 186).

Not only has sociology set forth a deterministic view of man, but other social sciences have also done so. In a critique of the behavioral sciences Bolton (1967) points out that behavior in that perspective is conceptualized as "a mechanical response to or expression of some other activating force--that is, a reaction to stimuli, to organic tensions, to internalized norms, to social sanctions, to dysfunctional change, etc." (p. 103).

Berger and Luckmann (1966) offer an alternative perspective. They stress the dialectical relationship that exists between the individual and social reality: the individual produces the social world and in turn that social world shapes the individual. 3 This dialectic of individual

$3_{B}$. F. Skinner (1971) also admits the existence of a dialectical relationship. He acknowledges that man's environment is "almost wholly of his own making," but also that man is shaped by this environment. But Skinner's fundamental thesis is that man is controlled--not just shaped--by his environment. Individual behavior is changed, i.e., controlled, by changing the physical or social environment. Skinner believes that he has avoided portraying man as "victim" or "passive observer," since the environment--although controlling man--is largely of his own making. According to Skinner man controls himself by manipulating the world he lives in--he is both the controller and the controlled. But if man is controlled (by the environment) to be controller (of himself and the environment), it seems to follow that his behavior is merely a reaction to environmental forces. Skinnerian man ultimately is both "passive" and "victim." See especially Chapter 9, "What Is Man?". 
and society is the perspective accepted in this dissertation--with the added assumption that the human person has the capacity to selectively and creatively relate himself to his world." 4 "The individual is in the fullest sense an actor (not a mere field or receptacle) who creatively determines his environment by selecting and reconstructing the materials of experience in terms of his own sensitivities and makeup--his unique personal perspective" (Matson, 1966, pp. 171-73).

\section{Social Interaction}

A conception of human interaction in harmony with the view of human nature outlined above is that provided by theorists known as symbolic interactionists. Herbert Blumer, a leading exponent of this view, explains:

The term "symbolic interaction" refers, of course, to the peculiar and distinctive character of interaction as it takes place between human beings. The peculiarity consists in the fact that human beings interpret or "define" each other's actions instead of merely reacting to each other's action. Their "response" is not made directly to the actions of one another but instead is based on the meaning which they attach to such actions. Thus, human interaction is mediated by the use of symbols, by interpretation, or by ascertaining the meaning of

${ }^{4}$ Hampden-Turner (1970) and Matson (1966) both hold a similar perspective. Hampden-Turner rejects a strict determinism, recognizing that "man is free yet bound by his human condition" (p. 25). In his view man has capacities for synthesizing, symbolizing, and exploring. For this discussion refer to Chapter 2, "The Existential Perspective."

In his treatment of the history of ideas Matson (1966) explores the impact of classical mechanics on man's image and finds that the legacy is a "radically broken self-image." He criticizes the contemporary paradigm of a "natural science" of man and society--behaviorism, and traces the countermovement which is laying the groundwork for an alternative science of human behavior. According to Matson several traditions are converging on a view which emphasizes man's freedom of choice. Man is more than what his behavior reveals--there is an inner dimension to that behavior. Matson argues for this broader view of the "whole man," man "indivisible." 
one another's actions. This mediation is equivalent to inserting a process of interpretation between stimulus and response in the case of human behavior (1962, p. 180).

Interaction is seen as an interpretative process. In a given situation man interprets things or actions, imputes meaning, and then acts on the basis of that meaning. Although action is situated in a social context, it is constructed or built up rather than determined or released.

In Chapter 11 a systems perspective was adopted as a framework for conceptualizing the causes of social problems and the factors that shape the responses to these problems. How does social interaction fit in a systems perspective? ${ }^{5}$ System components, such as structure, theory, and technology, provide a framework for action, but they do not determine action. People do not act toward structure, theory, or technology. These system components will enter into action only to the extent to which they shape situations in which people act and to the extent to which they supply fixed sets of symbols which people use in interpreting the situation. 6

An important assumption is that man acts on the basis of the meaning he assigns to objects or actions. It is important to note that in

${ }^{5}$ The response that follows is a simplification of a very complex problem in sociological theory, but one that suits our purposes here. Social interactionist theory does not deny social structure--action is situated in a framework that includes structural and cultural features. However, many interactionists have focused on micro-processes stressing the interpretative process and have largely ignored the contextual base of interaction. Brittan (1973, Chapter 10) calls for a "transituational" sociology that would avoid both relativism and socio-cultural determinism. Other theorists see the problem as relating micro-theory to macro-theory.

$$
{ }^{6} \text { These two sentences are a paraphrase from Blumer (1962, p. 190). }
$$


this perspective man responds not to a meaning that is intrinsic to an object $^{7}$--rather it is man that confers meaning. It is through interaction that meanings arise and are sustained. However, since meaning is socially constructed by individuals in particular societies or sectors of society, it is relative to some perspective. ${ }^{8}$

Individuals may bring noncongruent and competing definitions to an interaction situation. Therefore, in the process of interaction meanings will not only be sustained, but they may also be negotiated-being modified or transformed in the process.

In short, basic features of symbolic interaction are: "that individual action is a construction and not a release, being built up by the individual through noting and interpreting features of the situations in which he acts; [and] that group or collective action consists of the aligning of individual actions, brought about by the individuals

7 The term object encompasses "not only physical things, or human or social structures, but also relations between such structures, interactions among them, processes that occur within and between them, interface phenomena, and most importantly, human activity guided by intention" (Ozbekhan, 1969, p. 53).

${ }^{8}$ The sociology of knowledge is the field that studies the relationship between thought and society. Marx and Mannheim are major contributors to its development. Marx's thesis that thought and systems of thought are dependent upon economic and class factors is well known. Mannheim expanded this notion--asserting that thought is related to social status, roles, and positions, such as generations.

A more recent theorist, George Herbert Mead, has developed the thesis that "mind arises through communication by a conversation of gestures in a social process or context of experience" $(1934, p .50)$. It seems "very difficult to deny his claim that if determinants of thought other than society itself exist, they can structure mind only through the intermediary of the social relations in which it is necessarily enmeshed" (Coser, 1968, p. 432). 
interpreting or taking into account each other's actions" (Blumer, 1962, p. 184). These presuppositions underlie the concept of planning presented in this dissertation.

\section{PLANNING THEORY}

In addition to the usual difficulties that face those who are attempting to construct theory, planning theorists are handicapped by confusion about the very meaning of the term "planning theory" (Bolan, 1974). There are few writings that focus on planning theory, and thus little light is shed on the confusion. However, two recent articles-one by Friedmann and Hudson (1974) and the other by Bolan (1974)--do afford insight into the current state of planning theory, and merit some consideration.

Friedmann and Hudson (1974) provide an historical review of the literature of planning theory, and distinguish four intellectual traditions: (1) the tradition of philosophical synthes is whose theorists go beyond the boundaries of a single discipline in an attempt to achieve an integrated view of planning as a social process; (2) those with a rationalistic focus whose concern is with how decisions can be made more rationally; (3) the tradition of organizational development which focuses on ways to achieve changes in organizational structure and behavior and casts the planner in the role of change agent; and (4) the tradition of empiricism which is concerned with studies of national and urban planning processes.

A major part of Friedmann and Hudson's article is devoted to reviewing each of these traditions. Although they do find coherence with- 
in the various traditions, they admit that no unified planning theory exists--there is no coherent body of theoretical propositions (1974, p. 13). Friedmann and Hudson suggest the tradition of philosophical synthesis as one that may possibly provide a framework for the integration of planning theory, yet they express doubt that this convergence will occur in the near future. They maintain:

We still lack a body of experience that would demonstrate the usefulness of a unified approach to guided social change and indeed, there is not even the promise that such an approach and the theory underlying it might soon be shaped in the mold of social practice ( $p$. 13).

While the approach of Friedmann and Hudson (1974) is largely an historical one, Bolan (1974) examines the current state of planning theory. His rather elegant map of planning theory "terrain" contains twelve cells ( $p .17)$, representing "twelve distinct areas which together map the total reach of a theory of planning" (p. 16). His framework includes four levels of social relations: a substantive level (where interaction occurs with other humans and the environment), a cultural level, an institutional level, and a psychological level.

Bolan's major goal was to critically examine the current state of planning theory, yet some planners may be overwhelmed by all that Bolan has included as the terrain of planning theory. According to him, "a broad sweep of many intellectual strains" and "a host of accumulated knowledge of the physical and social world" (p. 20) has found its way into planning theory. The recent planning thought that Bolan has considered requires a new perspective on planning. 9

9 Bolan's framework obliterates the distinction between procedural theories and substantive theories of planning made by Hightower (1969)-a distinction many planners may feel more comfortable with. 
Bolan clearly sets forth that perspective by specifically describing what he means by planning theory:

My orientation is toward the general body of knowledge dealing with planned social change. I am interested in understanding that confluence of human purposes and interests, and that array of activities employing social, economic, and physical resources which alter human affairs, relationships, institutions, and artifacts in accordance with some mutually agreed to, desired, and purposeful goal (pp. 13-14).

Our concern--as Bolan's--is with planned social change, which we have referred to as resolving social problems. We do not claim to present a unified or fully developed theory of social planning. However, we do intend to discuss some concepts that seem promising for social planning theory. We will first consider what implications the nature of social problems has for social planning. Then social planning will be discussed in relationship to the social construction of reality.

\section{SOCIAL PROBLEMS AS THE OBJECT OF SOCIAL PLANNING}

A premise basic to this dissertation is that social planning theory and practice must grow out of a consideration of its content or object--and that is social problems. An exploration of the nature of social problems from both an historical and a sociological perspective has yielded two different ways of conceptualizing social problems as Figures 4 and 5 indicate. However, these are not conflicting views, but may be seen as complementary. Both permit the formulation of two propositions. One is that if social problems are to be dealt with effectively, social planning must treat the structural causes of these problems. It is evident that this proposition is in line with the social systems framework (Figure 4), but it also flows from the perspective derived 


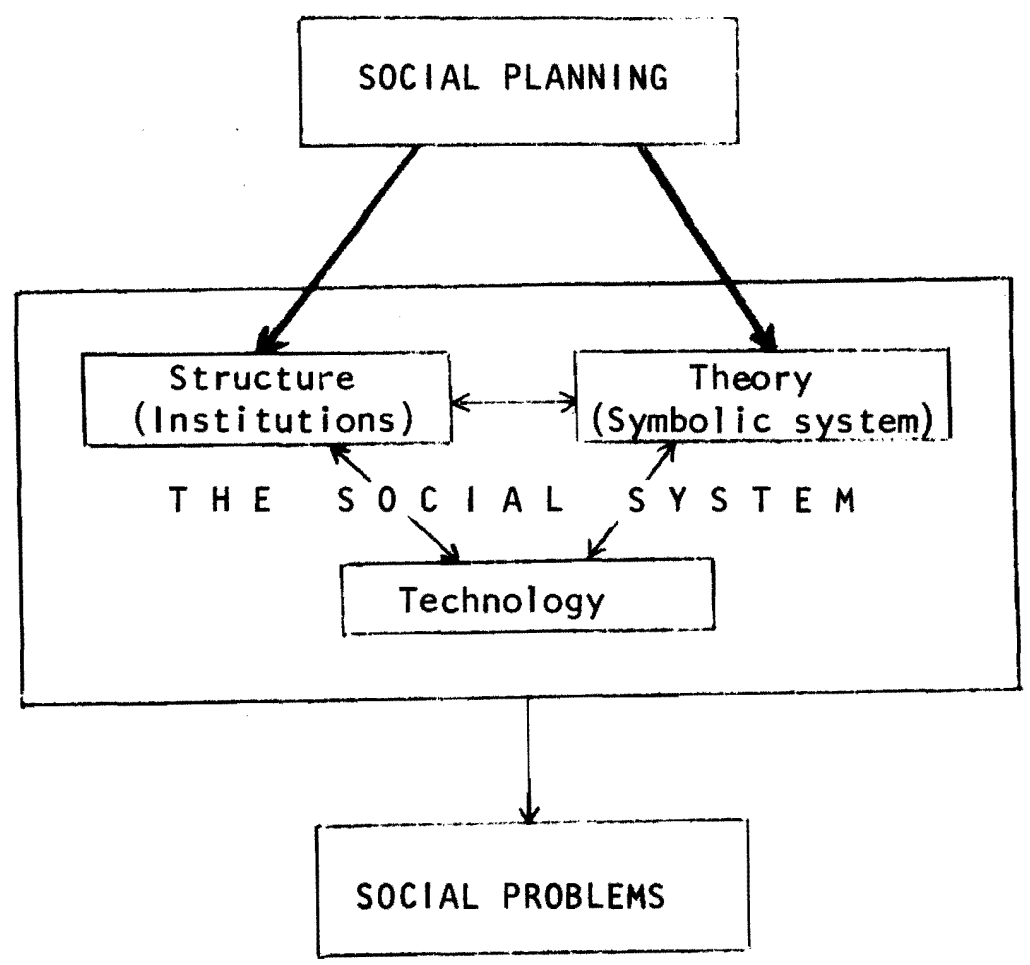

Figure 4. Social planning conceptualized as confronting the systemic causes of social problems.

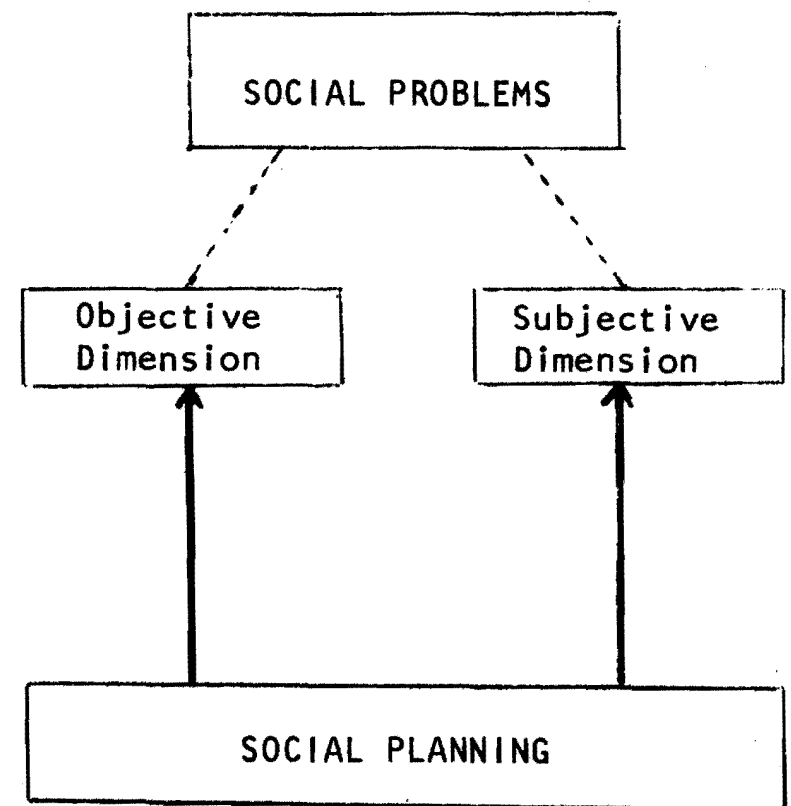

Figure 5. Social planning conceptualized as confronting the objective and subjective dimensions of social problems. 
from our consideration of sociological theory and social problems (Figure 5). Conceptualizing social problems as having two dimensions permits us to focus on objective conditions, such as causes, seriousness, and scope. In attending to objective conditions, in assessing the relationship between problem definition and solution, it has been contended that it is necessary to consider the structural factors that cause or perpetuate these conditions. For too long problems have been dealt with as being those of the individual.

The second proposition is that if social problems are to be dealt with effectively, social planning must address itself to the values, beliefs, definitions, etc. that obstruct social change. A consideration of the subjective dimensions of social problems has given rise to the assertion that planners must be concerned with how persons define social problems and that the definition process must be brought into the planning process. According to this perspective unless persons collectively consider a condition as a social problem and define it in structural terms, it is not possible to cope effectively with the problem. The social systems perspective also supports this proposition. "Theory," that is, norms, values, ideology, etc., may serve to legitimate existing social structures. If this is the case, beliefs and values become important factors in shaping efforts to deal with social problems. Social planners must acknowledge this--making "theory" the target of change.

The investigation into the nature of social problems (in Chapters II and (II) has supported these two propositions, and has also yielded two perspectives on social problems: considering their dimensions and 
their systemic causes. Figures 4 and 5 illustrate these two different ways of conceptualizing social problems. Although these two perspectives do not present us with a unified or general theory of social problems, they are complementary rather than contradictory views of social problems. Their value for us lies in their giving us two ways of thinking about social problems and two ways of conceptualizing social planning (Figures 4 and 5).

In relation to social planning, these two perspectives on social problems do converge--permitting us to conceptualize social planning as planning that treats the structural causes of social problems and addresses the values, beliefs, definitions, etc. that obstruct social change. Our analysis of social problems has provided the basis for a reconceptualization of social planning.

\section{SOCIAL PLANNING AND THE CONSTRUCTION OF REALITY}

Planning theory belongs in the context of a general theory of social reality. Of the traditions identified by Friedmann and Hudson (1974) only the tradition of philosophical synthesis attempts explicitly to do this. Since planning theory (and practice) grows out of one's view of man and society, it is appropriate for planning theorists to situate planning theory in a broader theoretical framework.

At the beginning of this chapter our assumptions about the nature of social reality, man, and social interaction were set forth. It is suggested that these theoretical concepts can contribute to planning theory and that they have important applications for planning practice. These concepts are used to place planning in a larger theoretical frame- 
work. Planning is considered as a process in which reality is socially constructed. This conceptualization is illustrated by Figure 6 .

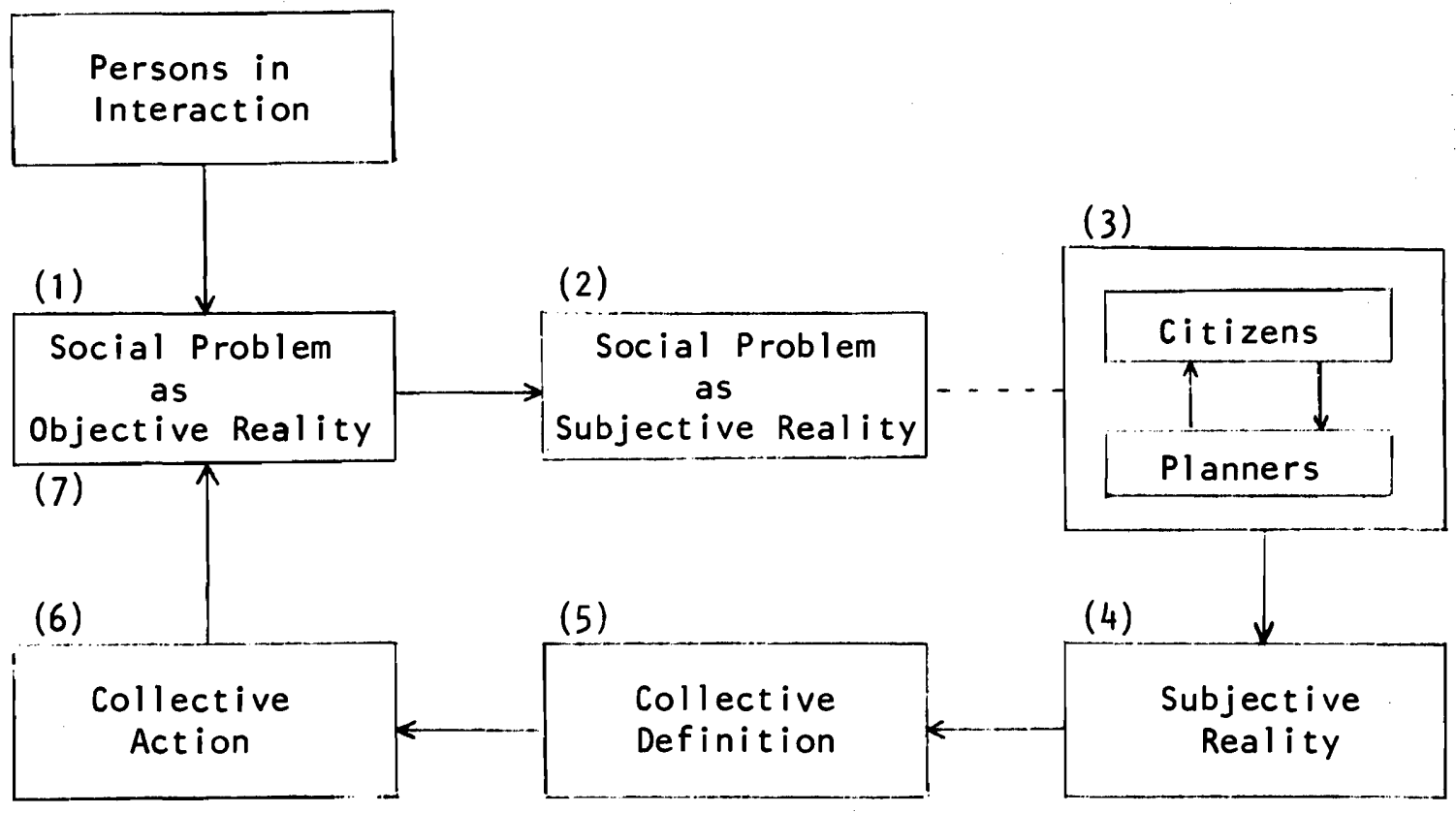

Figure 6. Social planning and the construction of reality.

The construction of reality is considered as occurring in seven phases--with planning beginning in the third phase. To facilitate discussion the blocks in Figure 6 have been numbered.

1. The social world is produced by man in interaction. These institutionalized arrangements give rise to social problems--with both the arrangements and the problems they generate being experienced as objective reality. An example may serve to clarify. Unemployment is integral to the institutionalized economic arrangements that man himself has created, that is, it is structurally generated and maintained. Contemporary economic institutions, including unemployment, can only be fully understood when one considers the historical process by which they 
were produced--and produced by man. Unemployment is an objective fact. It is experienced as objective reality--a problem or reality confronting some persons as an external and coercive fact, a reality over which they exercise little or no control.

2. Each society has specific ways of defining and perceiving the socially constructed world. Each individual born into that society undergoes a process by which that world becomes subjectively his world. "What is real 'outside' corresponds to what is real 'within'" (Berger and Luckmann, 1966, p. 133).

The experience of individuals and society leads to the accumulation of knowledge--making it possible for knowledge to be transmitted from generation to generation. This social stock of knowledge ${ }^{10}$ is available to individuals within the society, and although individuals differ in their knowledge, they share in at least part of this knowledge. Berger and Luckmann write of the social distribution of knowledge, referring to the fact that knowledge of social reality is not shared equally by individuals.

An example of the social distribution of knowledge that is pertinent to the planning process is the knowledge possessed by the planner and by the non-planner. Friedmann (1973) develops this distinction,

10 Pertinent to Berger and Luckmann's (1966) discussion of the social stock of knowledge are concepts such as recipe knowledge, degrees of familiarity, typificatory schemes, and relevance structures. Development of these concepts is not necessary here, but the reader who is interested in how participation in the available social stock of knowledge affects interaction should refer to pp. 41-46. 
calling one personal knowledge and the other processed knowledge. 11

[Personal knowledge is] based on the direct experience of the knower with the facts at hand. Personal knowledge is neither formally codified nor subject to a process of systematic verification. Rich in detailed observation, it is incapable of being generalized beyond the specific case from which it has been drawn ( $p p .245-46$ ).

[Processed knowledge is] another term for scientific-technical knowledge and [is] expressed in statements that can be formally communicated, critically examined, and revised on the basis of both new observations and the critique received ( $p$. 246).

Individuals then differ in their knowledge of social reality--in their definitions and perceptions. This means that conditions may be defined as social problems by some and not by others, or individuals may agree that a social problem exists, but define it differently.

3. It is possible for persons to share their views of reality and for one person to apprehend another's subjective processes. One's subjectivity can be made objectively available to others and can be subjectively meaningful to them. This does not necessarily mean that a person fully understands another or that there is necessarily congruence between their subjective processes. 12

The planning process can be viewed as an opportunity for the participants--planners and citizens--to share their subjectivity, to en-

11 our use of Friedmann's distinction does not deny that planners have "personal" knowledge about some aspects of social reality, nor that non-planners may have processed knowledge. This distinction is used in an ideal-typical sense to indicate that with regard to a specific planning task persons differ in the kinds of knowledge brought to the task. Each type of knowledge is incomplete in itself--needing the other to complement it.

${ }^{12}$ See Berger and Luckmann (1966, pp. 129-30) for a discussion of intersubjectivity. 
gage in a process of interaction through which their definitions of social reality--of social problems--not only can be shared and understood, but are actually subject to negotiation and modification.

4. If we accept the concept of the social distribution of knowledge, it follows that no one person possesses a complete view of reality. If it is true that persons share limited views of social reality-of social problems, the purpose of participation in the planning process is not just to share definitions, or to ensure that one's definition predominates, or to educate citizens, or to legitimate decisions. Rather it is to make different definitions and counter-definitions accessible to the participants in the planning process, and to make the participants subject to the possible modification of their own definitions of reality.

If the personal knowledge of the non-planner and the processed knowledge of the planner can be joined, new understandings and definitions can emerge. Friedmann (1973) refers to this process as mutual learning. But not only do planner and non-planner have different kinds of knowledge, but individuals, especially those occupying different socio-economic positions, also possess knowledge differently. The concept of mutual learning can be extended to include the joining of the unique personal knowledge of various individuals. In a broader sense then, mutual learning refers to the process in which participants share their knowledge, their understandings, in the joint exploration of social problems, their definitions, and their possible solutions. 13

${ }^{13}$ This definition of mutual learning is a modification of Friedmann's (1973, p. 245). 
If citizens and planners join together in the planning process, engage in the process of mutual learning, each person's view of social reality--of social problems--will change. One's subjective reality is thereby subject to modification.

5. What is sought in the planning process is a collective definition of the social problem. This requires that participants jointly define a condition as a social problem--and define it in structural terms.

6. Once meanings have been shared and negotiated, common understandings and a definition constructed, planners must assist participants in designing lines of action--plans--that will deal with the causes of social problems. Just as a social problem is a social construction of reality, a product of a process of collective definition, so too the "plan" that emerges from the process is socially constructed. It is a collective social creation--and not merely the planner's "product."

7. Once the collective action, the plan, is agreed to and implemented, social arrangements--the object of the plan--are changed. Man is again constructing social reality and social problems--objectively and subjectively. The definitions and the plan that emerge from the process cannot in any sense be considered as final, for any definition of reality or plan is precarious. Definitions are always subject to redefinition in the course of everyday interaction.

Our consideration of the definitional or subjective dimension of social problems in the last chapter led to the assertion that planners need to study the definitional process and make it a part of the planning process. This perspective on social problems challenges planners to reconsider the role citizens are to play in the planning process--that is, 
if social problems are to be resolved.

Conceptualizing social planning as the construction of reality further develops these concepts. The interaction that takes place between citizens and between planners and citizens is seen as crucial in constructing a collective definition of the problem and a collective action to deal with it. Our discussion of social planning as the construction of social reality has developed more fully a theoretical basis for the participation of citizens in the planning process.

This conceptualization also has consequences for the role of the planner. For if persons, individually and collectively, are prepared to act on the basis of the meanings of the objects that comprise their world, planners need to attend to the process by which meanings emerge. They have a role to play in facilitating the process in which participants note, interpret, and assess the situations facing them. This role will be discussed in more detail in our presentation of the planning mode 1 .

\section{CONCLUSION}

In this chapter social planning has been conceptualized in relation to social problems. It has been considered as a process that confronts the systemic causes of social problems (Figure 4 ) as well as the objective and subjective dimensions of social problems (Figure 5). These two perspectives on social problems have given rise to a new conceptualization of social planning. It has been our contention that if social problems are to be dealt with effectively, social planning must (1) treat the structural causes of these problems, and (2) address itself to 
the values, beliefs, definitions, etc. that obstruct social change.

Social planning has also been placed in a broad theoretical framework, being conceptualized in the context of the social construction of reality. Within this basic theoretical framework a model of social planning will be constructed. This model and the planner's role in it are the focus of the next chapter. 


\section{CHAPTER $V$}

TOWARD A THEORY AND MODEL OF SOCIAL PLANNING- II

This dissertation is grounded in the belief that we can improve our capacities to treat our problems, and this chapter specifically is addressed to this issue. A model of social planning that grows out of a consideration of the nature of social problems and that has problem resolution as a focal concern is presented.

This presentation treats three components of the model: (1) characteristics of the planning process; (2) phases of the process; and (3) roles for planner, citizen, and decision maker. Five characteristics of the planning process will be discussed, and it will be argued that these premises or characteristics are essential if social planning is to deal effectively with social problems. A diagram illustrating the phases of the process and planning roles in each of the phases will be set forth. The role of the planner will be considered in more detail than that of the others.

Because assumptions about the planning environment and the nature of knowledge influence how persons approach planning, these assumptions will be explicated before elements of the planning model are presented. 
I. ADDITIONAL ASSUMPTIONS: ENVIRONMENT AND KNOWLEDGE

The Environment of Planning

Contemporary society is characterized by rapid change (Schon, 1971, p. 23; Friedmann, 1973, p. 106). Changes in professions and occupations, regions, organizations, institutions, intellectual disciplines, values, and even in personal identity have caused Schon (1971) to announce the "loss of the stable state." He contends: "Currents of change roll through every domain of society, shaking the stable state. No established institution in our society now perceives itself as adequate to the challenges that face it" (p. 17).

Emery and Trist (1965) have focused on the environmental contexts in which organizations exist. They find that the environment is changing rapidly under the impact of technological change. Differentiating four types of environmental contexts, they identify one as a "turbulent" one. "The turbulence results fron the complexity and multiple character of the causal interconnections" (p. 31). The environment is "so complex, so richly joined, that it is difficult to see how indidivual organizations can, by their own efforts, successfully adapt to them" (Emergy, 1967, p. 223). The actions of individuals and organizations have unplanned and sometimes negative consequences on others.

Planning, therefore, is challenged by "turbulence"l--by a rapidly changing, interrelated, increasingly complex environment. 
$\underline{\text { Knowledge }}^{1}$

The diversity, complexity, and rapidity of change that characterize the social environment are closely related to the following assumptions about the knowledge that is brought to bear on the planning task.

1. The difficulty of identifying and measuring key variables limits our ability to explain relationships, and therefore our ability to predict consequences is limited. ${ }^{2}$

2. Knowledge is scarce and therefore costly.

3. The data available to planners are often incomplete and in a form that is not useful.

4. On the other hand, sometimes there is not a lack of information, but "an information overload, too many signals, more than can be accounted for; and there is as yet no theory in terms of which new information can be sought or new experiments undertaken" (Schon, 1971, p. 13).

5. Knowledge is socially distributed. Therefore no one person knows "what's best," nor is one particular perspective "the best." Scientific knowledge, as well as knowledge from any one discipline, has

${ }^{1}$ For an extended discussion of the contemporary "crisis of knowing," see Friedmann (1973, pp. 98-112). Dror (1968, pp. 225-32) al so examines what he terms "barriers" that face the development of policy knowledge in the social sciences.

${ }^{2}$ This assumption will be treated again in the next chapter when Dunn's (1971) concept of "evolutionary experimentation" and "developmental hypotheses" is discussed. It is central to his concept of planning. 
its biases and needs to be complemented by other perspectives. 3

In summary, a good deal of uncertainty--and even ignorance--characterize our knowledge of social reality.

\section{TOWARD A SOCIAL PLANNING MODEL: PROCESS CHARACTERISTICS}

The elements of the social planning model that will be developed are based on the theoretical concepts and assumptions that have been discussed in the preceding pages. The model is built on (1) what has been presented as the nature of social problems, (2) the theoretical concepts dealing with the nature of social reality, man, and social interaction; and (3) the assumptions that were just discussed regarding the planning environment and the nature of our knowledge.

Five characteristics are proposed as essential to the social planning process, and hence, are integral to the model. The contention, based on the assumptions that have been made, is: if social problems are to be resolved, planning must be a (1) "task-oriented," (2) "experimental," (3) "cybernetic," (4) dialogic, and (5) collaborative process. These characteristics or premises are interdependent and overlapping; however, they will be discussed separately.

\section{A "Task-oriented" Process}

If social problems are to be dealt with effectively, the planning

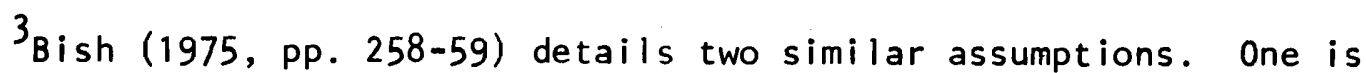
"relative increasing ignorance." The expansion of knowledge means that each person knows relatively less. The second is that the scientific bias leads to the neglect of "time and place specific information." These two assumptions are offered by Bish as counter to assumptions of perfect and complete knowledge. 
process must be "task-oriented." This term has been selected in preference to "goal-oriented" which has often been associated with designing effective means to attain goals. A task-orientation includes this, but in addition requires that every step of the planning process be directed toward resolving the problem. This means defining the problem in structural terms, and after the problem has been defined, translating goals into measurable criteria so that programs can be evaluated in terms of how much progress has been made towards resolution of the problem. If the plan that is finally selected represents a compromise between competing interests, it is unlikely that it will be relevant in dealing with the problem. The plan must be oriented toward "the task," not to competing interests.

Attention especially needs to be paid to implementation, for we know that in the process of implementation problems are often restructured and redefined (Blumer, 1971, p. 305). The question arises whether it is possible for organizations that are responsible for implementation to focus on problem resolution--to be task-oriented. ${ }^{4}$ Michel's famous study of reformist movements in Germany led him to conclude that it is inevitable for organizations in the course of time to relinquish original goals and become more concerned with their own survival--with organizational maintenance (Blau, 1956, pp. 94-95). Selznick's (1949)

${ }^{4}$ Wildavsky (1972) refers to a task-oriented organization as a "self-evaluating organization." "It would continuously monitor its own activities so as to determine whether it was meeting its goals or even whether these goals should continue to prevail" (p. 509). Although Wildavsky is not certain that self-evaluating organizations can exist, he considers how the ideal organization would function and discusses some of the obstacles to its realization. He sees the development of trust as an essential requirement for the self-evaluating organization. 
study of the Tennessee Valley Authority also revealed that the TVA gradually altered the objectives of its programs, becoming more conservative in the course of its development. Blau (1956), however, contends that organizational or bureaucratic structures of themselves do not necessarily generate a conservative trend.

Thus, it must be recognized that organizations and participants in the planning process may experience difficulty in focusing on the task of problem resolution--especially over an extended period of time. However, commitment to that task is essential if problems are to be resolved.

\section{An "Experimental" Process}

A commitment to problem resolution, i.e., a "task-orientation," requires an "experimental" approach. Experimental--as used here--refers to the provisional or tentative nature of all the phases of planning. It is not being used in the sense of a scientific approach--one requiring the specification and control of variables.

An experimental approach is essential, for the social planner is handicapped by the lack of two kinds of knowledge: first, "there is insufficient information of a 'base-line' character about the extent of a problem--the kinds of people affected by it and its indirect consequences or associated phenomena," and second, we have only "a meager understanding of the complexity of relationships among social forces" (Riecken and Boruch, 1974, p. 2).

Presently many planning efforts do not reflect the state of our knowledge. "Specific reforms are advocated as though they were certain to be successful" (Campbell, 1972, p. 188). In a critique of urban 
problem solving Brewer (1973, p. 234) states that there is a tendency for technical professionals "to hold out hope that a specific project, a particular computer model, or a given demonstration project... will provide the much-desired answer."

Besides those who advocate specific plans/programs as "the answer," there are administrators and staff who also fail to view programs as "experimental." Campbell (1972) makes a pertinent distinction between the trapped administrator--the one who is committed to a specific program--and the experimental administrator who is committed to problem resolution rather than to a specific reform. The former cannot afford to permit the program to undergo serious evaluation, whereas the latter is willing to use evaluative information to retain, modify, or abandon a particular program--he is committed to the task of problem solving.

If one acknowledges the complexity of social problems and the limitations on our knowledge, it follows that a plan that has been evaluated in the light of goals and finally selected for implementation will not necessarily lead to goal achievement or problem resolution. Even though consequences may have carefully be projected and analyzed, the results are uncertain. Thus, an approach more in harmony with the nature of our knowledge and the nature of social problems would be an experimental one. In this approach to social planning, a program/plan is hypothesized as leading to goal attainment, and all those with a stake 
in the planning process need to acknowledge the possibility of failure. 5 The commitment is to problem resolution--not to a specific plan or program.

Experimental refers not only to plans and programs, but requires that every phase of the planning process be considered provisional or tentative. Does this mean that goals too are subject to revision or even abandonment? The answer is partially contingent on how we define goals. ${ }^{6}$ We will consider a goal as referring to an ideal or a value. It is abstract--to be pursued, not attained. Objectives, on the other hand, are more specific and are possible to achieve.

Ordinarily goals do not change; objectives do. The following example will illustrate. "A decent home for every American family" was declared a national goal by Congress in the Housing Act of 1949. A specif:c objective of that act called for a total of 810,000 public housing units to be constructed in the next six years. That objective was revised downward in 1954. By 1972 there were 310,000 fewer public

5 Michael (1973) and Wildavsky (1972) discuss the importance of organizations acknowledging the possibility of failure. Michael devotes a chapter (pp. 131-43) to the topic, "embracing error." His thesis is that in order to engage in long-range social planning we must acknowledge uncertainty, expect error, seek to discover it, and then use it as a basis for learning. To encourage this behavior organizations must reward error-embracing.

Because Wildavsky postulates that knowledge is contingent, that improvement is always possible, that organizations must learn from experience, evaluation becomes critical. Yet because evaluation depends upon accurate information, Wildavsky too contends that organizations must reward "bad news."

${ }^{6}$ Young (1966) points out that the term goal is used in many ways, and also that terms, such as objectives, aims, policies, purposes, and alternatives are often used more or less interchangeably for goals-without distinguishing their meanings. Our discussion of goals and objectives is based on the distinction Young makes between goals and objectives. 
housing units than the 1968 Housing Act had specified as an objective to be reached by 1973, and far short of what had been called for in 1949 . Specific housing objectives have changed and will continue to change, while the goal of "a decent home" is, and more than likely will remain, a stated national goal.

Young (1966) points out that a hierarchy of goals exists (some are less important) and that some of the goals may actually be incompatible. Thus, even abstract goals need to be reexamined, and perhaps be given a different priority. 7

It is important, therefore, for goals to be analyzed in the light of other goals. And in order to resolve social problems, programs must be evaluated to determine whether they are reaching their objectives, and objectives must be examined to see if their fulfillment leads in the direction of goal attainment. Since our knowledge is incomplete and uncertain in many respects, efforts to resolve social problems require a planning approach that acknowledges this, and then tests knowledge by action. In other words, social planning requires an experimental approach to problem solving.

7 Young (1966) discusses conflict over public goals, and proposes a procedure the planner can use to handle multiple goals. Included in that process is the examination of the relationship between the goals, the relative evaluation of goals or sets of goals, and finally, the establishment of goals which are prioritized. 


\section{A "Cybernetic" Process}

When it is acknowledged that our efforts at problem resolution are subject to error, provision must be made to monitor and evaluate these efforts, and then redirect them when necessary. We will borrow the term "cybernetic" and adapt it to the planning process which involves human beings and a turbulent environment rather than machines. 9

Planning, as a cybernetic process, implies an openness to the environment and requires an information system ${ }^{10}$ that provides data for monitoring and evaluating programs. Even more significantly, it requires that the planning system have the capacity to respond to feedback information--using the knowledge that is gained to improve perform-

${ }^{8}$ Bauer (1969) and Jantsch (1969) both conceive of planning as a cybernetic process. In Bauer's view the detection of the consequences of the plan and its subsequent adjustment become essential to planning, and thus he is concerned with feedback and information systems.

Jantsch develops the notion of adaptive or "cybernetic" institutions. He argues that it is necessary for institutions to continuously relate "planning objectives and potentials to the changing environment, and to provide suitable information systems" (p. 473). Planning, according to Jantsch, is a "flexible process of continuous search and modification" ( $p$. 477).

9"Cybernetics is the study of steering, of the ways groups of machines, or persons, or combinations of machines and persons, are guided to work jointly to realize goals set by the cybernetic overlayer. Cybernetics is most highly developed in mechanical and electrical systems, where it consists of (1) one or more centers which issue instructions to the units which do the work, and (2) communication lines which carry the instructions from the center(s) to the working units, and return ifeedback' information and responses from the subject units. While many cybernetic models omit power, we see it as a third main factor. If the steering units cannot back up their signals with rewards or sanctions, they will be frequently disregarded" (Etzioni, 1970, p. 223).

${ }^{10}$ An information system, according to Bauer $(1969$, p. 66$)$, has four functions: (1) detection, (?) evaluation, (3) diagnosis, and (4) prescription for action or guidance. 
ance. The important point is to use feedback information in a systematic way, or in other words, to learn from experience, thereby improving problem solving efforts. Accordingly, the plan may require some modification, major adjustments, or may need to be abandoned and a new plan adopted. Or the problem itself may need to be redefined. All efforts are judged by their effectiveness in confronting the structural causes of the problem and need to be continually directed to that end. 11

\section{A Dialogic Process}

Planning has been conceptualized both as a process in which reality is socially constructed and as a process of mutual learning (Chapter IV). However, mutual learning can only take place through dialog. 12 And it is in a face-to-face situation that persons can most fully share their subjectivity, i.e., what social reality is to them. ${ }^{13}$

Therefore, it is important to consider the threefold features

11 John Platt, a humanistic scientist (1974, pp. 124-25), argues that a "cybernetic working-through" of the problems facing us is essential. His view is similar to what has been expressed as a task-oriented, experimental, cybernetic process. He explains: "The cybernetic view of man and society is that we move ahead by a steering process, individually and collectively. We must continually look ahead to see which direction we are going in and how it needs to be changed, and what we must do to change it. No direction is permanent. No prophecy is sure. No recommendation is absolutely certain. So we must proceed by continually evaluating, choosing and acting, with lookouts (or 'prophets') and with feedback-monitoring as we work through current problems and continually adjust our human course in the light of new dangers or new possibilities, experimenting but being ready to correct the course when we see we have begun to go wrong."

${ }^{12}$ See Friedmann's (1973, pp. 177-83) discussion of dialog.

${ }^{13}$ Berger and Luckmann (1966, pp. 28-34) discuss the importance of face-to-face interaction for experiencing the other as "real." 
that are essential to dialog,,$^{14}$ and thus, to the model of social planning that is being proposed:

1. The ability and willingness of each participant to state the other's view of reality to the other's satisfaction (the ability to take the role of the other and to express one's interpretation).

2. The ability and willingness of each participant to state the conditions under which the other's view of reality is valid or has merit (recognition that the other's subjective reality has some validity).

3. The ability and willingness of each participant to assume that in many respects the other is like himself; that is to say, that a common ground exists where they share common values and perspectives, and each is aware of this common ground, and perhaps, of the circumstances which have led the other to the position he holds (empathy).

The collaborative model is premised on the willingness and ability of persons to engage in the process of mutual learning through dialog.

\section{A Collaborative Process}

It is common today to refer to planning as a process. Many acknowledge that this represents a change in the focus of planning, for previously the primary concern of urban planners was the preparation of a product--a "master plan." Their task was ordinarily considered completed when the plan was produced--and hopefully adopted. "Planning is now viewed as a continuing process of moving towards provisional goals rather than the delineation of an ideal end-state to be achieved at

${ }^{14}$ These features of dialog are a modification of those set forth by Anatole Rappaport and are discussed by Dunn (1971, p. 230). 
some future datal' (Robinson, 1972, p. 21, emphasis added). In current theory and practice it is recognized that the planner is engaged in a dynamic, developmental activity.

In earlier views of planning the planner was viewed primarily as an expert--standing outside or beyond the political process. He was a technician: value-free, providing an objective, impartial analysis. Current theories of the planning process set the planner in the midst of the political process (Bolan, 1969; Rondinelli, 1969).

A few theorists have given process another meaning, that is, they conceptualize planning as a process of social interaction. Friedmann (1973) advocates "transactive planning," in which planner and client groups join together in a process of mutual learning. He has outlined a style of planning in which interpersonal relations between planner and client are central. Although Friedmann does not use the term "social interaction," he does conceptualize transactive planning as a "sequence of interpersonal relations" $(p .170)$ and as a "web of interpersonal transactions' (p. 200).

Perlmann and Gurin (1972) have developed a social problem solving model which requires that the practitioner perform both analytical and interactional tasks. According to this model the practitioner performs the technical tasks that planners have traditionally seen as belonging to their professional competencies. In addition the practitioner is involved in a process of interaction with others. To deal effectively with problems, he must also be concerned with building working relationships with his client.

In his conceptualization of planning Bolan (1971) draws on knowl- 
edge from group dynamics, role theory, and organization studies. He presents planning as a social process with the planner enmeshed in a social interaction network. According to this framework, planning involves not just a role for the planner, but three interrelated roles: a planning role, a client role, and a community decision network. ${ }^{15}$ In Bolan's scheme the planner is involved in interaction at two levels: with the client group and with the larger community. Planning is also placed in a political context with his model realistically capturing the relationships that shape urban planning decisions. Negotiation and bargaining are integral to that process.

By conceptualizing planning as a social process and situating the planner in that process, Friedmann (1973), Perlmann and Gurin (1972), and Bolan (1971) have made important contributions to planning theory. The planner is no mere technician whose role is to objectively develop and propose an efficient, effective plan. Neither is he just involved in an on-going developmental process; the planner is now viewed as acting in relation to others.

Planning has been conceptualized in this dissertation as a process of social interaction. We are now asserting that if planning is to resolve social problems, interaction must be characterized by collaboration. By collaboration is meant that participants in the planning process join in a common effort to solve social problems.

This notion of collaboration has two implications. The first is

${ }^{15}$ Besides conceptualizing these three roles, Bolan (1971) sets forth a framework encompassing factors that influence the interaction between planner and $c l i e n t(p .388)$ and one that includes those factors that influence client and community interaction (p. 391). 
that participants enter into the process in order to work toward the resolution of a social problem. If the planning process is characterized primarily by competition, and if the outcome is largely shaped by bargaining, experience seems to support the conclusion that the policy/ plan will not be directed toward problem resolution (Piven, 1971; Jones, 1971; Ross and Staines, 1972).

Planning as a collaborative process has a second implication: participants--citizen and planner--are viewed as collaborators or partners in the process. Planning is not the exclusive domain of the planner. If knowledge of social reality is socially distributed (as we maintained earlier), more than one perspective is needed on the problem and its "solution."

Most planners would agree that input from others is needed. And most do seek to involve others in goal formulation and make efforts to assess values and preferences. ${ }^{16}$ But collaboration here means more than this: citizens, planners, and decision makers--al though each has a different role in the planning process--come to the planning task as equals. Each brings his special knowledge, i.e., either personal or processed, to bear on the planning task. Table 111 , which is borrowed from Friedmann (1973, p. 187), clarifies these distinct contributions.

Planning as collaboration means that each participant brings a specific contribution to the process. Each contributes to the task and each has something to learn from the other participants. Planning to resolve social problems requires joint efforts to do so. This concept

${ }^{16}$ For an excellent discussion of the planner's task of assessing values and preferences refer to Kahn (1969, Chapter IV). 
TABLE $\| 1$

\section{CONTRIBUTIONS TO PLANNING}

\section{Planners}

- concepts

- theory

- analysis

- processed knowledge

- new perspectives

- systematic search procedures

\section{Citizens}

- intimate knowledge of context

- realistic alternatives

- norms

- priorities

- feasibility judgments

- operational details

of planning as a collaborative process is so essential to dealing with social problems that we will identify the concept and model of social planning proposed in this dissertation as collaborative social planning.

In sum, we have assumed that planning is situated in a turbulent environment and that our knowledge of that environment is incomplete and uncertain. Five characteristics have been identified as necessary requirements of the social planning process. That process, it has been argued, must be a task-oriented, experimental, cybernetic, dialogic, and collaborative process. These process characteristics are integral to our social planning model.

III. THE SOCIAL PLANNING PROCESS: PHASES AND ROLES

Phases of the planning process and roles in that process are aspects of the social planning model that will now be considered.

\section{Phases}

Friedmann (1969) describes the classical decision model of the planning process as involving four distinct steps: "(1) preparation of alternative plans by planners; (2) adoption of one of these plans by 
deciders; (3) implementation of the chosen plan by administrators; and (4) recycling information concerning the results of implementation to planners who use this information to revise the current plan" (p. 312 , emphasis added).

In place of this classical model Friedmann proposes an actionplanning model that "fuses action and planning into a single operation so that the conceptual distinctions of planning-decision-implementationrecycling are washed out" $(1969$, p. 312). Friedmann maintains that this model is closer to empirical reality--that it is difficult to isolate the four steps in the classical model.

Because of its relegating planners, decision makers, and administrators to a particular phase of the planning process, the classical decision model described above by Friedmann is rejected. However, we will also reject Friedmann's suggestion to abandon entirely the conceptual distinctions of planning--decision making--implementation--recycling. Although he is correct in maintaining that it is often difficult in reality to isolate these steps, conceptualizing the planning process as a series of phases or stages is useful.

Examples of various conceptualizations of planning phases are set forth in Table IV. They represent the thinking of persons from varied backgrounds: Schein (1969), a process consultant who deals with group problem solving; social workers, Perlman and Gurin (1972), who consider social problem solving from the perspective of social planning and community organization; Kahn (1969), a social worker, whose concern is social planning; Riecken and Boruch (1974), social scientists who are interested in experimentation; and of Robinson (1971), an 


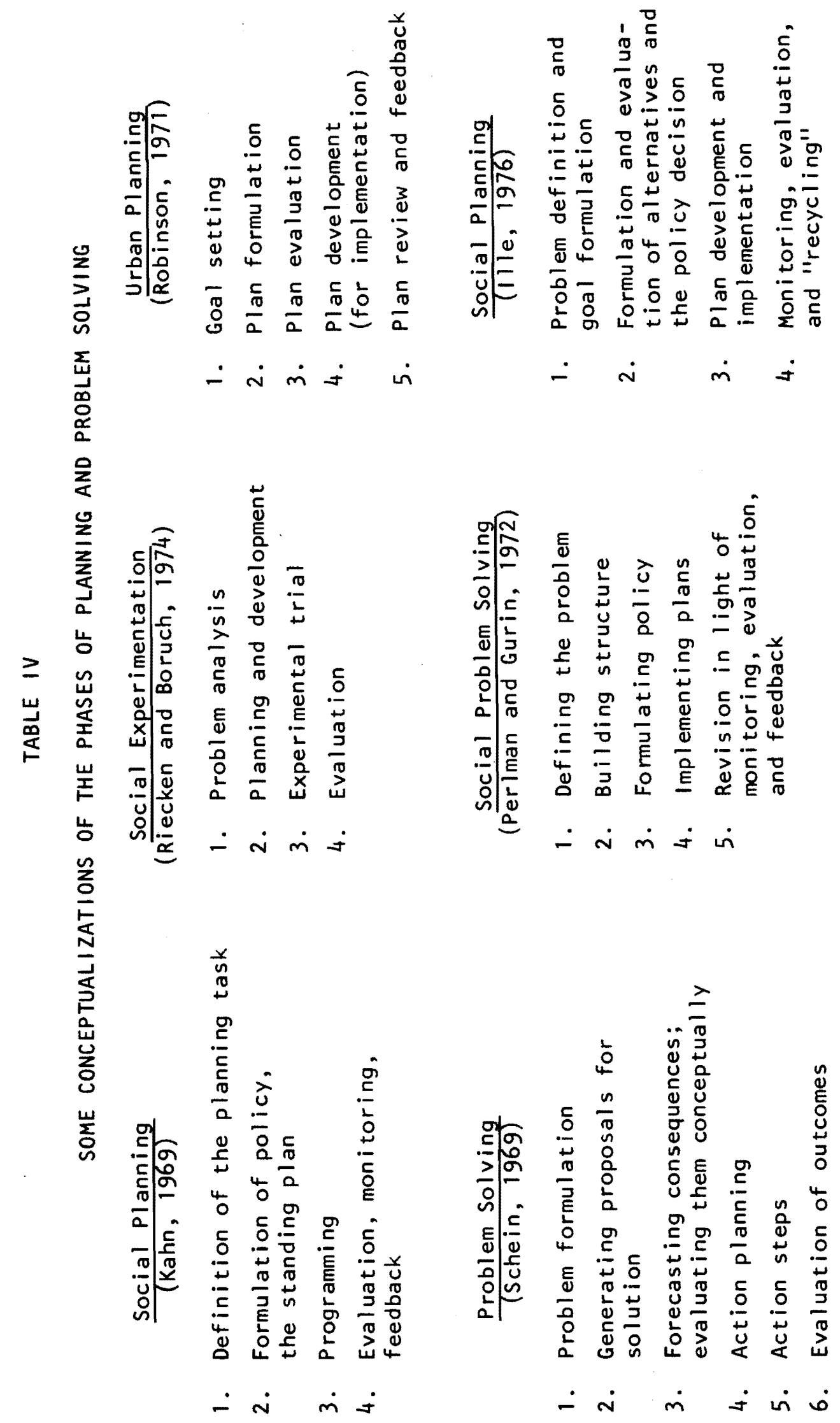


urban planner. Although a great deal of similarity is apparent, when one explores their views of planning or problem solving, differences also appear.

However, our purpose is not to compare these conceptualizations of planning phases, but to point out that when the planning process is conceptualized in phases, those selected are of necessity going to resemble other formulations. The collaborative model conceptualizes the planning process as having four phases or stages: (1) problem definition and goal formulation; (2) formulation and evaluation of alternatives and the policy decision; (3) plan development and implementation; and (4) monitoring, evaluation, and recycling. These should be recognized as analytical distinctions--not as clearly defined stages. The process could easily have been conceptualized as having five or six steps instead of four as do the formulations of Schein (1969), Robinson (1971), and Perlman and Gurin (1972).

Two other points are to be noted about the phases of the planning process. First, both the policy decision and implementation are included as part of the planning process. Some planning models omit one or both-with planning viewed as preliminary to a decision and/or sometimes planners are given an evaluation role after the plan/program has been implemented. Both Kahn (1969) and Robinson (1971) omit the policy/plan decision and implementation from their models (although both include evaluation and feedback as part of the planning process). In the collaborative model, as in the models of Schein, Riecken and Boruch, and Perlman and Gurin, the roles of decision makers and program administrators-although differing from that of the planner--are integral to the process 
of coping with social problems. In the collaborative model then, decision making and implementation are considered integral to the planning process.

Second, the process is considered a cyclic or continuous one. The stages do not necessarily proceed one through four in a rigid sequence. The process is characterized by flexibility--it is a cybernetic process. Therefore, it may be necessary to return to an earlier phase of the cycle (as illustrated by arrow "c" in Figure 7).

This view of planning as a flexible process is a rather common one today. For example, Kahn (1969, pp. 60-62, 132) discusses the "spiral" or "intersecting circle" nature of the planning process. Although planning steps are specified in a logical sequence, planning often requires returning to an earlier stage to refine or revise an outcome. Or, as Kahn notes, two phases are sometimes intermingled.

In addition to considering planning as a flexible or a "spiral" process, in the collaborative model the process is not ended until the problem is resolved. This in reality demands "continuous" planning.

Roles

The collaborative model includes roles for citizens, planners, and decision makers as has been mentioned several times. Figure 7 illustrates the basic relationships that characterize each planning phase in the model.

"Citizen" is used in a generic or "residual" sense--it refers to any participant who is not a planner. Citizens ("X") will include persons from the target population, academic persons, those involved in operational programs, persons representing the decision makers, and other 


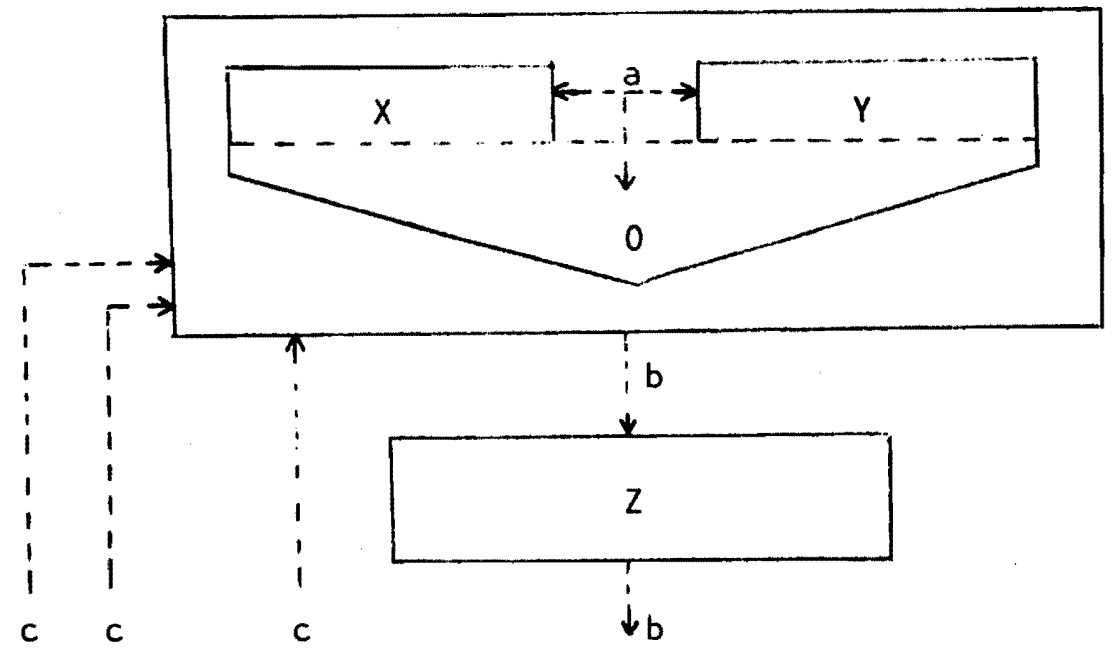

Figure 7. Planning as a collaborative process: Roles for citizens, planning team, and decision makers.

interested persons. Each citizen ("X") and planner ("Y") has a unique contribution to bring to the planning task. The arrow ("a") from citizen to planner indicates that dialog characterizes the process. Through the process of mutual learning the knowledge of each undergoes a change. The outcome ("0") results from planner and citizen joining together in a collaborative effort. The broken lines under " $X$ " and "Y" indicate that planner and citizen have contributed to the task: the outcome ("0") is a collective one, differing from what either citizen (" $X$ ") or planner ("Y") originally brought to the process.

Although the decision maker is represented (or may be directly involved) in contributing to the outcome ("O"), this model reserves a specific role to him (them). That role (" 2 ") is to formalize the collective outcome, or for some reason, to make another decision. For example, a collective outcome may not have been reached. Then the task of the decision maker is to weigh the different views and make a decision.

The collaborative model then has a role for citizen, planner, and 
decision maker in every phase of planning.

\section{Roles and Phases Illustrated}

The roles of citizens, planners, and decision makers in each phase of planning are illustrated in Figure 8 . Three points should be noted.

First, as already indicated, the phases in the collaborative planning process do not differ significantly from those conceptualized in many other models.

Second, the greatest value of the diagram lies in its clearly indicating a role for the citizen in each phase of planning and relating that role to the planner's. Other planning models do not set forth as explicitly this kind of a role for the citizen.

Third, although the collaborative and dialogic nature of the planning process is somewhat illustrated by the diagram, it fails to portray what have been proposed as other important features of the planning process; that is, its experimental, task-oriented, and cybernetic characteristics (although to some extent the cybernetic nature is indicated by the arrows). Because this diagram fails to adequately convey these five characteristics of the collaborative planning model, it cannot be considered a diagram of the model, rather it is a diagram of roles and phases of the model.

\section{THE ROLE OF THE PLANNER IN THE COLLABORATIVE PLANNING MODEL}

Al though the collaborative model includes three roles, we will focus on the role of the planner. By planner, we are actually referring to a team of "planners," because planning for structural change and planning in collaboration with citizens requires that the planner possess 
PLANNINg ROLES

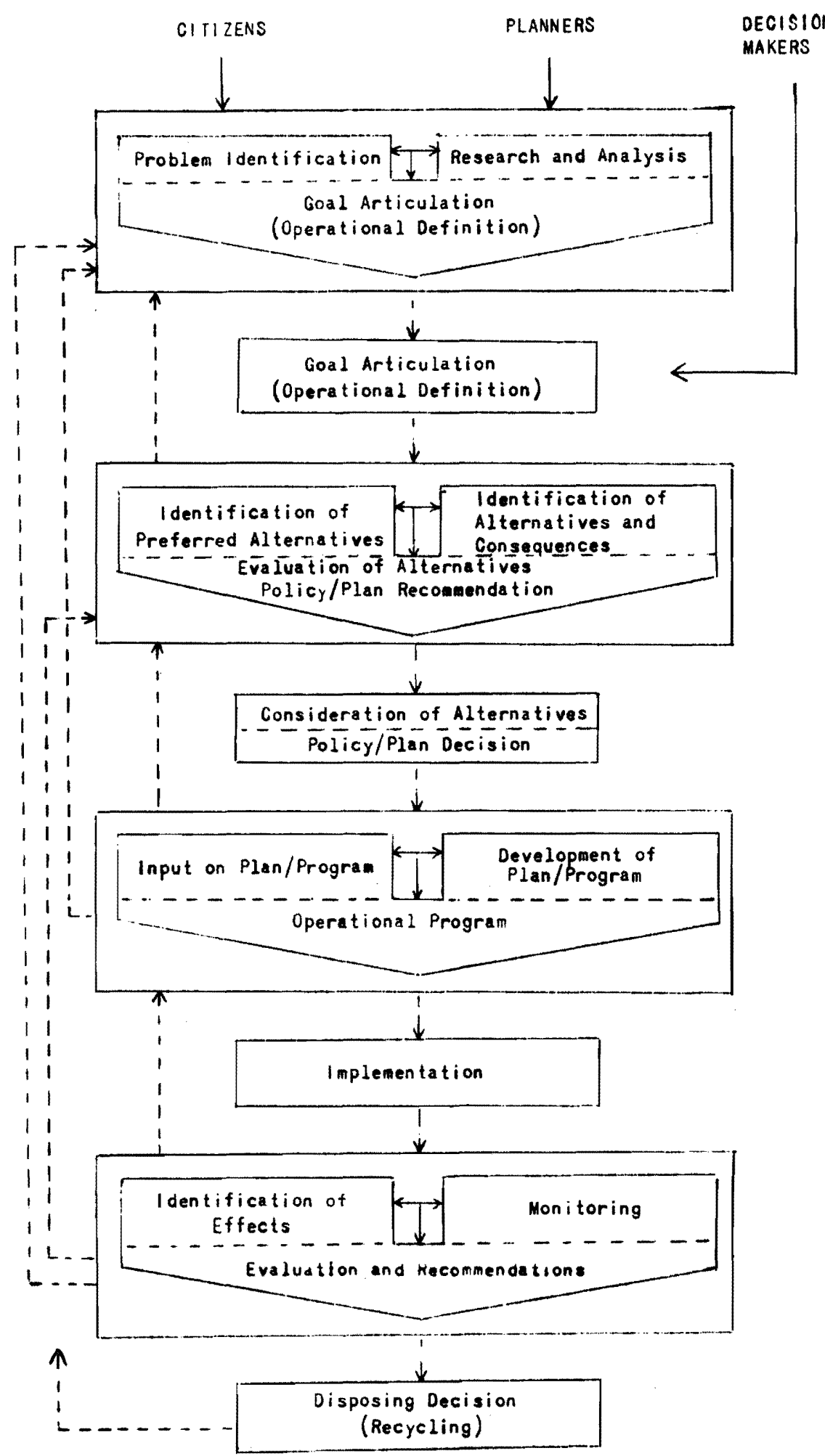

Figure 8. Roles and phases in the collaborative social planning process. 
technical planning skills, familiarity with social science knowledge, the ability to critically assess its relevance to concrete problems, knowledge about the management of complex organizations and interrelationships, interpersonal skills that can facilitate the process of mutual learning through dialog, and a commitment to collaborative planning for social change. It is evident that no one person can embody these necessary skills and knowledge; therefore, an interdisciplinary team is necessary to fulfill the tasks that are required by collaborative social planning.

Before developing the role of the planner in the collaborative social planning model, some of the basic roles that have been performed by social scientists/planners will be considered. These roles will then be related to that demanded by collaborative social planning.

\section{A Review of Planning Roles}

Three kinds of professional roles have been identified by Vollmer (1970) as ones currently performed by applied social scientists. In the role of analyst the professional brings his analytic and theoretical skills to bear on problem analysis and the design of a plan for problem resolution. In the role of advocate the professional "seems to identify completely with his client's interests, point of view, and total situation as he brings his professional talents to bear on the solution of client problems" (p. 33). Professionals have also become involved in a third role--that of mediator when there are conflicting points of view. For this role "one must be able to identify with the interests, aspirations, and points of view" of others (p. 33) in working toward a resolution. 
How do these three roles relate to that played by the planner in the collaborative model? The role identified by Vollmer as analyst is one that is required for dealing with social problems. Theoretical, analytical, and technical skills are essential.

We will reject the role of advocate as a planning role, for that role demands an adversary relationship, whereas collaborative planning is premised on joint effort. The concept of "advocacy planning" is a familiar one to planners (Davidoff, 1965; Peattie, 1968; Kaplan, 1969), and most often has been promoted by those whose concern is for powerless, low-income groups. The advocate planner (as Davidoff conceived the role), representing certain interest groups, would present alternatives that differed from the public planning agency's plan. It was postulated that the competition that resulted would yield superior plans.

A variant of this concept is described in a recent article by staff members of Cleveland's City Planning Commission (Krumholz et al., 1975). The authors relate how that public agency is applying the concepts of advocacy and activism--in the interests of the city's poor and powerless--to the problems of cleveland. ${ }^{17}$ From their experience of using professional talents as advocates for the poor, they call for a redefinition of the planner's role along these lines.

17 Krumholz et al. (1975) note that these problems "have less to do with land uses, zoning, or issues of urban design--the traditional domain of city planners--and more to do with personal and municipal poverty, unemployment, neighborhood deterioration and abandonment, crime, inadequate mobility, and so on" (p. 298). The article gives a broad overview of The Cleveland Policy Planning Report, its goals, and examples of how the planners have applied the concepts of advocacy, activism, and policy. planning. The article described a significant change that has occurred in planning thought and practice. 
Although we agree with the equity goal that is the basis for their policy recommendations and also agree with their analysis of problems and proposed solutions, their model is rejected for three reasons.

First, this model casts the planner in the role of one who knows "what is best" for the city. In their own words they view planners as "the guardians of our cities' futures" (p. 304). Al though the planners are on the side of the poor and the powerless, theirs is an elitist perspective.

The second objection is closely related: nowhere do the authors describe their commitment to the participation of citizens, or the poor in particular to whom they give priority attention. From the theoretical perspective of this dissertation--unless attention is given to the process of collective definition, efforts to impose definitions and solutions will not be successful in the long run.

Third, it appears that the greatest strength of the advocacy model is ultimately its greatest limitation. Advocacy is premised on a pluralistic political process where many interests are in competition. The advocate planner chooses sides, devoting his professional talents and moral commitment to the poor, seeking to influence decisions so that they will reflect these interests. Using the political system, however, has built-in limitations. For in advocating the interests of the poor, one comes in opposition to the most powerful. Although some gains may be made for the poor, decisions made within the pluralistic political process will ultimately reflect the interests of the most powerful.

Vollmer (1970) suggests that when there are divergent or conflict- 
ing views the planner can assume the role of mediator. Because mediation often involves compromise, it too will be rejected as a role for the planner in the collaborative model. However, the planner does need the skills a mediator possesses--namely, the ability to identify with the other--with his interests and perspective.

A role closer to that needed for collaborative planning is that of a process consultant. Process consultation has been defined as "a set of activities on the part of the consultant which help [sic] the client to perceive, understand, and act upon process events which occur in the client's environment" (Schein, 1969, p. 9). Although the literature on process consultation deals with organizations and their development, the key assumption of process consultation is similar to what we have concluded after examining the nature of social problems, that is, "the client must learn to see the problem for himself, to share in the diagnosis, and to be actively involved in generating a remedy" (Schein, 1969, p. 7). The planner needs to establish a working relationship with participants in the planning process, facilitate mutual learning through dialog, so that social problems can be collectively defined and acted upon .

\section{A Collaborative Role: An Elaboration}

It has been maintained that in collaborative social planning the role of analyst is required. In this role the planner brings "processed knowledge" to the task, and a role similar to that of process consultant is also needed so that participants may be facilitated in sharing their "personal knowledge" and in mutual learning as together they engage in the task of social planning. For purposes of discussion we will consid- 
er that planners in each phase of planning have tasks in three areas:

(1) technical ones, utilizing special planning skills and social science knowledge, (2) interactional tasks relating to citizen participants, i.e., promoting mutual learning through dialog, and (3) interactional ones relating to the decision makers. These three task areas are the framework that will be used as we consider the planner's role.

The tasks that are outlined as technical ones differ little from those identified by cthers as belonging to the planner. They are tasks that have been traditionally seen as the planner's. However, our emphasis on the collaborative nature of the planner's role does constitute an approach that differs from most planning models. Although other models may describe the planner in interaction with others, assigning the planner the role of facilitating mutual learning through dialog is unique to the collaborative model. 18

The three tasks in each of the four stages of planning are summarized in Table $V$ and will be discussed in more detail.

1. Problem Definition and Goal Formulation. Problem definition and goal formulation are closely related, but they are distinct. To illustrate this relationship we will consider the housing goal of "a decent home for every American family" and definitions of the housing problem. Although persons may hold the same goal, they may define the problem differently. The housing problem may be defined as a shortage of low-rent housing, or research may lead to another definition as it

${ }^{18}$ Friedmann (1973) does consider planning as mutual learning. However, he does not elaborate the planner's role in facilitating mutual learning, nor does he conceptualize planning in phases as we have proposed. 

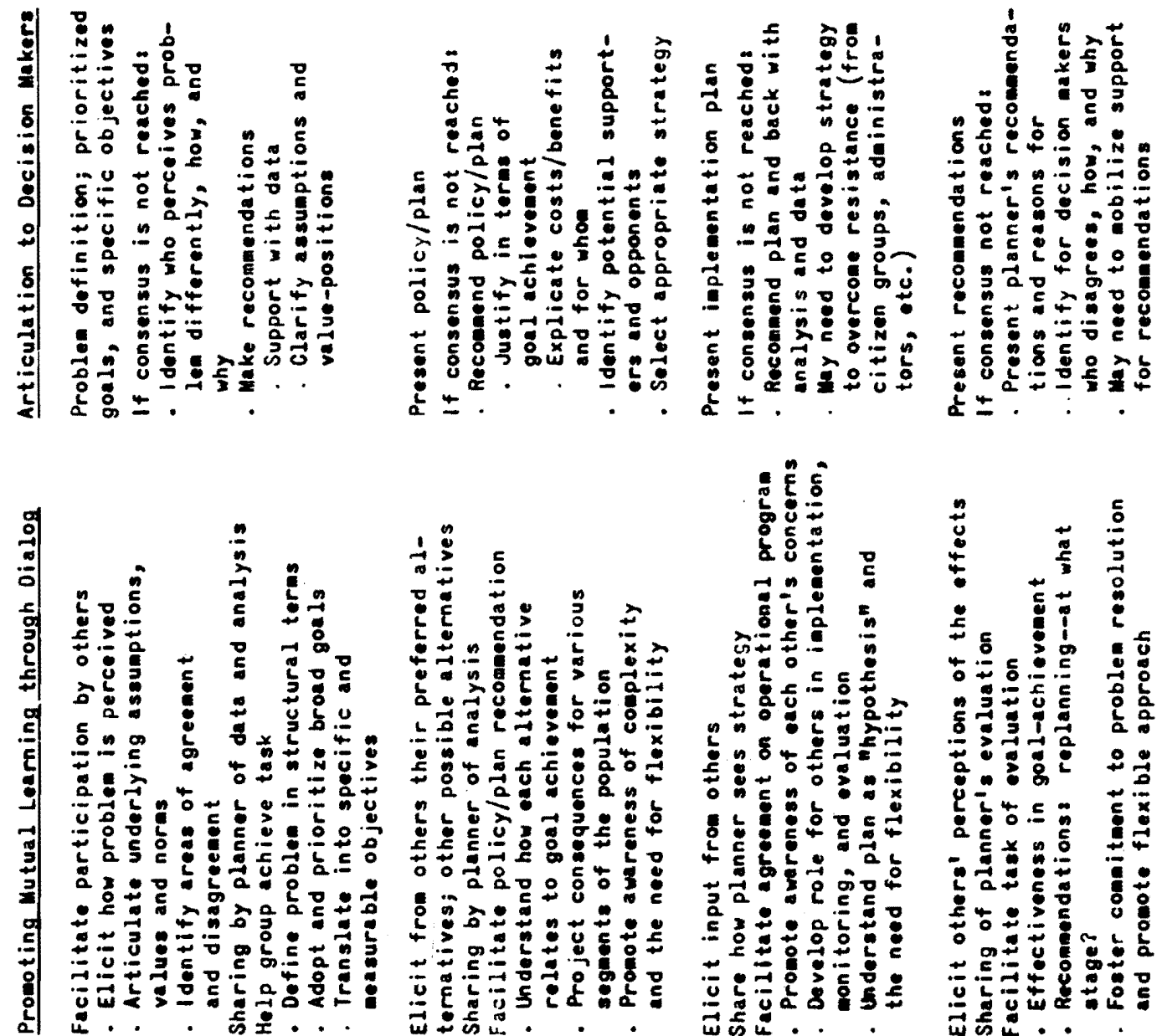
210
0 1 至的。
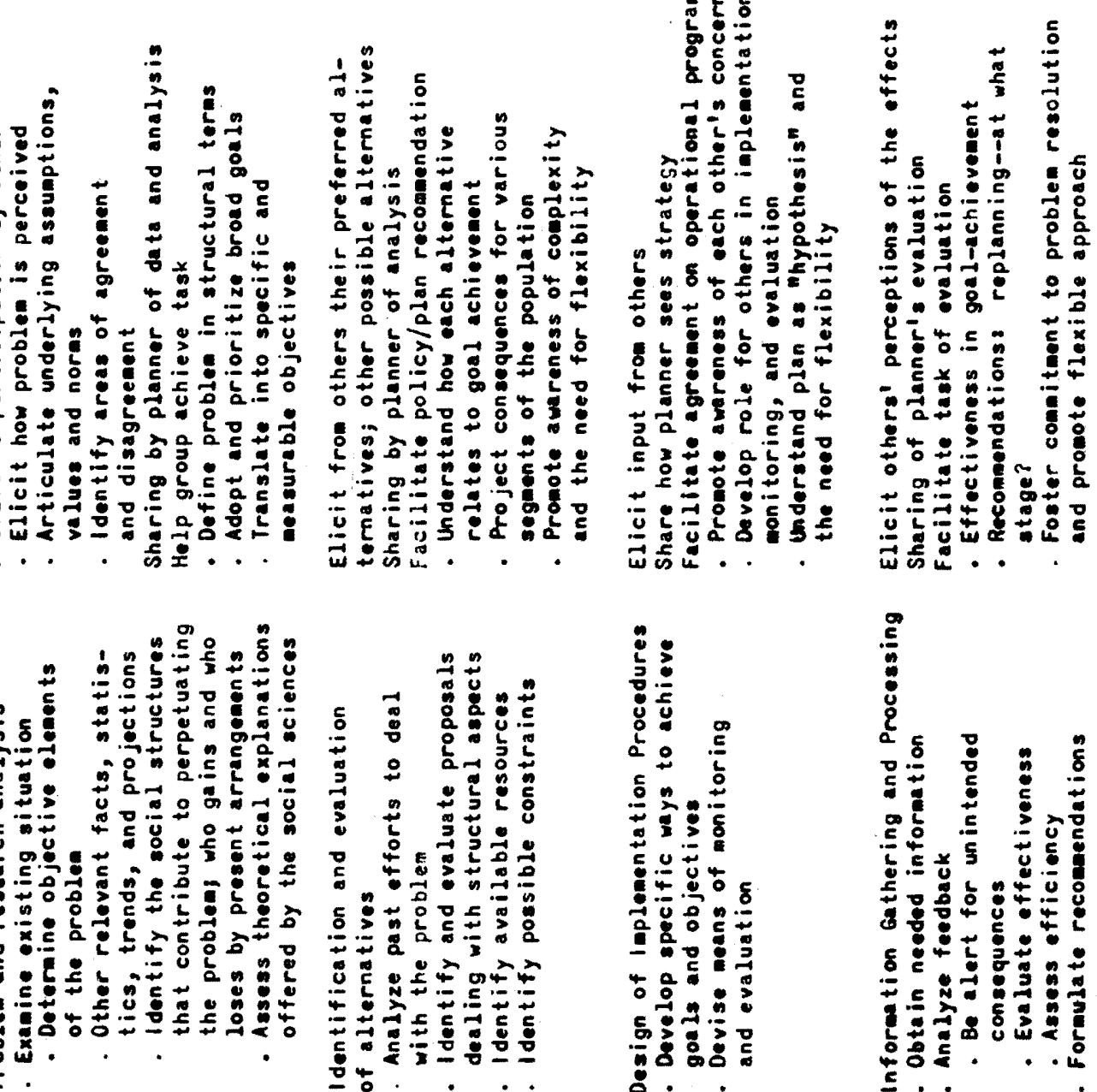

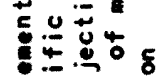

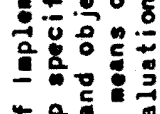

$\leftarrow \div 5:$

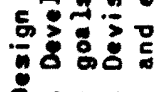
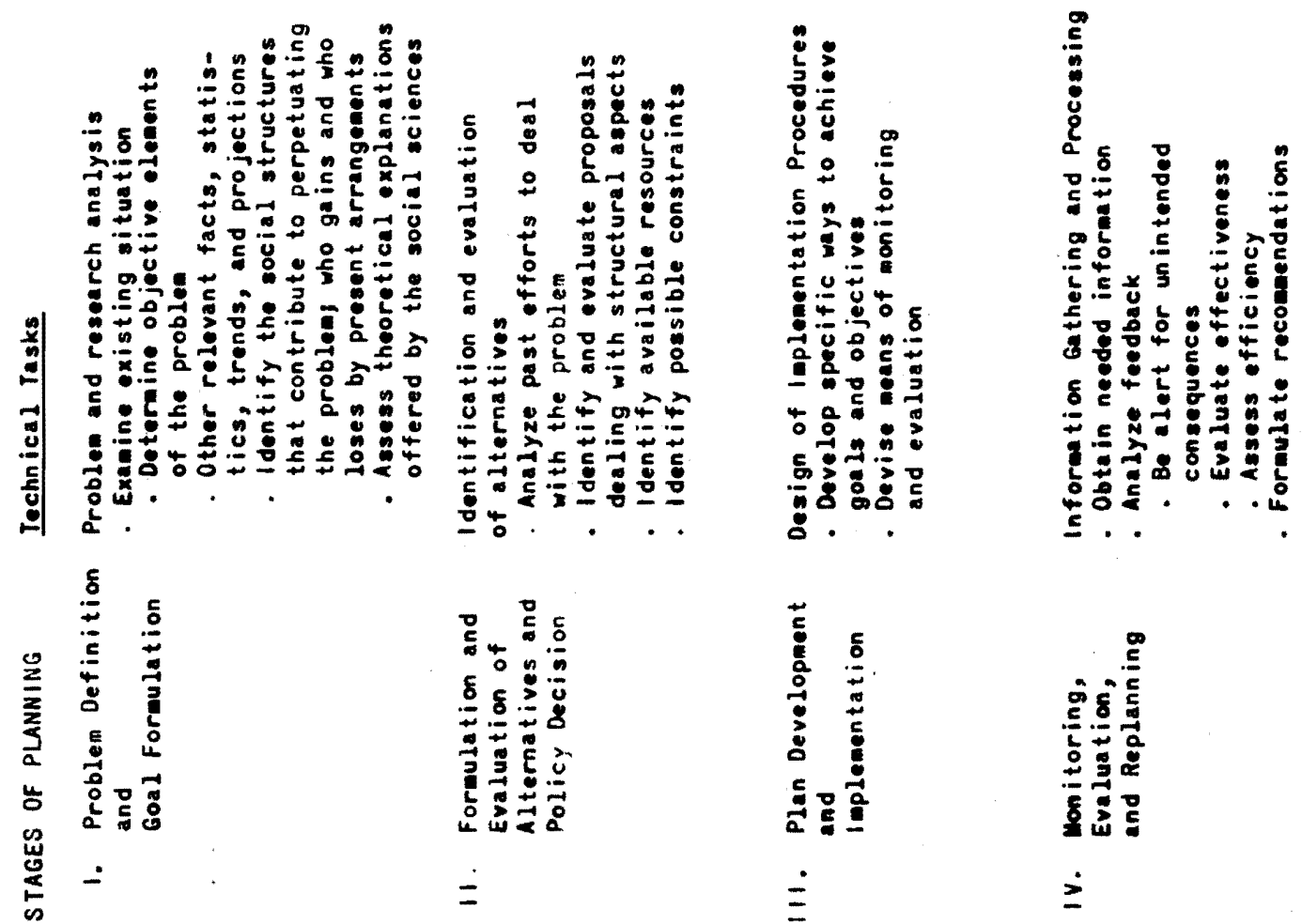
did in Cleveland. Research by Cleveland's City Planning Commission revealed--not a shortage, but that a surplus of low-cost marginal quality housing existed in that city, therefore a more detailed analysis of the problem was necessary (Krumholz et al., 1975). A housing surplus, vacancy rates, migration data, abandonment, deteriorating housing units, and low-income families call for different policy solutions from those which would be the case if the problem were defined as a housing shortage .

The importance of problem definition and its relation to policy has been discussed in some detail. Planners in this first phase of planning need to be cognizant that the definition process determines the fate of the problem; understand that social positions give rise to different values, beliefs, interests, and thus, different definitions; and that individuals and groups normally work for the acceptance of their definition. It is evident that resources and power are unequally distributed. Presently the policy process works to the advantage of those who are already favored. ${ }^{19}$

Although no one phase of planning merits being designated the most important, this first phase is crucial. It is essential to bring interested persons, including administrators and program staff persons,

${ }^{19}$ In their article, "The Politics of Analyzing Social Problems," Ross and Staines (1972) discuss three meihods of handling the conflict that arises between competing definitions of publicly recognized social problems. According to the authors the outcome of the conflict tends to preserve present privileges. They maintain that "the approach to social problem definition that stresses political process leads to the conclusion that the nature of the outcomes is related over the long run to constellations of power, influence, and authority which process and filter the problems a society sets itself" (p. 38). 
into this phase. Facilitating the group to arrive at a collective definition is a challenging task for the planner.

(a) Technical Task: Problem and Research Analysis. The planner has three general technical tasks. First, the existing situation must be examined and the "objective" elements of the problem established. Data about the seriousness and magnitude of the problem as well as other relevant social and demographic information must be collected. Trends need to be identified and projections made. Second, the social structures that contribute to perpetuating the problem must be identified. These structures may be societal, regional, state, local, and neighborhood. $^{20}$ Those who gain and who lose by the existence of the present arrangements need to be identified. Third, theoretical explanations of the problem that are found in social science literature need to be considered and their relevance assessed.

(b) Promoting Mutual Learning through Dialog. This task refers to the exchange between planner and citizen. The planner's role is to facilitate this exchange and help the group achieve its task. This task of the planner in each phase of planning will be discussed in three parts: (1) eliciting input from others, (2) sharing by planner, (3) facilitating the group's task.

It is important for persons and groups to share their definition of the problem. The planner needs to facilitate the expression of definitions, grievances, preferences, priorities, and other relevant information. Underlying assumptions should be made explicit, and values

${ }^{20}$ Though these structures may be beyond the direct control of the planning system, their role in maintaing the problem must be considered. 
and norms that are threatened or seem threatened must be clarified. Areas of agreement and disagreement should be identified. The planner also needs to inject the relevant findings of his research analysis, and in a manner that is comprehensible to those involved. The group should be enabled to establish and place priorities on broad goals, and then translate them into specific and measurable objectives. The problem should be clearly defined--and in structural terms.

(c) Goal Articulation to Decision Makers. The decision maker (who may be a single person, such as mayor, commissioner, agency head, etc.; or a group--council, commission, etc.) may have participated-either personally or by representative--in the dialog between citizen and planner. Although the goal of that process of dialog is a collective definition (and eventually action), the responsibility for the decision itself belongs to the decision maker.

In this stage of planning ${ }^{21}$ planners should present the decision makers with the prioritized goals, and the specific objectives that have been agreed to. If no consensus was reached, the planners need to identify for the decision makers the various perspectives, who holds them, and why. They should make recommendations 22 and support them

${ }^{21}$ This is not necessarily a discrete step in the planning process, for the goals may be presented simultaneously with the recommended plan.

${ }^{22}$ Collaborative social planning is presented as a normative model. However, the difficulties involved in reaching a collective definition and action are recognized. Therefore, when the group does not arrive at a collective decision, it becomes necessary for the planner to present his recommendations to the decision maker. Although this may cast him on someone's "side," the planner should avoid assuming the role of advocate for any special group. This would seriously jeopardize the collaboration that is needed in future planning endeavors. 
with data--clarifying their assumptions and value-position.

The decision makers may choose to approve the action recommended by the planners and citizens, or having objections or reservations may send the recommendations back for further consideration. If there was no consensus on goals and objectives, then the dicision makers have the responsibility for selecting the goals and objectives.

1I. Formulation and Evaluation of Alternatives and Policy Decicision. The process of formulating policy to deal with a problem has inherent difficulties. Some are of a technical nature: difficulties of projecting consequences, of developing measures to compare alternatives, of choosing between alternatives that offer different combinations of benefits, of dealing with uncertainty, etc.

Besides these "technical" planning problems, this stage also offers special challenges to the collaborative process. Presently in the process of formulating an official plan of action interest groups mobilize to influence the decision. "The official plan is always a product of bargaining, in which diverse views and interests are accommodated" (Blumer, 1971, p. 304).

The plan that emerges from compromise, and as a response to power, may be only weakly related to the goals that were originally formulated. In the process the problem may be redefined.

Realizing the tendency of groups to engage in strategies to promote their interests, and being aware that bargaining can divert efforts away from effective problem solving, the planner must develop methods to foster a collaborative approach to developing a policy/plan.

(a) Technical Task: Identification and Evaluation of Alternatives. 
In the attempt to identify alternatives to deal with the problem, past efforts should be examined--with the planner analyzing circumstances involved and then assessing reasons for the success or failure of the policy. Policies that will deal with the structural causes of the problem are the concern. They must be identified and evaluated. In projecting and comparing consequences, the planner needs to hypothesize the chances of goal achievement, compare the costs and benefits of each alternative--noting especially their differential impact on groups, the possible effects beyond the system under consideration, and how the policy may affect other goals.

Resources, such as money, personnel, and facilities, must be identified. Constraints too must be considered: resources, values, beliefs, and institutions that are beyond the scope of the planning system.

(b) Promoting Mutual Learning through Dialog. Planners need to elicit from others what their preferred alternative is and what they see as other possibilities. Consequences, including costs and benefits, should be probed. Values, beliefs, and assumptions underlying different alternatives should be explicated. Planners too need to share their analysis, projections, and assumptions. The participants should understand how each alternative relates to goal achievement and understand how costs and benefits impact differently on certain groups. The group should be facilitated to arrive at a policy/plan recommendation. This means that bargaining that might divert from the problem must be avoided. The task is to select an alternative that promises to deal with the structural aspects of the problem. All should be aware of the complexity and uncertainty involved, the possibility of error, and of the need for flexibility. 
(c) Recommendation of Policy/Plan to Decision Makers. The planner should communicate the policy/plan to the decision makers with the pertinent analysis. If consensus was not reached on the policy/plan, the planners should present their recommendations justifying them in terms of goal achievement, making it clear what the costs and benefits seem to be. They should also present reasons for the disagreement between the participants.

It may be necessary for the planner to identify those who support and who oppose their recommendations. They should identify the resources and the possible strategy of their opponents. Then they should select an appropriate strategy, carefully weighing the likely benefits as well as the disadvantages.

111. Plan Development and Implementation. "Invariably to some degree, frequently to a large degree the plan as put into practice is modified, twisted and reshaped, and takes on unforeseen accretions" (Blumer, 1971, P. 304). According to Blumer, "the unforeseen and un intended restructuring of the area of a social problem that arises from the implementation of an official plan of treatment" (p. 305) is not well understood and is in need of much study.

One way to begin to deal with this problem is to overcome the dichotomies between planning and implementation. In this model planners have a role in developing implementation procedures and in monitoring and evaluating programs. It has been recognized too that administrators and program staff must be drawn in some way into the planning process from the very beginning. If administration and staff do not have a role in problem definition and in planning the program, it is easy to 
understand how they may redefine the problem and substitute a different policy in the process of implementation.

(a) Technical Task: Design of Implementation Procedures. In developing programs to achieve specific goals and objectives the expected impact of the program on costs and benefits must be projected. The normal details of programming, such as determining needed staff, facilities, budgeting, etc. must be attended to and placed in a time frame. We have postulated that effectiveness in confronting the causes of social problems demands that the planning process be characterized by a task-oriented, experimental approach. Devising means of monitoring and evaluation becomes an important task. This requires the design of information gathering and processing mechanisms. A plan of evaluation--including measures--must be developed. A means of adjusting implementation procedures to feedback must also be provided.

(b) Promoting Mutual Learning through Dialog. Efforts to reform the organization and delivery of social services usually are directed at four kinds of problems: fragmentation, inaccessibility, discontinuity, and unaccountability (Gilbert, 1973, p. 1). Gilbert points out that these problems are related to a broad range of issues.

Problems of fragmentation concern organization characteristics and relationships, especially coordination, location, specialization, and duplication of services... . Problems of inaccessibility concern obstacles to a person's entering the network of local social services. . . Problems of discontinuity concern a person's movement through the network of services and the gaps that appear as an agency tries to match resources to needs. . . . Problems of unaccountability concern relationships between persons served and the decisionmakers in service organizations. . (Gilbert, 1972, p. 1).

After discussing methods of dealing with these problems, Gilbert concludes that uncertainty surrounds the selection of the "right method." 
While further investigation of basic issues is needed, Gilbert argues that present policy choices must not foreclose other possible options. Gilbert's analysis pertains specifically to the delivery of social services and problems that are largely organizational. Although our concern is with attacking the structural causes of problems, these practical administrative problems must be dealt with as well as the prime one of developing a plan/program that will work toward problem resolution.

Uncertainty surrounds both developing a plan/program to attack social problems and the concrete problems of program administration. Citizens, administrators, and organizational staff have their own perspectives on problems of implementation and insights on how methods might be improved. The exchange between them must be fostered, and in facilitating agreement on an operational program, the planner must promote an awareness and understanding of the concerns expressed. Specific roles in implementation, monitoring, and evaluation must be agreed to. The plan must be considered a "hypothesis," as a possible mearis of attaining the objectives. The importance of feedback, learning from experience, and flexibility needs to be stressed.

(c) Communication with Decision Makers. The implementation plan is presented to the decision makers. If consensus on the plan was not reached, the planners present their recommendations with supporting analysis. They need to identify for the decision makers who disagrees and the areas of disagreement. Planners may need to develop a strategy to overcome resistance--whether it be from citizen groups, administrators, etc.--always mindful of what may be long term consequences of their action. 
IV. Monitoring, Evaluation, and "Recycling." An experimental, cybernetic approach and a commitment to problem resolution (a "taskorientation") have been proposed as important characteristics for an effective social planning process. The plan in action--its implementation--has been proposed as the test of effectiveness. It is therefore essential that we be able to assess plan effectiveness. Yet evaluations of social programs have been inadequate, and it is widely agreed that evaluation has not affected decision making in a significant way (Wholey et al., 1971, p. 46).

John W. Evans (1969) admits that we lack adequate evaluation methodology, yet he cites other factors as more important in accounting for the dearth of good evaluations. The most significant obstacle, Evans maintains, is that persons in key positions, such as decision makers and program directors, lack backgrounds in either the physical or social sciences and therefore do not understand the importance of objective empirical evaluation. Another important factor, according to Evans, is that the role of program evaluator is seen to be in conflict with the role of program administrator. Program administrators seem to be program advocates.

If evaluation is going to provide us insight into the effectiveness of social programs and then be used as a basis for decision making and replanning, the planner must find ways of overcoming these obstacles.

(a) Technical Task: Information Gathering and Processing. This task is a twofold one. First, the planner must obtain needed information from all sources. This will include measures, such as social indicators, and information from persons involved, such as the target pop- 
ulation and administrators. Second, the information must be processed. In analyzing feedback data the planner must be alert for unanticipated consequences--both positive and negative. Plan effectiveness must be evaluated. The "objective" elements of the problem need to be considered. Has the magnitude and severity of the problem been affected?

What improvements have been made with regard to the initial problem situation? Who has been affected? In what ways (values, resources, attitudes, etc)? In evaluating effectiveness the planner is relating effects to objectives and goals. Program efficiency also needs to be assessed. This requires relating costs to benefits. Have benefits justified the costs? Have resources been used efficiently? Is there a better way to utilize resources?

(b) Promoting Mutual Learning through Dialog. In sharing their perceptions of the effects of the plan, citizens should be asked to consider how responsive the plan was to their needs and to identify the costs, benefits, and difficulties they experienced. Planners and administrators too need to share their assessment of plan effectiveness and efficiency.

In facilitating the task of evaluation and recommendations, the planner should promote an understanding of the perceptions and concerns of all involved. It is essential to determine how effective the plan/ program has been in reducing the problem--in reaching the goals and objectives. In grappling with the issue of how to more effectively and efficiently deal with the problem, the decision regarding "recycling" must be made--where to "replan"--to look at goals and objectives again, to consider other policy/plan alternatives, or to focus on plan develop- 
ment and problems of implementation. In the process of formulating recommendations, the planner needs to foster commitment to problem resolution among participants.

(c) Comunicating with Decision Makers. Planners then present the evaluation and recommendations to the decision makers. If agreement was not reached, planners need to identify for the decision makers the areas of disagreement and who disagrees. Planners should support their recommendations with adequate data and clear analysis. Decision makers must be encouraged to use the evaluation as a basis for their decisions. Planners may need to mobilize support for their recommendations.

\section{CONCLUSION}

This chapter has examined three components of the collaborative planning model which are based on theoretical concepts and assumptions presented earlier. First, the planning process has been discussed as a task-oriented, experimental, cybernetic, dialogic, and collaborative process. It has been contended that these must characterize the planning process if social problems are to be resolved. Second, the planning process was conceptualized in four phases with citizen, planner, and decision maker having roles in each phase of the process.

Third, the role of the planner has been elaborated--with his tasks falling in two main areas: technical and interactional ones. Recognizing that social problems have objective dimensions and are structurally generated and maintained, we have contended that the planner has an important role to play in bringing his technical skills (or processed knowledge) to bear on social problems. But also cognizant of 
the subjective or definitional dimension of problems--that the citizen has a role to play, bringing his unqiue knowledge to the planning task, the planner has been given the role of facilitating the process of mutual learning so that social problems may be resolved. Although other planning models may assign interactional tasks to the planner, the collaborative planning model is the only one which specifies the planner's role in these terms.

This presentation of the planning model: the characteristics and phases of the process; a role for citizen, planner, and decision maker in each phase; and the elaboration of the planner's role has completed our goal of linking social planning to social problems. Now we undertake an assessment of what has been done. 


\section{CHAPTER VI}

\section{COLLABORATIVE SOCIAL PLANNING: AN ASSESSMENT AND POSSIBILITIES}

In this final chapter the theory and model of collaborative social planning will be assessed. In this evaluation we will briefly consider how others have approached the task of improving the policy/planning process. Specifically we will examine why the collaborative model is proposed as an improvement over other planning models. Some of the challenges facing collaborative social planning will also be considered. Finally, the thesis will be advanced that dissatisfaction with present planning theory and models is giving rise to a new planning paradigm. Writings of several theorists have converged on a new conceptualization of planning: planning as learning. This dissertation is considered as an effort toward the formulation of this emerging paradigm.

\section{IMPROVING THE POLICY/PLANNING PROCESS ${ }^{1}$}

The contention that contemporary planning does not adequately address the problems of cities underlies this dissertation. Because planning practice is not relevant to the pressing problems of the city and because present planning models seem to offer little promise of dealing more adequately with these problems, a collaborative model has been developed and presented as one more suited to these problems.

${ }^{1}$ Dror $(1968$, p. 8) uses the term metapolicy to refer to "policy about making policies." 
Collaborative social planning will be assessed at two levels of analysis. First, the approach that has been used to build the collaborative model will be compared with ways in which others have approached the subject of improving the policymaking/planning process. Second, the collaborative model will be compared with several other planning models. This evaluation will support the contention that the collaborative model promises to be more effective in dealing with urban problems than these other models. Since the collaborative model is a normative one, we will also briefly consider the place of normative theory in planning.

\section{Some Contemporary Approaches}

We will examine some of the ways in which persons concerned with reform seek to improve planning/policymaking. Three different approaches--identified as the policy sciences, political realities, and scientific management approaches--will be discussed. Our concern is somewhat philosophical, that is, we are interested in how they set about to improve planning/policymaking--in their intellectual approach.

Policy Sciences. Dror $(1968$, p. 73$)$ contends that a main task facing us is "to engage in an empiric study of policymaking, and to integrate the findings of such a study with insights and abstract thought to form a comprehensive, systematic, and reliable theory of public policymaking." He assigns this responsibility to what he considers an emerging discipline, policy science.

One of Dror's main objectives in his book, Public Policymaking ReExamined (1968), is to contribute to the improvement of public policymaking. His procedure was to first analyze and evaluate the actual 
state of public policymaking. From this analysis he concluded that there are substantial gaps between what policymaking is in actuality and what it might be (pp. 120-25). Next he critically analyzed the main normative policymaking models (Chapter 12). Dror then designed his model (which he calls the "optimal model") by building on the strengths of other models and seeking to avoid their weaknesses.

Political Realities. An empiric study of policymaking/planning also underlies the political realities approach. Bolan $(1967,1969)$ and Rondinelli (1971, 1973) have both attempted to develop conceptual frameworks that reflect existent reality--hence, our labelling their approach "a political realities" one. In their frameworks both include what they consider the important variables that shape policy or the policy process, and both hypothesize relationships between the variables.

Although Bolan's (1971) conceptualization of planning as a process of social interaction has been referred to earlier, his approach to the study of planning/policymaking will be considered. Bolan's framework (1969) includes four sets of independent variables (process roles, decision field characteristics, planning and action strategies, and issue attributes) that are hypothesized as influencing the character and quality of decision outcomes. The model and hypotheses were tested by data gathered from four case studies (Bolan and Nuttal, 1975).

Rondinelli (1971) has proposed a framework that also includes four sets of independent variables: ecological and spatial, organizational and institutional, perceptual, and policy interaction process variables. These variables are identified as the important ones influencing the structure and process of policymaking. Rondinelli also has proposed 
several hypotheses concerning the interaction among these variables.

Although both identify different sets of variables--Bolan's focus is on decision outcomes, while Rondinelli's is on the structure and process of policymaking--a working assumption shared by both Bolan and Rondinelli is that a better understanding of the relationships that affect the policymaking/planning process will enable the planner to be more effective in dealing with urban problems. Both theorists explicitly state that their intent is to contribute to the improvement of policymaking/planning. Bolan's $(1967$, p. 233) desire is to "aid planners. - to come to grips with the complex and crucial process of managing urban change." Rondinelli (1971, p. 32) wants to further the understanding of the variables that shape policy decisions so that the planner may more effectively initiate, facilitate, and guide social change.

In identifying and working with dependent and independent variables Bolan and Rondinelli have taken an approach to planning/policymaking that is distinctively different from the traditional approach to urban planning.

Scientific Managenent. A third approach to improving decision making relies on "the powerful tools of technology." ${ }^{2}$ A special issue of the Journal of the American Institute of Planners (May, 1965) was devoted to exploring these tools and their relationship to planning. The editor of that issue, Britton Harris (1965, p. 90), ventured to write:

${ }^{2}$ While this section only mentions sytems analysis and its tools, methods of cost/benefit analysis and program budget systems are also included as techniques of "scientific management." 
Experience so far accumulated and amply displayed in this issue . . . tends to suggest that the problems of metropolitan growth and development are . . . problems which are best handled through extensive computations on high-speed computers.

Two years later Eldredge (1967, p. 616) observed:

There seems little question that the massive novelle vogue in planning is the use of hard data managed through computer information storage systems, or data banks, and put to work by various types of mathematical simulation models in computer language for predictive purposes and for aid in decision-making.

In the sixties computer technology appeared to many to be an important addition to the planner's repertoire of tools--a tool which could contribute to making planning more "scientific." Thus, models developed for the Pittsburgh and San Francisco Community Renewal Programs seemed to be promising aids--and perhaps, even "breakthroughs"--in urban decision making (Stegner, 1965; Loewenstein and Herrmann, 1967). But from the perspective of the seventies it is evident that these models have contributed little to coping with problems in either city (Brewer, 1973).

Brewer (1973), a systems scientist, describes and analyzes the sophisticated problem solving techniques used in the San Francisco and Pittsburgh Community Renewal Programs. He contends that the models were based on both inadequate theory and data, that there were no stated criteria by which to appraise the models, and that they were formulated by "outsiders" with little or no input from residents. Brewer" ${ }^{3}$ is highly critical of urban problem solving methods that rely heavily on tech-

3 Besides offering the reader valuable insights into the limitations of computer models, Brewer (1973) discusses four appraisal functions he considers necessary in problem solving. They are theoretical, technical, ethical, and pragmatic functions. The last chapter includes some specific recommendations for improving problem solving. 
nical professionals, concluding that--at least in these two cases--they provided little useful information for the decision makers.

Hoos (1973) also criticizes the reliance on technicians, decrying "the mystique of technique." In a short and focused critique of systems techniques Hoos describes what she considers the basic weaknesses of the systems approach" and contends that a "review of 10 years' literature and experience with systems analytic techniques in the public sector discloses iteration and reiteration of platitudes and promises, but little improvement in either the state-of-the-art of systems analysis or of government" (p. 158).

Yet despite its weaknesses and the failure of systems analysis to improve problem solving Hoos finds that "the trend in the journals and meetings of diverse professional societies is unmistakably toward 'scientific management of public affairs'" (p. 158). 5

\section{Collaborative Social Planning: Approach and Theory}

Rationale for Our Approach. The three approaches discussed above-policy sciences, political realities, and scientific management--are contemporary attempts to improve the policymaking/planning process. In

${ }^{4}$ Hoos (1973) discusses the basic weaknesses as: (1) the fiction of completeness, (2) the lack of rigor in the conception of such key concepts as models, (3) the myths surrounding objectives and objectivity, and (4) the fallibility of facts.

${ }^{5}$ One enthusiast is Robinson (1972, pp. 95-102) who endorses the use of mathematical techniques and the computer for explanation and prediction purposes as well as for the design of alternative plans. Although admitting that many of the models have not been operational, he believes that simulation modeling will make the planner more effective $(p, 100)$. Thus, in his recent reader in urban planning and decision making, Robinson's (1972) overriding concern is with improving planning methodology--largely relying on technological means. 
attempting to develop a model for the social planning process we might have pursued one of these recognized approaches. Yet we did not--choosing instead to link social planning to social problems. Therefore, it is necessary to consider why this approach has been taken.

Some criticism of computer models and systems analysis has already been offered. This was done because so many seem to rely heavily on technology as a means of improving planning. Technical expertise or scientific management has a role in problem solving, but improving techniques--in itself--will not resolve urban problems.

The political realities approach too has a place in the study of planning/policymaking, for it can help us understand factors that shape the process and the outcome. But if one is interested in attacking problems at their source, this approach is seen to be rooted in present political realities, and thus, is too oriented toward the status quo.

The policy sciences also approach policy empirically with the intention of improving policymaking. Dror (1968) explicitly admits that the approach is normative in nature. The policy sciences approach has positive features, and through it a greater understanding of the policy process has been gained. However, the policy sciences approach seems to offer little hope of improving the process so that substantive changes can occur.

Although these remarks do not comprise a thorough analysis of these approaches, they do indicate why still another approach was selected. Our rationale: if we want to resolve social problems, planning theory and practice must be geared toward them. Thus, to improve planning we should examine the nature of social problems and then build 
planning theory and a model from this analysis. We will now consider what has been gained from this approach.

Theoretical Contributions. While not setting forth a fully developed theory of planning or social planning, this dissertation has made three contributions in that direction.

First, as has been stated, the approach is unique in that the nature of social problems was explored and then related to planning. A reconceptualization of social planning--one in harmony with the nature of social problems--was formulated. Social planning has been defined as planning that treats both the structural causes of social problems and the values, beliefs, definitions, etc. that obstruct social change.

Second, not only was social planning related to the nature of social problems, but it was placed in a broader theoretical context. Conceptualizing the planning process as part of the social construction of reality provides a framework that can be used even if one rejects the notion of planning as a collaborative process. Few theoreticians have considered planning in the framework of broad theory--and more theorizing reeds to be done along these lines.

Third, although citizen participation is not the focus of this dissertation, the participation of citizens has been recognized as integral to the planning process. Our approach does provide a theoretical basis for the participation of citizens in the planning process.

From our consideration of the subjective dimension of social problems (Chapter 111 ), it was contended that planners need to attend to the process by which social problems emerge, are defined, and are handled. Social problems are more than objective conditions, and planners 
must recognize the role that citizens play in the process of collective definition and incorporate that process into the planning process. In other words, it is a reality that others play an important part in how problems are defined and dealt with. Thus, planners must bring others into the process of planning to resolve problems.

When planning was placed in the broader theoretical framework and was conceptualized as the construction of reality (Chapter IV), we held that each person's perception of reality differs. Because of this, each person brings a unique perspective to bear on social problems. If these persons are brought into interaction in the planning process, if their views of reality can be shared, if the personal knowledge of the citizen and the processed knowledge of the planner can be joined, if persons engage in the process of mutual learning, we have contended that social problems are more likely to be resolved.

It is recognized that presently there is no adequate theory underlying citizen participation ${ }^{6}$ (Spiegel and Mittenthal, 1968, p. 4). It is also contended that "there is a definite need for a working theory of participation that can both persuade public officials to utilize partic-

${ }^{6}$ Godschalk (1972) is a planner who has made recent contributions in this direction. Drawing upon exchange theory, he has formulated planning and participation as a process of exchange: of exchange between citizens, government officials, and planners. This exchange, as Godschalk conceptualizes it, has three forms: collaboration, competition, and conflict. Godschalk's preference and focus is a collaborative planning paradigm which he sees as one which opens the planning process, decentralizes planning authority, and maximizes citizen participation. Because Godschalk's theoretical framework is exchange theory, his focus is on what participants can gain from the process. Because planning in this dissertation has been placed in a different theoretical framework--that of the social construction of reality, our focus is on what participants can bring to the process.

Refer to Brooks' (1975) review of Godschalk's work and also Godschalk's (1976) rejoinder. 
ipatory approaches and inform them about the conditions and processes necessary to achieve authentic participation. Such a theory can be very helpful in winning public officials' commitment to participatory practices" (Godschalk, 1976, p. 206).

Although needing to be more fully developed, the perspective offered in this dissertation is a promising one for a theory of participation. With research into collective definitional processes, it is possible that it can be developed into a "working theory" as well.

Collaborative Social Planning: The Model Evaluated

We are now ready to consider why the collaborative model is proposed as one that is more responsive to urban problems than other planning models. Those models which seek to reflect reality can be empirically tested. For example, Bolan (1975) tested his conceptual model (first presented in 1969) with data gathered from four case studies. The findings led to a modification of the model (Bolan and Nuttal, 1975, Chapter 6). However, when one develops a model that does not claim to be a reflection of existent reality, it cannot be tested as Bolan's was. The collaborative model would best be tested if it were to be implemented. Since at this time this is not the case, the model can only be evaluated theoretically.

We will proceed with our assessment in terms of two criteria. First, since it has been maintained that a planning model must be in harmony with the nature of its subject matter, several planning models will be evaluated on the basis of whether they take into account the objective and subjective dimensions of social problems--making them the object of planning. And second, it has been asserted that to effec- 
tively deal with social problems, planning must be task-oriented, experimental, cybernetic, dialogic, and collaborative. Different planning models will be evaluated in terms of these characteristics.

Seven planning models have been selected for evaluation along with the collaborative model. Three of the models--the optimal, political realities, and systems--flow from the three approaches we have just considered. Three others--the rational, incremental, and advocacy models-are ones that urban planners are familiar with and are ones that have been mentioned earlier. A seventh model--Alfred Kahn's (1969)--is also considered since it is specifically a "social planning" model. These seven models are broadly representative of current planning models.

Table VI evaluates the seven models and the collaborative model on the basis of the first criterion.

TABLE VI

MODELS EVALUATED:

DIMENSIONS OF SOCIAL PROBLEMS

AS TARGETS OF PLANNING

\begin{tabular}{l|c|c|c}
\hline \multirow{2}{*}{ PLANNING MODELS } & \multicolumn{3}{|c}{ SOCIAL PROBLEMS } \\
\cline { 2 - 4 } & $\begin{array}{l}\text { Objective } \\
\text { Dimension }\end{array}$ & $\begin{array}{c}\text { Structural } \\
\text { Components }\end{array}$ & $\begin{array}{c}\text { Subjective } \\
\text { Dimension }\end{array}$ \\
\hline Rational & + & - & - \\
Incremental & + & - & - \\
Optimal (Dror) & + & - & - \\
Political Realities & + & - & - \\
Systems & + & + & +- \\
Advocacy & + & +- & +- \\
Kahn's S. P. Model & + & +- & + \\
Collaborative & + & + & + \\
\hline
\end{tabular}


All the models are concerned with objective conditions, therefore the table separately considers whether structural components are a focal concern of the model. Structural conditions enter into only some of the models. The advocacy model may sometimes focus on structural change, but most of ten services or amenities have been the prime concern of advocacy planning. By its nature systems models include structural components.

Kahn $(1969$, p. 144) takes a systems approach to the formulation of policy and expresses the need for planners to have the freedom to consider fundamental innovation as an alternative. However, when addressing the role of planning in institutional changes, Kahn states that the planner "is not likely to be in a position to effect them formally" (p. 168). He does agree that structural issues may be the focus of planning efforts ( $p$. 339), but because he takes "the situation, certain system boundaries, laws or policies" as "givens," Kahn's concern is with planning in the social "sectors" (p. 167), not systemic change. According to Kahn, the social planner ordinarily does not consider institutional change, and "there is little precedent for an approach to them" (p. 167).

Conceptualizing social problems in structural terms and dealing with them accordingly is the principal goal of collaborative social planning. Thus, social structure is a prime target of intervention. The first five models pay little attention to the subjective dimension of problems, al though, of course, someone's subjective definition must prevail. The advocacy model does consider subjective dimen- 
sions, yet its concern is limited to the client's definition ${ }^{7}$--rejecting other definitions. Kahn recognizes the importance of task definition and views it as the outcome of an integration of the "assessment of the relevant aspects of social reality and the preferences of the relevant community" (p. 61). Kahn devotes a chapter (1969, Chapter IV) of his book on social planning to values and preferences and the task that the planner has in assessing them. The importance of subjective dimensions is acknowledged by Kahn, but he considers them as "givens" to be assessed, not as the object of change. 8

Although Kahn's model is cognizant of the importance of the definitional process--and much more explicitly than most planning models, only the collaborative model takes the subjective dimension of social problems as the target of social planning.

The evaluation of the planning models on the basis of the second criterion is presented in Table VII. The models will be discussed in terms of each of five characteristics, that is, whether they are task-

7 It might be argued that it is actually the planner's perception of the client's definition that prevails. Although Gilbert and Eaton (1970) do not deal directly with advocacy planning, they do confront the issue of "who speaks for the poor?" They point out that a survey of poverty neighborhoods in Pittsburgh revealed a discrepancy between professional assessments of neighborhood conditions and those of the residents. A further discrepancy was found between activists in the neighborhood and the majority of residents.

The collaborative social planning model would make this discrepancy the basis for dialog and mutual learning.

8 In the two sentences that conclude his chapter dealing with values and preferences Kahn states: "Plans need not be seen as always bound by values; they may also be inspired by them. The planner is, by his very assignment, both technician and agent of change" (p. 129). Although we agree with this claim, Kahn does not develop the planner's role as "agent of change." 


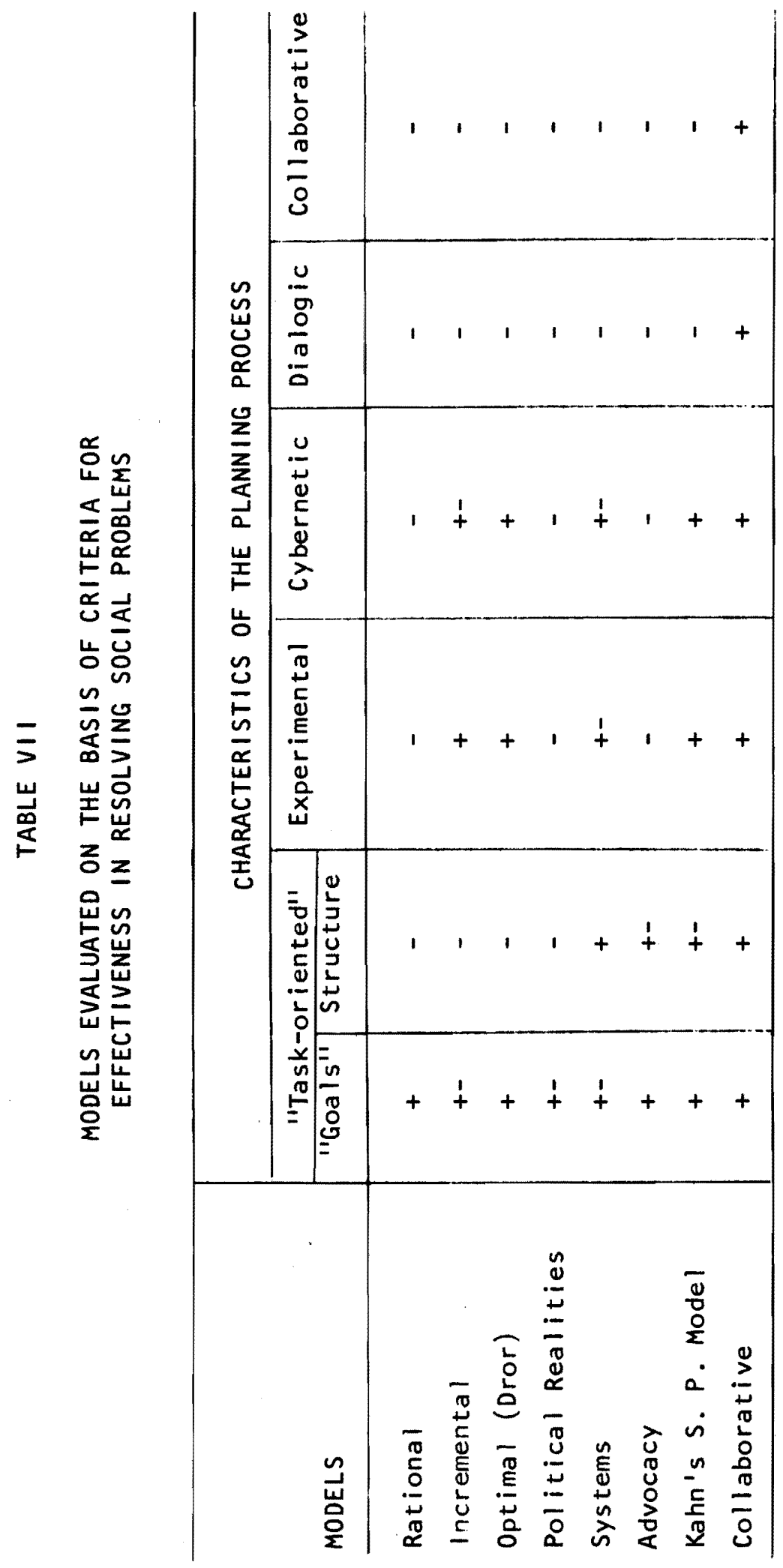


oriented, experimental, cybernetic, dialogic, and collaborative. These characteristics must be understood as they were described in Chapter V.

(1) "Task-oriented." Although the concept, task-oriented, was described in terms of dealing with problems in structural terms, the table evaluates the models in terms of both goal-orientation and whether that goal is structural change. The rational, optimal, advocacy, and collaborative models are goal-oriented--no doubt, because they are normative models. The incremental and political realities models, because they reflect the pluralistic political system, are often diverted from the goal of problem solving. The goal of most of these models ordinarily is not a structural one. Although systems models include structural components, they are given a mixed rating when evaluated for goal-orientation. Because of limitations of data or of the model itself, the problem may become redefined so that the model can handle it. Consequently, rather than coming to grips with the original or meaningful goals, the model may pursue another (Brewer, 1973).

Kahn grasps the significance of the planning phase that deals with the formulation or definition of the planning task, and he emphasizes the consequences of definition and redefinition on the emerging plan. His treatment of the planner's role in the definition of the planning task is probably the most comprehensive available. Kahn rates high in our evaluation of planning theorists who view planning as goal-oriented. Yet because our concern is with planning that is directed toward resolving social problems, we have specified that a "task-orientation" requires dealing with structural aspects of problems. Kahn's model of social planning is not task-oriented in this sense. 
of all these models, only the collaborative model has this concept of the planning task.

(2) "Experimental." The rational, political realities, and advocacy models do not consider plans as tentative or flexible. The other models do to some extent. Some systems models--"open" ones--theoretically do allow for flexibility. The incremental model's basic orientation to policy making is that it is typically a process of successive steps, with the assumption that there is always the possibility of doing better the next time (Lindblom, 1968, Pp. 24-25).

Kahn does not discuss complexity, uncertainty, a turbulent environment--nor does he stress the importance of the "experimental" nature of "plans." However, in his brief treatment of evaluation, Kahn recognizes that sometimes there is a need for a period of trial and error and for systematic research and study of implemented programs (1969, p. 326). Thus, the incremental, optimal, and Kahn's model to some extent conceptualize planning as "experimental."

(3) "Cybernetic." Although the incremental model claims that feedback is essential (Lindblom, 1968, pp. 24-25), the requirement of political feasibility limits its use. Systems models require information systems that can lead to adjustment, yet when given a role in problem solving, as they were in the San Francisco and Pittsburgh renewal programs, no efforts were made to utilize feedback information (Brewer, 1973). The political realities and advocacy models do not consider feedback as essential. Some rational models do include feedback as part of the process, but in reality, its use is minimal. Feedback is central to Kahn's model: it is built in to each phase of planning, and accord- 
ing to Kahn, can make planning "efficient, responsive, and effective" p. 327). Dror has similar views and his optimal model also conceives the policy/planning process as a cybernetic process.

(4) Dialogic and (5) Collaborative. All seven models have negative ratings on these two characteristics. Consequently, it is on the basis of these two characteristics that the collaborative model differs markedly from these other models. In general, this evaluation reflects the place each model gives to the participation of citizens. The rational, optimal, and systems models rely primarily on "experts," not citizens for input. Attention is paid principally to the objective dimension of problems. The incremental and political realities models, because they place planning in a political context, do recognize that citizens have a role, but they are not concerned with bringing all. those affected by problems into the process.

Advocacy does value citizen participation and seeks to insure that the interests of the less powerful are represented. Yet the advocacy model enters into the competitive nature of the political process, and does not seek to foster collaboration and dialog.

While some planners stress "rationality" and their own technical expertise--and consequently attempt to minimize citizen involvement, Kahn shows that "values are ever present and permeate each phase of empirical analysis and all aspects of a planning discussion" (p. 114). In Kahn's model the assessment of values and preferences is an essential part of the planner's task.

Kahn also sees the planner as technician providing maximum information--facts and projections--to others, and assisting them to make 
choices. He also states that "layman and technician must collaborate" (p. 120). Although Kahn's notion of collaboration is similar in some ways to what we have proposed, there is a basic difference. We have underpinned the notion of collaboration with concepts from the sociology of knowledge--holding that both citizen and planner have contributions to bring to the planning process. In this view the planner has more to do than "appraising reality" and assessing values and preferences: he has a role to play in facilitating an exchange between participants so that mutual learning can occur.

Kahn also calls for a diversity of planning efforts which he holds would increase the possibility of making more intelligent choices ( $p p$. 124-26). He would encourage and build interest group participation into the planning process. Accordingly, planners should become advocates "of the interest of government... or of various groups with which they might work" (p. 124). Clearly this approach espoused by Kahn is not in harmony with what we have called "dialog" and "collaboration."

Thus, while Kahn is to be commended for his excellent treatment of values and preferences, for stressing that the role of the planner is more than that of technician, and for developing components of "a total approach" to dealing with values and preferences (pp. 118-26), in his model the planning process is not "dialogic" or "collaborative" in the same sense as the collaborative model.

Since none of these seven models attempts to promote collaboration and dialog in the planning process, it is our contention that their effectiveness in confronting social problems is limited.

In summary, the collaborative model is the only model that meets 
the two criteria. It alone takes both subjective and objective dimensions of problems into account--dealing with them as objects of planning, and it alone is characterized by all five features assumed to be necessary for dealing effectively with social problems.

Beyond meeting the two criteria above, two other features are central to the model. One is that it has a role for citizens, planners, and decision makers. And second, the role of the planner involves both technical and interactional tasks. These two factors are considered essential in dealing with social problems and are definite strengths of the model.

For these reasons the collaborative model is proposed as one that would be more effective in confronting the problems of our cities than these other models. And our approach--building a planning model that is responsive to the nature of social problems--is offered as one that can contribute to the improvement of planning/policymaking.

Normative Theories and Models

Because the collaborative model is normative in nature, a more basic question should be addressed: Do normative models have a place in planning theory? To answer this we will consider the views of three theorists--each of whom represents diverse approaches to planning.

In discussing whether anything can be gained from constructing normative models of planning, Banfield $(1959$, p. 368$)$ defended his rational model by stating:

If the interest is normative--if it is in describing how organizations would have to act in order to be in some sense more effective or efficient--it is hard to see how reference to such a model can be avoided, or, indeed, why its lack of realism should be considered a defect. 
Dror (1968, p. 130), in defending normative models, has distinguished between the purpose of non-normative models and that of normative models:

A non-normative behavioral model is good enough for analyzing policymaking, but to make improvements in policymaking, one needs a model which is suitable not only for scientific analysis of actual behavior, but also for evaluating that behavior, and for deriving suggestions for improving that behavior.

According to a third theorist, Faludi (1973, p. 5), the most pressing problem for planning theory is "to provide a basis for improvements to planning procedures and planning agencies, or what has been called meta-planning." He goes on to state:

Clearly for a long time to come such meta-planning will have to rely on a theory of planning devoid of adequate empirical backing. Besides, assuming even all the requisite research effort being spent, the significance of a positive theory may simply be that of elucidating what the obstacles in the way of achieving alternative ideals are, not which ideal to choose. . - The world-as-it-is does simply not provide a final clue to how we should wish to see it! (pp. 5-6).

This brief consideration of the views of three theorists supports the contention that meta-planning or normative theory has not only a legitimate place, but an essential one in planning theory. If we are interested in solving social problems, we must focus on how to improve planning--and that means constructing normative models. And that may also mean a "lack of realism" (Banfield, 1959, p. 368), or may require relying "on a theory of planning devoid of adequate empirical backing" (Faludi, 1973, p. 5).

\section{CHALLENGES FACING COLLABORATIVE PLANNING}

In assessing the theory and model of collaborative social planning only the strengths have been examined. There is no intention to either 
deny the weaknesses or ignore the obstacles that stand in the way of implementing collaborative planning. However, instead of discussing either limitations of the model or obstacles, we shall consider some areas where change is needed ${ }^{9}$--that is, if planning is to be collaborative, if social problems are to be resolved. These changes will include ones dealing with individuals, with planning structure, and changes in the planner's knowledge and skills.

Individual Changes

The collaborative model is premised on the willingness and ability of persons to enter into dialog with each other. Is it realistic to expect those with conflicting interests to join together to define social problems and agree to collective action to deal with them? Will people give the time and energy that is demanded? Are persons from diverse backgrounds--from different socio-economic classes or racial groups--able to participate in dialog even if they are willing to devote their efforts to collaborative planning?

Two planning theorists, Friedmann (1973) and Michael (1973), have written in detail about changes that are necessary for persons to engage in a process of mutual learning. Their ideas will be briefly summarized.

Friedmann (1973) admits that the transformation of society requires the transformation of man. In his book, Retracking America

9 Dror (1968, pp. 217-18) lists sixteen areas in which he believes policymaking must be improved. He also devotes six chapters (16-21) to changes he considers necessary. As Dror sees it changes are needed in knowledge, in personnel, in structure and process patterns, in input and stipulated output, and in the environment. Dror deals with these changes in a normative fashion, but they are grounded in an analys is of current policymaking and are informed by his explicitly stated assumptions. His book is well worth study. 
(1973, Chapter 9), he discusses the issue of "re-educating man." Friedmann finds that both cognitive and interpersonal skills need development. He states that a "heightened capacity for effective learning" is necessary. This requires the strengthening of four abilities: (1) the ability to question existing reality, (2) the ability to draw general lessons from concrete experience, (3) the ability to test these lessons in practice, and (4) the ability to sincerely examine the results (pp. 232-37). While Friedmann recognizes our deficiencies with regard to interpersonal skills, he contends that we can increase our capacity for dialog.

Although these cognitive and interpersonal skills can be developed in small working groups of adults, Friedmann believes that the most effective learning occurs in childhood, and, therefore, our formal educational system must aim to develop these skills in students.

Michael devotes his entire book, On Learning to Plan--and Planning to Learn (1973), to the social psychological resistances of individuals and groups in organizations to what he terms "long-range social planning" or "future-responsive societal learning." Six chapters (pp. 10198) examine the personal and interpersonal "burdens of changing." His discussion, which covers nearly one hundred pages, can be summarized by the following list of requirements that Michael finds necessary for individuals.

1. Live with and acknowledge great uncertainty.

2. Embrace error.

3. Seek and accept the ethical responsibility and the conflictladen interpersonal circumstances that attend goal-setting.

4. Evaluate the present in the light of anticipated futures, and commit themselves to actions in the present intended to meet such long-range anticipations. 
5. Live with role stress and forego the satisfactions of stable on-the-job, social group relationships.

6. Be open to changes in commitments and direction (p. 281).

In summary, collaborative planning requires that individuals develop certain cognitive and interpersonal skills. It also has social psychological demands as well. These have only been highlighted--for a fuller discussion Friedmann (1973) and Michael (1973) can be referred to. Both writers also discuss the possibility of these changes occurring. Whether these changes will occur is purely speculative; however, we admit that these changes are necessary if social problems are to be resolved.

\section{Structural Changes}

The collaborative model calls for the participation of citizens in the planning process. Of immediate concern is who will participate: all who may be interested, or selected representatives? If representatives, how will they be selected? Another structural issue: how to bring persons from urban planning departments and operating agencies together so that their expertise can be brought to bear on the city's problems. 10

${ }^{10}$ Needleman and Needleman (1975, Chapter 9) discuss four assumptions held by community planners that conflict with persons in operating agencies. These contradictions involve "(1) multiple versus singlepurpose objectives, (2) service versus unit-cost concern, (3) bureaucratic enfranchisement versus product delivery as the measure of success, and (4) 'outside' versus 'inside' reference groups" (p. 252). In their concern for the total quality of life in a specific community most community planners assume an expanded role that leads them into conflict with operating agencies ( $p .323$ ). Needleman and Needleman offer some penetrating insights into the resistance of operating agencies, the response of community planners, and the response of the planning department. Conflicts such as these must be resolved to ensure a collaborative approach to social problems. 
Friedmann (1973) addresses the question of institutional arrangements in a general way. He envisions task-oriented working groups that would be temporary, small, interpersonal, self-guiding, and responsible. (See pp. 196-97.) Groups would be joined to others through clusters of networks. At another level members of the groups would participate in assembly meetings. Then each assembly would delegate some members to meet in still higher level assemblies. Technical secretariats would provide information to the groups, and technical experts would participate in the activities of both groups and assemblies.

Although Michael (1973, pp. 199-280) is concerned primarily with organizations, he too deals with the structural changes that he believes are necessary. However, he does not formulate concrete proposals. He does maintain that different management styles are needed: ones that "forego conventional hierarchical means of control in favor of more self-regulating, self-organizing processes" (p. 201).

A "Program Planning Model" developed by Delbecq and Van de Ven (1971) may be instructive along these lines, for it has been used successfully in business, industry, government, and education. When used by a government agency, first-line staff, external resource persons, internal specialists, key administrators, resource controllers, and organizational staff are all involved in the planning process. The interfacing of these diverse persons in a joint effort is essential to the model. All are involved in the final approval and evaluation of the program; otherwise each group participates in only certain phases of planning. However, monitoring and evaluation of the implemented program are not part of the model. 
Although this model deals with planning for a specific group or organization, and does not deal with an entity as complex as a community or a city, it does prove two points. First, diverse groups of people can be brought together to plan in a cooperative process. Second, it is possible to encourage innovation and creativity in problem solving. Methods and experiences such as these can be utilized in the creation of a new structure for social planning as well as for useful insights into process .

Working out specific structural arrangements is beyond the scope of this dissertation, ${ }^{11}$ as well as beyond the writer's expertise. Delbecq arid Van de Ven (1971) drew upon contemporary small group theory for their model as well as on community planning studies. Organization development and the sociology of organizations are other areas that can contribute to this task. If social planning is to be successful in bringing diverse persons and groups together to collaborate in solving social problems--a task that requires both individual and social change, then persons from many fields must bring their expertise and commitment to the task. Urban planning--or any other single field by itself--is not adequate to the need.

We must learn to solve our problems, but to do so we must learn

11 In a review of Godschalk's book (1972) Brooks (1975, p. 360) criticizes him for failing to "tell us how to make citizen participation work," for failing "to provide us with useful guidelines for moving from 'here' to 'there.'"' In his response to Brooks, Godschalk (1975) argues that planners are not really committed to citizen participation, and that therefore, a theory of citizen participation needs to be developed to persuade them of its legitimacy. The next task, according to Godschalk, is to back theory wi th "working methods." My position is similar to Godschalk's. 
"to create the systems for doing so and to discard the structure and mechanisms grown up around old problems. The need is not merely to cope with a particular set of new problems, or to discard the organizational vestiges of a particular form of governmental activity which happen at present to be particularly cumbersome. It is to design and bring into being the institutional processes through which new problems can continually be confronted and old structures continually discarded" (Schon, 1971, p. 116, emphasis added).

The need for new institutions should be evident. The challenge is to build them.

Planning Knowledge and Skills

The collaborative model has cast the planner in the role of technical expert, bringing "processed knowledge" to the task of structural change, and in a role that requires a high degree of skill in interpersonal relations. We will briefly consider how the collaborative model challenges--and actually depends upon--the development of knowledge and new skills, and especially those that are concerned with managing conflict and encouraging innovation.

Knowledge. The collaborative model is not only responsive to the concerns that have been voiced by "humanistic" or "radical" planners, 12 but because it is concerned with objective conditions that are defined as social problems, it contains elements from the rational model as

12 Grabow and Heskin (1973) propose a "radical" definition of planning. It is based on "system change and the realization of a decentralized communal society which facilitates human development by fostering an appreciation of an ecological ethic based on the evolutionary process: spontaneity and experimentation" (p. 109). 
well. We are interested in formulating alternatives, projecting consequences, evaluating alternatives, and selecting a plan that promises to be effective. Although our knowledge and the environment--its complexity and uncertainty--limit rationality, planning for structural change requires that planners strive to improve the rational components ${ }^{13}$ of planning (Dror, 1968, p. 222; Bolan and Nuttal, 1975, p. 3).

of prime importance is to construct information systems for collecting and processing information and encouraging the use of feedback. Techniques for measurement and evaluation, such as social indicators, meaningful criteria, and cost/benefit analysis, also need to receive priority attention. Also required are improved ways to handle goal formulation and ways of linking goals. Adequate theory--particularly that dealing with structural change--needs to be built.

Much more discussion could be given to areas where planning knowledge needs development, but ive will assume that planners themselves are familiar with most of these areas and that literature dealing with this subject is readily available to them. 14

Interpersonal Relations. A point that has been repeatedly emphasized is that planners need to attend not only to the objective aspects

${ }^{13}$ Dror (1968, pp. 149-53) also contends that extrarational processes are important in policymaking, and that pure rationality is impossible to achieve. He argues that to improve policymaking we need to know how to strengthen extrarational components (p. 222). These elements are included in his optimal model. His argument is convincing.

${ }^{14}$ For example, Dror (1968) devotes Chapter 17 of his book to a discussion of the changes needed to improve policy knowledge. Robinson's book (1973) also provides the reader up-to-date articles dealing with concrete efforts to improve planning methodology. 
of social problems and their resolution, but also to the subjective dimensions. Fundamental to the collaborative model is the joining of the processed knowledge of the planner to the personal knowledge of the citizen. The discussion of the planner's role in Chapter $V$ stressed the importance of interactional tasks--particularly important is what has been designated as "promoting mutual learning through dialog." This role definitely calls for skills that have been lacking in the education of planners. Planners will require a great deal of training to be able to activate the process of collaborative planning.

Several planners have discussed the need for new skills and the implications these have for educational programs. Table VIII sets forth some of the interpersonal skills and knowledge that Friedmann (1969) and Rondinelli (1973) maintain are necessary for planners.

TABLE VIII

INTERPERSONAL SKILLS AND KNOWLEDGE NEEDED BY PLANNERS

Friedmann (1969, p. 317)

Sharpened knowledge of self Consciousness of roles that need to be played Insight into his biases, strengths, and weaknesses Understanding of how he appears to others Increased capacity for learning

Ability to empathize

Ability to live with conflict Knowledge of the dynamics of power

Knowledge of the art of persuasion

Professionally responsible
Rondinelli (1973, p. 20)

Persuasion and manipulation

Communication skills

Client analysis

Mediation and negotiation skills

Resource mobilization ability

Advocacy and organizing ability

Interpersonal relations

Small group decisionmaking

Organization behavior

Intragroup dynamics

Social psychology

Coalition management

Entrepreneurial experience

Techniques of conflict resolution

Sociopolitical exchange processes 
These two lists are indicative of what new concepts of planning demand of the planner. ${ }^{15}$ Although we hesitate to cite any of the skills as more important than others, it seems that two areas especially need attention: techniques of conflict resolution and skill in fostering social change or innovation.

Management of Conflict. It may appear that the collaborative model naively denies conflict. That is not the case: conflict--and even deep cleavages--are recognized as existing in our cities; however, the collaborative model still requires that conflict be managed, ${ }^{16}$ and assumes that in most cases it can be. Is this a realistic assumption?

Deutsch (1969, pp. 23-24), a student of conflict, claims that it

is. He states:

In a cooperative context, a conflict can be viewed as a common problem in which the conflicting parties have the joint interest of reaching a mutually satisfactory solution... There is nothing inherent in most conflicts which makes it impossible for the resolution of conflict to take place in a cooperative con-

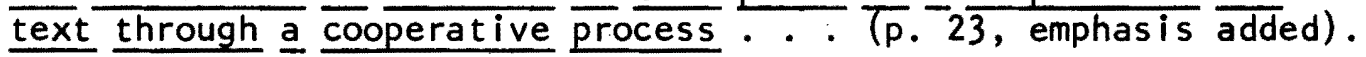

Because urban planners deal with groups whose interests frequently conflict, they must learn how to foster a cooperative context to

${ }^{15}$ In a study of community planners Needleman and Needleman (1975) stress the importance of interpersonal skills that are necessary for planning with community residents. According to the authors, it is especially crucial for the planners to be able to establish rapport and gain the trust of the community. Conflict, hostility, and minimal successes demand that planners have a high tolerance for frustration. See especially Chapter 9, "The Deeper Disillustionment."

${ }^{16}$ By "management" of conflict we do not mean the suppression or denial of conflict whereby less powerful persons and groups are "controlled." For a clarification, see footnote 18 which deals with integration as the goal of conflict resolution. 
deal with conflict. 17 This requires that planners draw upon knowledge and experiences of other disciplines.

An example of a model that may be beneficial to planners is one developed by Wedge (1971). It is a process model for intercession in intergroup conflict. Five steps are identified by Wedge: "(1) the intercessor establishes dialogue with each involved party; (2) particular interests of the parties are defined and complementary or mutual interests are identified; (3) members of the conflicting groups are brought together on neutral ground in the presence of neutral buffers; (4) limited cooperation toward achieving 'partial superordinate goals' for self-interested purposes is encouraged; and (5) the intercession is terminated as soon as communication concerning concrete and limited cooperative goals is established" (p. 733).

From his experiences in the Dominican Republic Wedge concludes that it is possible to institutionalize linkages between hostile groups. With new institutional arrangements that will bring groups together and encourage their collaboration, with planners who have heightened interpersonal skills, and with a commitment on the part of leadership to resolving the problems of our cities, there is reason to believe that conflict resolution or cooperative problem solving is possible (Deutsch,

17 Deutsch $(1969, p .24)$ discusses why a cooperative process is likely to lead to productive conflict resolution. (1) "It aids open and honest communication of relevant information between the participants. - . (2) It encourages the recognition of the legitimacy of each other's interests and of the necessity of searching for a solution which is responsive to the needs of each side. . . . (3) It leads to a trusting, friendly attitude which increases sensitivity to similarities and common interests, while minimizing the salience of differences. . ." (numerals added). 
1969; Stagner, 1971; Wedge, 1971; Derr, 1972; Follett, 1940)..$^{18}$

Encouragement of Innovation. Collaboration in itself will not insure that efforts to deal with social problems will be successful. Resolution of social problems requires social change. Therefore, it is essential that planners also learn how to encourage creativity, flexibility, and innovation. A literature dealing with social change (Zaltman et al., 1972; Cartwright, 1951; Bennis et al., 1969; Kelman, 1961) and innovation (Zaltman et al., 1973) is available for planners to draw upon.

Taylor (1970) reports a process through which social innovation in a vocational rehabilitation project was successfully introduced. An interdisciplinary team was also involved in the process. The model for innovation called for a high degree of staff involvement, creativity and innovation were encouraged, and the staff enjoyed a great degree of fexibility. From projects such as this, we can learn how to adapt similar methods to the social planning process, and thus encourage innovative approaches to problem resolution.

In encouraging innovation and social change, in facilitating collaborative efforts, the planner must be aware of tendencies he--and others--may have to manipulate either the process or the participants.

18

Mary Parker Follett (1940, pp. 30-49) has written on constructive conflict. She discusses domination, compromise, and integration as methods of dealing with conflict. The bases of integration are bringing the differences into the open, and then taking the demands of both sides and breaking them up into their constituent parts. This means getting beyond the symbols that might hide the true basis of the conflict. The aim is to integrate the two desires, to find a solution in which both sides can find something. Interestingly one of the obstacles to integration that Follett identifies is that "it requires a high order of intelligence, keen perception and discrimination, more than all, a brilliant inventiveness" ( $p .45)$. 
In discussing this Kelman (1972) acknowledges a dilemma. "The two horns of the dilemma, then, are represented by the view that any manipulation of human behavior inherently violates a fundamental value, but that there exists no formula for so structuring an effective change situation that such manipulation is totally absent" (p. 575).

In moving into a new role the planner's professional ethics must include respect for the other and for his freedom. He must learn how to minimize the manipulative aspects of planning situations.

The Possibility of Collaborative Social Planning

In describing integration as a way to handle conflict follett (1940, p. 32) wrote: "I am talking enither of what is, to any great extent, nor of what ought to be merely, but of what perhaps may be. This we can discover only by experiment."

This statement describes well what has been stated in regard to collaborative social planning. We have reviewed some of the challenges that confront collaborative planning: the changes that are needed in individuals, the need for creating new institutional arrangements, and the requirement of improved knowledge and new skills for the planner. The challenges are indeed formidable, but possible. To paraphrase Follett, collaborative planning "perhaps may be." This we can discover only by experiment. 


\section{II. TOWARD A NEW PLANNING PARADIGM}

The theory and model of social planning that has been set forth in this dissertation differs radically from present planning practice and its underlying theory. What has been presented is a new planning paradigm. This last section will discuss the notion of paradigm and examine how it is applicable to planning. 19

The Notion of Paradigm

While we do not maintain that planning is a science, a book on the development of science, The Structure of Scientific Revolutions (Kuhn, 1970), does present some concepts that will be discussed and then applied to planning.

Kuhn maintains that a science is governed by a specific paradigm (p. 175). That paradigm determines the criteria for the choice of problems which are assumed to have solutions ( $p$. 37). Problems are rejected that cannot be stated in terms of accepted conceptual and methodological tools ( $p .37)$. Rules also designate how the problem is to be solved as well as limit the nature of an acceptable solution (p. 38).

${ }^{19}$ 0strom (1973) advances and supports the thesis that the field of public administration is undergoing a crisis due to the insufficiency of its traditional paradigm. Sociologists too have dealt with the issue of whether Kuhn's notion of paradigm is applicable to that field. Lebowitz (n.d.) maintains that sociology is preparadigmatic, while Ritzer (1975) contends that sociology is a multiple paradigm science. Grabow and Heskin (1973) have contrasted a new paradigm, "radical planning," with the "rational-comprehensive model of modern planning," but do not deal with the notion of paradigm itself. 
Kuhn uses the term paradigm in two ways: ${ }^{20}$ (1) as standing for "the entire constellation of beliefs, values, techniques, and so on shared by the members of a given community;" and (2) denoting "the concrete puzzle-solutions which, employed as models or examples, can replace explicit rules as a basis for the solution of the remaining puzzles of normal science" (p. 175).

In a period of normal science scientists accept the dominant paradigm and their endeavors are mainly puzzlesolving (Chapter 4). There exists a "strong network of commitments--conceptual, theoretical, institutional, and methodological" (p. 42). In time anomalies arise. These are findings that were not expected or cannot be explained (Chapter 6). Crisis occurs when the rules of the dominant paradigm continue to fail, and the awareness of anomalies deepens and spreads (Chapter 7). The paradigm is called into question and its rules become blurred (p. 83). Competing articulations proliferate (Chapter 8), and eventually a revolution occurs. The older paradigm is replaced, in whole or in part, by a new paradigm (Chapter 9).

The Paradigm Problem in Planning

As stated above Kuhn formulated his model as an explanation for the development of the physical sciences. His notion of scientific activity as puzzle-solving and as research-oriented does not apply in a

${ }^{20}$ Kuhn (197C, p. 181) notes that one of his critics found that the term paradigm was used twenty-two different ways in his original text. Due to this and other criticisms, Kuhn added a postscript in the second edition (pp. 174-210)--commenting on some of the criticisms and offering some revisions. It is in this postscript that Kuhn clarifies the two different senses in which he uses the term paradigm--and which we have cited. 
strict sense to planning. However, when paradigm is used as standing for "the entire constellation of beliefs, values, techniques, and so on shared by the members of a given community" (p. 175), then the notion of paradigm is applicable to planning, and perhaps, fruitfully so.

Kuhn's model also appears applicable: (1) reigning paradigm,

emergence of anomalies, (3) crisis--awareness of anomalies spreads, (4) response to crisis (with competing paradigns articulated), (5) revolution--the overthrow of the old paradigm and the establishment of a new paradigm.

We will use Kuhn's model and examine the nature of the crisis in planning and responses to that crisis.

Crisis. Within the last twenty-five years the urban planning profession has faced challenges on many fronts: the nature of the planning problem has expanded from land use to include social phenomena; the planner's role--from value-free expert to one involved in the political process; technical skills alone do not suffice; comprehensive, longrange planning is questioned as an ideal; master plans are no longer in vogue; citizen participation, although required, threatens planning; and so on.

When we survey planning endeavors, we see: many urban renewal projects have failed to "renew" the city, and have been criticized for actually creating more serious problems than they may have solved; social programs of the sixties, public housing projects, Model Cities, etc., are criticized for "poor" planning or for a lack of planning; crime is increasing, housing deteriorating, problems worsening, residents flee the city. Many perceive the city as being in crisis. 
We have charged that current city planning theory and planning techniques are incapable of confronting the problems of cities. To provide further support for this contention, the views of Jane Jacobs (1961, Chapter 22) will be summarized. This will also afford another person's insight into the crisis in planning and in the city.

Jacobs identifies three kinds of problems: (1) problems of simplicity, (2) problems of disorganized complexity, and (3) problems of organized complexity (p. 249). Planning, she maintains, can deal with problems of simplicity which are two-variable problems. Planning methods and tools, such as probability theory and statistical analysis, can also deal with the second type of problem, those of disorganized complexity. But Jacobs argues that the problems of the cities are largely of the third type. They are problems of organized complexity--with multiple and interrelated variables, yet according to Jacobs, planners have persistently applied "the two-variable system of thinking and analyzing to big cities" (pp. 435-36). Statistical and probability techniques have been added by planners to deal with these problems, but these methods are inadequate since the city's problems are largely of the third type (pp. 437-38).

We could continue to discuss difficulties, but these comments should indicate why it is maintained that a sense of crisis exists in planning. The point is that the traditional planning paradigm has given rise to anomalies, that is, problems exist that it cannot address. Its concepts, methodology, and the structure of urban planning departments do not enable planners to handle the city's problems. The awareness of this is spreading, and thus, the crisis. 
Responses to Crisis. Some of the responses to anomalies have led to attempts to adjust the paradigm so that the anomaly would disappear. Examples of this kind of response would be expanding the scope of urban planning to include planning for social phenomena, admitting that planners are part of the political process, adding computer simulation to planning tools, and striving in various ways to improve the rationality of the process.

The Cleveland Policy Planning Report (Krumholz et al., 1975) cited in the previous chapter relates the efforts of one city's planners to make planning more responsive to the major problems of cities. They-and those who espouse advocacy planning--believe that the planning process has tended to exclude the socially and economically disadvantaged. They find that the dominant planning paradigm--the scope of its problems, its tools, goals, biases, the role it assigns planners, etc.--is inadequate. The Cleveland Policy Planning Report can be viewed as the response one group of planners has made to the inadequacies of the traditional planning paradigm.

A recent study of Needleman and Needleman (1975) offers us information and analysis of how planners within urban planning departments in major United States cities are currently responding to the needs of cities. $^{21}$ The authors interviewed 155 planners (out of 173) and all the directors of the urban planning departments in Boston, Philadelphia,

${ }^{21}$ The study of community planning by Needleman and Needleman (1975) offers insight into how community planning fits within the planning department, what happens to the structure and goals of the programs over time, accomplishments, how community planners deal with citizens, the relations between community planners and operating agencies, and the psychological responses of community planners to their work. 
Detroit, Providence, Cincinatti, Cleveland, Buffalo, Baltimore, and St. Louis. Six cities had established community planning programs which directly assigned planners to work with residents of specific areas of the city. The authors found that in practice community planners have become advocates for area residents.

We will use this study to illustrate the cleavage that exists among contemporary planners and to advance the thesis that a crisis exists today in the planning profession because "new" planners find the "old" paradigm inadequate for the problems of contemporary urban society. Table IX represents the divergent views of "old" and "new" planners.

TABLE IX

COMPARISON BETWEEN THE "OLD" AND "NEW" PLANNERS

"OLD"

IDEAL:

LEGITIMATE

SCOPE:

CITIZEN

PARTICIPATION:

ROLE OF

PLANNER:

ACCOUNTA-

BILITY:
Centralized

Comprehensive

Long-range

In the public interest

Physical or land use issues

Restricted

Public relations

Value-free technician Not involved in implementation

Rationality valued

To political officials and influential businessmen

I solated from citizens
Decentralized

Area-wide

Tends to be short-term

Interests of the area

Social problems are included. Focus is on quality of life in the community.

Involvement required for implement ation

Committed advocate Involved in implementation Interpersonal relations key Political activist

To citizens, and specifically, to residents of the area 
Planners are seen to differ in five areas: (1) planning ideal, (2) the legitimate scope of planning, (3) attitudes toward citizen participation, (4) the role of the planner, and (5) the accountability of the planner. The table needs no explanation.

Needleman and Needleman's study of planning in six major cities shows how the "new" is challenging the "old," lending support to the view that a revolution is underway in the planning profession.

\section{A Revolution in Planning: An Emerging Paradigm}

Community planning has come into existence to meet the needs of city residents. It has been sponsored by urban planning departments, yet because it challenges the dominant paradigm (and has also come in conflict with other agencies and departments), it has encountered stiff resistance. Efforts to either suppress or cutback on the programs will face strong pressures from community groups (Needleman and Needleman, 1975, p. 339). Thus, the Needleman's predict that some form of community planning will continue to exist until some type of major change in planning occurs.

A Competing Paradigm. Not only is a revolution occurring in planning practice, but one is underway in planning theory as well. The works of various theorists are converging on the articulation of a new planning paradigm--that is, planning as learning.

An economist, Dunn (1971), has conceptualized planning as "social learning." Social learning, according to Dunn, is "a process of evolu- 
tionary experimentation ${ }^{22}$ that constitutes the individual and group selfanalysis and self-transformation" (p. 245). Dunn's model also requires the design of new systems that promote dialog.

Schon (1971) argues the need for us to become adept at learning. He sets forth a model of social change by which we reflect on the experience of the here-and-now, build theory from this experience, and then project it to the next situation. It must be tested by the experience of the next situation, and thus, the process goes on. Our task is to "invent and develop institutions which are 'learning systems,' that is to say, systems capable of bringing about their own continuing transformation" (p.30).

Friedmann's (1973) concept of transactive planning, or planning as mutual learning, has been discussed previously. Michael (1973) too conceives of planning as learning, and contends that we need to "learn to plan," as well as "plan to learn."

22 Although Dunn (1971) uses the term "evolutionary experiment," he does not mean experiment in the strict or classical sense, but in the sense of a test that is systematically conceived and evaluated. He views the social experimenter as one who formulates and tests developmental hypotheses. By "developmental hypothesis" Dunn means "a presupposition that, if the organization and behavior of the social system were to be modified in a certain way, the goals of the system would be more adequately realized" ( $p .241)$. He maintains that it is not possible to test the developmental hypothesis under controlled conditions, for in the real world each situation is unique; rather the developmental hypothesis is "tested" by the extent to which goals are realized as a result of the "experimental" plan. Problem solving, that is, "hypothesis formulation and testing," as conceived by Dunn, "is an iterative sequential series of adaptations of an adaptable, goal-seeking, selfactivating system" (p. 241).

In Dunn's view, evolutionary experimentation is essential to social learning--and in this process social analysis and social action are merged. (Refer to Chapter 7, "The Social Learning Metaphor." Dunn's argument that the classical or scientific notion of experiment is not applicable to the social sciences is a well-drawn one. See pp. 132-37.) 
Although the model developed in this dissertation has been labelled a collaborative one, learning is central to it. Learning from practice--an experimental approach--since we are not really sure how to "solve" our problems, and learning from one another--mutual learning-since no one person or group of persons can grasp social reality in its entirety. Learning in these two senses is essential if social problems are to be resolved. Thus, it is argued that planning must become a learning process.

Demise of the "Old" Paradigm. The conceptualization of planning as learning offers an alternative or competing paradigm; however, it is too early to predict whether it will successfully emerge as the dominant one. We do maintain that ultimately the traditional planning paradigm will be superseded.

Two reasons are offered to support this contention. Kuhn (1970, p. 110) indicates that paradigm debates always involve the question: "Which problems is it more significant to have solved?" The old paradigm of planning will fail because it does not address urban society's most significant problems. The second reason is that the old paradigm will continue to give rise to anomalies causing the crisis to continue. 01 der planners, having an investment in the traditional paradigm, are not likely to embrace a new one. However, planners new to the profession will not be committed to "the old planning.",

New paradigms, according to Kuhn, are the invention of either young persons or those new to the field ( $p .90)$. Needleman and Needleman found that community planners as a group were much younger than their colleagues in the planning department. A gap was found in lan- 
guage, tools, techniques, and educational backgrounds. Many planners spoke to the interviewers of "ol d" and the "new" planning. "There is a pervasive sense that young planners are somehow different" (p. 188). Community planning may be seen as a response to anomalies or a crisis evoked by the dominant planning paradigm, and although it competes with that paradigm, it has too many weaknesses to become the reigning one. 23 However, "new" planners will continue to be attracted to it, since presently it is one of the few alternatives available in practice.

The findings from this study of community planners support the contention that adherence to the dominant paradigm--the "old" one--is lessening among planners. Moreover, it indicates that community planners are ripe for a new paradigm.

Planning as learning offers planners another paradigm, although in its present versions it is still an incomplete formulation. However, this is to be expected, for as Kuhn claims, "The early versions of most new paradigms are crude" $(1970, p .156)$. Thus, planning as learning which is in competition with the dominant paradigm is still in "crude" form. But as more planners begin to explore this emerging paradigm--as articles and books dealing with the paradigm multiply, more

${ }^{23}$ Needleman and Needleman (1975, p. 241) refer to community planning as "parochial pluralism." Among some of its weaknesses: (1) Planning is made a part of city politics with the outcome the result of bargaining and power. (2) 1 ts tendency is toward fragmentation of efforts with each community fighting for its self-interests. (3) often the skills of the planner are not utilized. Frequently he becomes merely the spokesman or advocate for the community.

Community planning fails to meet the two criteria by which several models were evaluated earlier in this chapter. It does not take into account the objective and subjective dimensions of problems and neither does it possess the five characteristics deemed necessary to deal effectively with social problems. 
planners are likely to become convinced of its possibilities. Then theory and methods can become more developed, and the necessary institutional arrangements can be created and experimented with. Yet even when the paradigm is developed more completely, it is unlikely that older planners will embrace the new paradigm, although they may do so.

Thus, it may require a generation before a new paradigm supplants the old one and becomes the reigning one (Kuhn, p. 152).

\section{CONCLUSION}

\section{Collaborative Social Planning: Toward a New Paradigm}

This dissertation reflects a belief in the inadequacy of the old planning paradigm and represents a commitment to a new one. In this emerging paradigm planning is conceptualized as a learning process. We have pointed out that Dunn (1971), Schon (1971), Friedmann (1973), and Michael (1973) are the leading theorists who have contributed to the development of this paradigm. Drawing upon different academic backgrounds and experiences, each has approached planning from a different perspective. Yet the approach of each supports and complements the work of the others.

We too have attempted to contribute to the development of this new planning paradigm. We examined the nature of social problems and then constructed theoretical concepts and a model responsive to the nature of social problems.

After an historical consideration of how we have responded to social problems--and poverty in particular, our analysis led to the conclusion that structure as well as theory, i.e., norms, values, beliefs, 
etc., generate and maintain social problems. Therefore, it was contended that to resolve problems, planning must focus on both structure and theory.

A review of sociological theory and social problems reinforced and complemented this historical examination and analysis. Social problems were conceptualized as having both objective and subjective dimensions--both of which must be taken into account when planning to resolve social problems.

This exploration and analysis of social problems was the basis for a conceptualization of social planning that makes structural change the focus of planning efforts as well as one that requires the definitional process be incorporated into the planning process.

Assumptions about the nature of social reality, man, social interaction, knowledge, and the environment were explicated. We also set forth the premise that social planning must possess five characteristics: it must be a task-oriented, experimental, cybernetic, dialogic, and collaborative process if social problems are to be solved.

On the basis then of what we hold as "the nature" of social problems and of these five characteristics, a collaborative model was developed. This model has been compared with other planning models. Table VI summarizes our argument that only the collaborative model is in harmony with the nature of social problems, and Table VII indicates that it too is the only model that is built on the five characteristics. Moreover, when the collaborative theory and model is compared with the work of other theorists who have conceptualized planning as a process of learning, differences appear. Although each of these the- 
orists deals with planning for social change, we have emphasized social problems and the need for structural change. Dunn, Schon, Friedmann, and Michael have dealt theoretically with planning as learning, but none have developed a specific planning model based on their theory. ${ }^{24}$ This dissertation's contribution to the emerging paradigm can be seen as a twofold one: first, it offers a different theoretical basis for the emerging paradigm, and second, it provides a model--one that is consistent with the new paradigm, yet one that is in a form that is familiar to traditional planners. Our theoretical concepts and conceptual model should contribute to the articulation of a new planning paradigm.

Collaborative Social Planning and the Urban Planner

We have repeatedly touched--implicitly and explicitly--on the inability of present planning theory and practice to meet the needs of our cities. Collaborative social planning has been proposed as being more responsive to these needs. Our concluding comments will focus specifically on how the theoretical concepts and model we have presented can benefit the planner. Three ways are pointed out.

First, as has already been stated, collaborative social planning offers an end to what many have referred to as the planning dilemma. Rather than a hindrance to planning, the participation of citizens is regarded as essential to our model of planning. The resolution of social problems requires the collaboration of planner and citizens.

${ }^{24}$ Friedmann actually rejects conceptualizing planning in phases as we did for our model. He holds that action and planning are so intertwined that these steps cannot be isolated (1969, p. 312). 
The second benefit is related. Collaborative social planning not only requires citizen participation, but also that the particular expertise of the planner be utilized. Technical knowledge and skills are no less important than in the traditional paradigm, yet they are seen in a different light. It is recognized that the planner brings a unique perspective to the planning task; however, it is not the only one nor the most important, but neither is it one that can be disregarded.

And third, collaborative social planning extends the scope of planning, requiring that the significant problems of the city be dealt with. Planning truly becomes concerned with the quality of life.

Collaborative social planning has its challenges for the urban planner. It demands the development of new attitudes, new knowledge and skills. Yet it also promises the planner a great deal. It offers him a role in joining together with other persons, bringing his unique contributions to the task of planning to resolve the problems of the city--not as "a guardian of the city," but as a collaborator and facilitator in the process of creating "the good city." That is the heart of collaborative social planning. 


\section{A SELECTED BIBLIOGRAPHY}

Abrams, Charles. The City is the Frontier. New York: Harper \& Row, Publisher, $1 \overline{965}$.

Aleshire, Robert. "Planning and Citizen Participation: Costs, Benefits, and Approaches." Urban Affairs Quarterly, 5 (June, 1970): 369-93.

Altshuler, Alan A. The City Planning Process: A Political Analysis. Ithaca, N. Y.: Cornel1 University Press, 1965.

Aptheker, Herbert. "Power in America." G. William Domhoff and Hoyt B. Ballard (eds.). C. Wright Mills and the Power Elite. Boston: Beacon Press, 1968, pp. 133-64.

Archibald, K. A. "Three Views of the Expert's Role in Policymaking: Systems Analysis, Incrementalism, and the Clinical Approach." Policy Sciences, 1 (Spring, 1970): 73-86.

Arnstein, Sherry R. "Eight Rungs on the Ladder of Citizen Participation." Journal of the American Institute of Planners, 35 (July, 1969): 216-24.

Bachrach, Peter and Morton S. Baratz. Power and Poverty: Theory and Practice. New York: Oxford University Press, 1970.

Banfield, Edward C. "Ends and Means in Planning." International Social Science Journal, 11 (1959): 361-68. Co., 1970.

. The Unheavenly City Revisited. Boston: Little, Brown and Co., 1974 .

Bateman, Worth and Hochman, H. M. "Social Problems and the Urban Crisis: Can Public Policy Make a Difference?" American Economic Review, 61 (May, 1971): 346-53.

Bauer, R. "Societal Feedback." Bertram M. Gross (ed.). Social Intelligence for America's Future: Explorations in Societal Problems. Boston: Allyn and Bacon, Inc., 1969, pp. 63-77.

Becker, Howard S. "Whose Side Are We On?" Social Problems, 14 (Winter, 1967): 239-47. 
Bellush, Jewel and Murray Hausknecht (eds.). Urban Renewal: People, Politics, and Planning. Garden City, N. Y.: Doubleday, 1967.

Bennis, Warren G., Kenneth D. Benne, and Robert Chin (eds.). The Planning of Change. New York: Holt, Rinehart and Winston, 1969 .

Berger, Peter L. Invitation to Sociology: A Humanistic Perspective. Garden City, N. Y.: Doubleday \& Company, Inc., 1963.

Berger, Peter L. and Thomas Luckmann. The Social Construction of Reality. Garden City, N. Y.: Anchor Books, 1966.

Bish, Robert L. "The Assumption of Knowledge in Policy Analysis." Policy Studies Journal, 3 (Spring, 1975): 256-62.

Blau, Peter M. Bureaucracy in Modern Society. New York: Random House, Inc., 1956.

Bloomberg, Warner, Jr. and Henry J. Schmandt (eds.). Urban Poverty: Its Social and Political Dimensions. Beverly Hills, Ca.: Sage Publications, 1968 .

Blumer, Herbert. "Social Problems as Collective Behavior." Social Problems, 18 (Winter, 1971): 298-306.

- "Society as Symbolic Interaction." Arnold M. Rose (ed). Human Behavior and Social Processes. Boston: Houghton Mifflin Co., 1962, pp. 179-92.

Englewood Cliffs, N. J.: Prentice-Hal 1, Inc., 1969.

Boguslaw, Robert. The New Utopians: A Study of System Design and Social

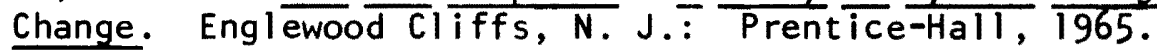

Bolan, Richard S. "Community Decision Behavior: The Culture of Planning." Journal of the American Institute of Planners, 35 (September, 1969): $301-10$.

. "Emerging Views of Planning." Journal of the American Institute of Planners, 33 (July, 1967): $233-45$.

- "Mapping and Planning Theory Terrain." David R. Godschalk (ed.). Planning in America: Learning from Turbulence.

Washington, D. C.: American Institute of Planners, 1974 , PP. 13-34.

"The Social Relations of the Planner." Journal of the

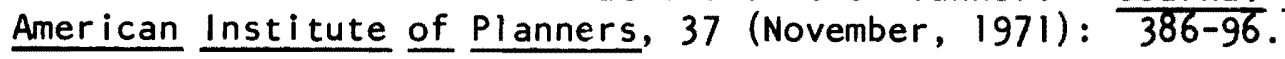

Bolan, Richard S. and Ronald L. Nuttal. Urban Planning and Politics. Lexington, Ma.: D. C. Heath and Company, 1975. 
Bolton, Charles D. "Is Sociology a Behavioral Science?" Jerome G. Manis and Bernard N. Meltzer (eds.). Symbolic Interaction: A Reader in Social Psychology. Boston: Allyn and Bacon, 1967, pp. $95-108$.

Boulding, Kenneth E. "The Boundaries of Social Policy." Social Work, 12 (January, 1967): 3-11.

Review of A Strategy of Decision: Policy Evaluation as a Social Process, by David Braybrooke and Charles E. Lindblom. American sociological Review, 6 (December, 1964): 930-31.

Brager, George A. and Francis P. Purcell (eds.). Community Action Against Poverty: Readings from the Mobilization Experience. New Haven: College and University Press, 1967.

Braybrooke, David and Charles E. Lindblom. A Strategy of Decision: Policy Evaluation as a Social Process. New York: The Free Press, 1963.

Bremner, Robert H. American Philanthropy. Chicago: The University of Chicago Press, 1960.

From the Depths: The Discovery of Poverty in the United States. New York: New York University Press, 1956.

Brewer, Garry D. Politicians, Bureaucrats, and the Consultant: A Critique of Urban Problem Solving. New York: Basic Books, $19 \overline{73}$.

Brittan, Arthur. Meanings and Situations. London and Boston: Routledge \& Kegan Paul, $1 \overline{973}$.

Brooks, Michael. Review of Participation, Planning, and Exchange in $01 \mathrm{~d}$ and New Communities: A Collaborative Paradigm, by David R. Godschalk. Journal of the American Institute of Planners, 41 (September, 1 $\overline{975): 3} \overline{59}-\overline{60}$.

- Social Planning and City Planning. Chicago: American Society of PTanning Officials, $19 \overline{970}$.

Brooks, Michael P. and Michael A. Stegman. "Urban Social Policy, Race, and the Education of Planners." Journal of the American Institute of Planners, 34 (September, 1968): 275-86.

Burke, Edmund M. "Citizen Participation Strategies." Journal of the American Institute of Planners, 34 (September, 1968): $287-94$.

Campbell, Donald T. "Reforms as Experiments." Carol H. Weiss (ed). Evaluating Action Programs: Readings in Social Action and Education. Boston: Allyn and Bacon, Inc., 1972, pp. 187-223. 
Caplow, Theodore. Toward Social Hope. New York: Basic Books, Inc., Publishers, 1975.

Caputo, David A. (ed.). General Revenue Sharing and Federal ism. The Annals of the American Academy of Political and Social Science, 419 (Mary, 1975).

Caro, Francis (ed.). Readings in Evaluative Research. New York: Russell Sage Foundation, 1971 .

Cartwright, Dorwin. "Achieving Change in People: Some Applications of Group Dynamics Theory." Gerald Zaltman et al. (eds.). Creating Social Change. New York: Holt, Rinehart and Winston, Inc., 1972, pp. 74-82.

Cartwright, T. J. "Problems, Solutions and Strategies: A Contribution to the Theory and Practice of Planning." Journal of the American Institute of Planners, 39 (May, 1973): 179-87.

Chadwick, George. A Systems View of Planning: Towards a Theory of the Urban and Regional Planning Process. New York: Pergamon Press, 1971.

Chinoy, Ely. Sociological Perspective. 2nd ed., revised and enlarged. New York: Random House, 1968.

Clark, Kenneth B. and Jeannette Hopkins. A Relevant War Against Poverty: A Study of Community Action Programs and Observable Social Change. New York: Harper \& Row, Pub Tishers, 1968.

Cohen, Percy S. Modern Social Theory. New York: Basic Books, Inc., Publishers, 1968.

Cole, Richard L. "Revenue Sharing: Citizen Participation and Social Service Aspects." The Annals of the American Academy of Political and Social Science, 419 (May, 1975): 63-74.

Commager, Henry Steele. The American Mind: An Interpretation of American Thought and Character Since the 1860's. New York: Bantam Books, 1970 .

Coser, Lewis. "Sociology of Knowledge." David L. Sills (ed.) International Encyclopedia of the Social Sciences. The MacMillan Company and The Free Press, 1968 , Volume 8, pp. 428-35.

Cox, Fred M. et al. (eds.). Strategies of Community Organization: A Book of Readings. I tasca, II.: F. E. Peacock Publishers, Inc., 1970. 
Cox, Steven R. 'Why Eradicating Urban Poverty Requires a Long Term Multi-Program 'War': A Review of Anti-Poverty Strategies for the Needs of the Late $70^{\prime} \mathrm{s} . "$ American Journal of Economics and Sociology, 34 (July, 1975): 249-65.

Dah1, Robert A. Who Governs? Democracy and Power in an American City. New Haven: Yale University Press, 1961 .

David, Stephen M. and Paul E. Peterson (eds.). Urban Politics and Public Policy: The City in Crisis. New York: Praeger Publishers, 1973.

Davidoff, Paul. "Advocacy and Pluralism in Planning." Journal of the American Institute of Planners, 31 (November, 1965)

- "Working Toward Redistributive Justice." Journal of the American Institute of Planners, 41 (September, 1975); $317-18$.

Davidoff, Paul and Thomas A. Reiner. "A Choice Theory of Planning." Journal of the American Institute of Planners, 28 (May, 1962):

Davis, Allen F. Spearheads for Reform: The Social Settlements and the Progressive Movement, $1890-1914$. New York: 0xford University Press, 1967.

Delbecq, Andre L. and Andrew H. Van de Ven. "A Group Process Model for Problem Identification and Program Planning." Journal of Applied Behavioral Science, 7 (September, 1971): 466-92.

Dentler, Robert A. American Community Problems. New York: McGrawHill Book Company, 1968.

Derr, C. Brooklyn. "Conflict Resolution in Organizations: Views from the Field of Educational Administration." Public Administration Review, 32 (September/October, 1972): 495-501.

Deutsch, Morton. "Conflicts: Productive and Destructive." Journal of Social Issues, 25 (January, 1969): 7-41.

Domhoff, G. William. "The Power Elite and Its Critics." G. William Domhoff and Hoyt B. Ballard (eds.). C. Wright Mills and the Power Elite. Boston: Beacon Press, 1968, pp. $251-78$.

Who Rules America? Englewood Cliffs, N. J.: Prentice-Hall, Inc., 1967.

Domhoff, G. William and Hoyt B. Ballard (eds.). C. Wright Mills and the Power Elite. Boston: Beacon Press, 1968.

Donovan, John C. The Politics of Poverty. New York: Pegasus, 1967. 
Dror, Yehezkel. Public Policymaking Re-examined. San Francisco: Chandler, 1968.

Duhl, Leonard J. "Planning and Poverty." Leonard J. Duhl (ed.). The Urban Condition. New York: Basic Books, Inc., 1963, pp. 29 $\overline{5-304}$.

(ed.). The Urban Condition: People and Policy in the Metropolis. New York: Basic Books, Inc., 1963.

Dunn, Edgar. Economic and Social Development: A Process of Social Learning. Baltimore: Johns Hopkins, 1971.

Durkheim, Emile. The Rules of Sociological Method. New York: The Free Press, 1964.

Dyckman, John W. "Social Planning in the American Democracy." Ernest Erber (ed.). Urban Planning in Transition. New York: Grossman Publishers, $19 \overline{70, \mathrm{pp}} . \overline{27-44}$.

- "Social Planning, Social Planners, and Planned Societies." Journal of the American Institute of Planners, 32 (March, 1966): $66-76$.

Dye, Thomas R. and L. Harmon Zeigler. The Irony of Democracy. Belmont, Ca.: Duxbury Press, 1971.

Ecklein, Joan Levin and Armand Lauffer. Community Organizers and Social Planners. New York: John Wiley $\&$ Sons, Inc., 1972.

Eldredge, H. Wentworth (ed.). Taming Megalopolis. Volumes $I$ and 11. Garden City, N. Y.: Anchor Books, 1967.

Emery, F. E. "The Next Thirty Years: Concepts, Methods, and Anticipations." Human Relations, 20 (August, 1967): 199-237.

Emery, F. E. and E. L. Trist. "The Causal Texture of Organizational Envi ronments." Human Relations, 18 (February, 1965): 21-32.

Erber, Ernest (ed.). Urban Planning in Transition. New York: Grossman Publishers, 1970.

Etzioni, Amitai. The Active Society: A Theory of Society and Political Processes. New York: The Free Press, 1968.

- 'Mixed-Scanning: A 'Third' Approach to Decisionmaking." Public Administration Review, 27 (December, 1967): 38592.

12 (Summer, 1968): 40-51. 
Etzioni, Amital. "Toward a Theory of Guided Societal Change." Louis A. Zurcher, Jr. and Charles M. Bonjean (eds.). Planned Social Intervention: An Interdisciplinary Anthology. Scranton: Chandler Publishing Company, 1970, pp. 222-27.

Erickson, E. Gordon. "Some Historical Perspectives on the Anti-Urban Bias." Jeffrey K. Hadden et al. (eds.). Metropol is in Crisis. Itasca, 11.: F. E. Peacock Publishers, Inc., 1967, pp. 176-82.

Evans, John W. "Evaluating Social Action Programs." Social Science Quarterly, 50 (December, 1969): 563-81.

Fagin, Henry. "The Evolving Philosophy of Urban Planning." Leo F. Schnore and Henry Fagin (eds.). Urban Research and Policy Planning. Beverly Hills, Ca.: Sage Publications, Inc., 1967, pp. 309-28.

Faludi, Andreas (ed.). A Reader in Planning Theory. Oxford: Pergamon Press, 1973.

Fava, Sylvia Fleis (ed.). Urbanism in World Perspective: A Reader. New York: Thomas Y. Crowell Company, 1968.

Ferrari, Art. "Social Problems, Collective Behavior and Social Policy: Propositions from the War on Poverty." Sociology and Social Research, 59 (January, 1975): 150-62.

Fine, Sidney. "The General-Welgare State in the Twentieth Century." Charles 1. Schottland (ed.). The Welfare State: Selected Essays. New York: Harper \& Row, Publishers, 1967, pp. 46-69.

Fitch, Lyle C. "Social Planning in the Urban Cosmos." Leo F. Schnore and Henry Fagin (eds.). Urban Research and Policy Planning. Beverly Hills, Ca.: Sage Publications, Inc., 1967, pp. 329-58.

Follett, Mary Parker. Dynamic Administration. New York: Harper $\varepsilon$ Brothers Publishers, 1940.

Forrester, Jay W. "Planning Under the Dynamic Influences of Complex Social Systems." Erich Jantsch (ed.). Perspectives of Planning. Paris: Organization for Economic Cooperation and Development, 1969, pp. 237-54.

Frieden, Bernard J. "Toward Equality of Urban Opportunity." Journal of the American Institute of Planners, 31 (Novermber, 1965) $\overline{320-30 .}$

. "The Changing Prospects for Social Planning." Jour$\frac{\text { nal }}{311}-\frac{2}{23}$. the American Institute of Planners, 33 (September, 1967):

Frieden, Bernard J. and Marshall Kaplan. The Politics of Neglect: Urban Aid from Model Cities to Revenue Sharing. Cambridge, Ma.: The MIT Press, 1975 . 
Frieden, Bernard J. and Robert Morris (eds.). Urban Planning and Social Policy. New York: Basic Books, 1968.

Friedmann, John. "A Conceptual Model for the Analys is of Planning Behavior." Administrative Science Quarterly, 12 (September, 1967): $225-52$.

-10 Institutional Context." Bertram M. Gross (ed.). Action under Planning: The Guidance of Economic Development. New York: McGraw-Hil1 Book Company, 1967, pp. 31-67.

. "Notes on Societal Action." Journal of the American Institute of Planners, 35 (September, 1969): $311-18$.

"Planning and the Good Society." Los Angeles: University of California, School of Architecture and Urban Planning, September, 1974. (Mimeographed)

- The Public Interest and Community Participation: Toward a Reconstruction of Public Philosophy." Journal of the American Institute of Planners, 39 (January, 1973): $2,4-7$.

. "A Response to Altshuler: Comprehensive Planning as a Process." Andreas Faludi (ed.). A Reader in Planning Theory. Oxford: Pergamon Press, 1973, pp. $2 \overline{11-15}$

- Retracking America: A Theory of Transactive Planning. Garden City, N. Y.: Anchor Press, 1973.

Friedmann, John and Barclay Hudson. "Knowledge and Action: A Guide to Planning Theory." Journal of the American Institute of Planners, 40 (January, 1974): $2-16$.

Friend, J. K. and W. N. Jessop. Local Government and Strategic Choice. London: Tavistock Publications, 1969.

Fuller, Richard C. and Richard R. Myers. "The Natural History of a Social Problem." American Sociological Review, 6 (June, 1941b): 320-29.

. "Some Aspects of a Theory of Social Problems." American Sociological Review, 6 (February, 1941a): 24-32.

Gans, Herbert J. "City Planning in America: A Sociological Analysis." (1968a). Herbert J. Gans. People and Plans. New York: Basic Books, Inc., 1968, pp. 56-77.

- "The Federal Role in Solving Urban Problems." Herbert J. Gans. People and Plans. New York: Basic Books, Inc., 1968, PP. $278-301$. 
Gans, Herbert J. "From Urbanism to Policy-Planning." Journal of the American Institute of Planners, 36 (July, 1970): $\overline{223-25}$.

\section{"The Goal-Oriented Approach to Planning." (1958a)}

Herbert J. Gans. People and Plans. New York: Basic Books, Inc., 1968, pp. 78-83.

Community Organization in Social Work: An Outsider's Perspective." Charles Grosser and Gertrude S. Goldberg (eds.). Dilemmas of Social Work Leadership: Issues in Social Policy, Planning, and Organizing. New York: Council on Social Work Education, 1974, pp. 19-38.

-1"-195emorandum on Social Planning." (1958b). Herbert J. Gans. People and Plans. New York: Basic Books, Inc., 1968, pp. 84-86.

-.---.-.-. "The Need for Planners Trained in Policy Formation." Ernest Erber (ed.). Urban Planning in Transition. New York: Grossman, 1970. tions. New York: $\frac{\text { People }}{\text { Basic Books, }} \frac{\text { Plans: }}{\text { Inc., }} \frac{\text { Essays }}{1968 .} \frac{\text { Urban }}{\text { Problems }}$ and Solu-

-Planning for Declining and Poor Cities." Journal of the American Institute of Planners, 41 (September, 1975) $1305-\overline{07}$.

-.---.-.-. "Social and Physical Planning for the Elimination of Urban Poverty." (1963). Herbert J. Gans. People and Plans, New York: Basic Books, Inc., 1968, pp. 231-48.

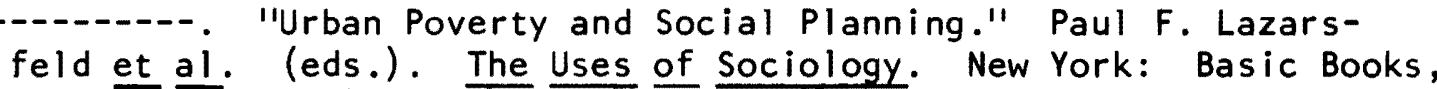
Inc., T967, pp. 437-76.

Gil, David G. Unravelling Social Policy: Theory, Analysis, and Political Action towards Social Equality. Cambridge, Ma.: Schenkman Pub1ishing Company, 1973.

Gilbert, Neil. "Assessing Service Delivery Methods: Some Unsettled Questions." Andover, Ma.: Warner Modular Publications, Inc., 1973, Reprint 483.

Godschalk, David R. "Participation: A Rejoinder." Journal of the American Institute of Planners, 42 (April, 1976): 205-06.

Participation, Planning, and Exchange in old and New Communities: A Collaborative Paradigm. Chapel Hill: Center for Urban and Regional Studies, University of North Carolina, 1972.

(ed.). Planning in America: Learning from Turbulence. Washington, $D . \overline{C .:}$ American Institute of Planners, 1974. 
Godschalk, David R, and William E. Mills. "A Collaborative Approach to Planning through Urban Activities." Journal of the American Institute of Planners, 32 (March, 1966): 86-95.

Goodman, William 1. and Eric C. Freund (eds.). Principles and Practice of Urban Planning. Washington: International City Managers'Association, 1968.

Gouldner, Alvin W. "Anti-Monotaur: The Myth of a Value-free Sociology." Social Problems, 9 (Winter, 1962): 199-213.

(The Sociologist as Partisan: Sociology and the Welfare State." The American Sociologist, 3 (May, 1968): 103-16.

Grabow, Stephen and Allan Heskin. "Foundations for a Radical Concept of Planning." Journal of the American Institute of Planners, 39 (March, 1973) 106, T08-14.

Gross, Bertram M. (ed.). Action under Planning: The Guidance of Eco-

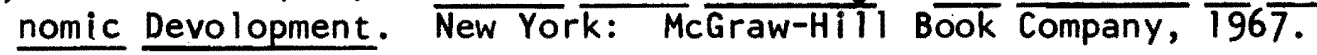

Grosser, Charles and Gertrude S. Goldberg (eds.). Dilemmas of Social Work Leadership: Issues in Social Policy, Planning, and organizing. New York: Council on Social Work Education, Inc., 1974.

Hadden, Jeffrey K., Louis H. Masotti, and Calvin J. Larson (eds.). Metropolis in Crisis: Social and Political Perspectives. Itasca, II.: F.E. Peacock PubTishers, Tnc., 1967.

Hallman, Howard W. "The Community Action Program: An Interpretative Analysis." Warner Bloomberg and Henry J. Schmandt, Jr. (eds.). Power, Poverty, and Urban Policy. Berverly Hills, Ca.: Sage Publications, 1968, pp. 285-311.

Hampden-Turner, Charles. Radical Man: The Process of Psycho-Social Development. Cambridge, Ma.: Schenkman Publishing Company, 1970.

Hancock, John L. "Planners in the Changing American City, 1900-1940." Journal of the American Institute of Planners, 33 (September, 1967): $\frac{290-304}{\text {. }}$

Harris, Britton. "The Limits of Science and Humanism in Planning." Journal of the American Institute of Planners, 33 (September, 1967): $324-35$.

-Urban Development Models: New Tools for Planners." Journal of the American Institute of Planners, 31 (May, 1965): 90-95.

Haworth, Lawrence. "Deprivation and the Good City." Warner Bloomberg, Jr. and Henry J. Schmandt (eds.). Power, Poverty, and Urban Policy. Beverly Hills, Ca.: Sage Publications, Inc., 1968, pp. 27-47. 
Heilbroner, Robert L. The Worldly Philosophers: The Lives, Times, and Ideas of the Great Economic Thinkers. New York: Simon and Schuster, Inc., 1964 .

Hightower, Henry C. "Planning Theory in Contemporary Professional Education." Journal of the American Institute of Planners, 35 (September, 1969): $326-29$.

Hill, Dilys. "Ambiguity and the Political System." University of Wisconsin: Institute for Research on Poverty, December, 1974, Reprint No. 236.

Himes, Joseph S. Social Planning in America: A Dynamic Interpretation. Garden City, N.Y.: Doubleday and Company, Inc., 1954 .

Hofstadter, Richard. The Age of Reform: From Bryan to F. D. R. New York: Vintage Books, 1955 a.

The American Political Tradition. New York: Vintage Books, 1948 .

1900-1915. Englewood Cliffs, N. J.: $\overline{\text { Prentice-Hall, Inc., } 1963 .}$

Beacon Press, $1955 \mathrm{~b}$.

Hoos, Ida R. "Systems Techniques for Managing Society: A Critique." Public Administration Review, 33 (March/April, 1973): 157-64.

Horowitz, Irving Louis. "The Sociology of Social Problems." Irving Louis Horowitz. Professing Sociology: Studies in the Life Cycle of Social Science. Chicago: Aldine Publishing Company, 1968, pp. $80-100$.

Horton, Paul B. and Gerald R. Leslie. The Sociology of Social Problems. New York: Appleton-Century, Crofts, 1970.

Hudson, Barclay M., Martin Wachs, and Joseph L. Schofer. "Local Impact Evaluation in the Design of Large-Scale Urban Systems." Journal

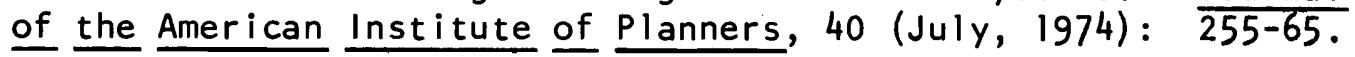

Hunter, Floyd. Community Power Structure: A Study of Decision Makers. Chapel Hili: The University of North Carolina Press, 1953.

Hyman, Herbert, "Planning with Citizens: Two Styles." Journal of the American Institute of Planners, 35 (March, 1969): $\frac{105-12}{10}$

Jacobs, Jane. The Death and Life of Great American Cities. New York: New York: Vintage Books, 1961. 
Jantsch, Erich. "Adaptive Institutions for Shaping the Future." Erich Jantsch. Perspectives of Planning. Paris: Organization for Economic Cooperation and Deve lopment, 1969, pp. 471-91.

--1ed.). Perspectives of Planning. Paris: Organization for Economic Cooperation and Development, 1969.

Jones, James A. "Federal Efforts to Solve Contemporary Social Problems." Erwin 0. Smigel (ed.). Handbook on the Study of Social Problems. Chicago: Rand McNally and Company, $\overline{1971} \frac{\text {, pp. } 547-90 .}{2}$

Kahn, Alfred J. Theory and Practice of Social Planning. New York: Russell Sage Foundation, 1969.

Kaitz, Edward M. and Herbert H. Hyman. Urban Planning for Social Welfare: A Model Cities Approach. New York: Praeger, 1970.

Kalba, Kas. "Postindustrial Planning: A Review Forward." Journal of the American Institute of Planners, 40 (May, 1974): 147-55.

Kaplan, Marshall. "Advocacy and the Urban Poor." Journal of the Ameri-

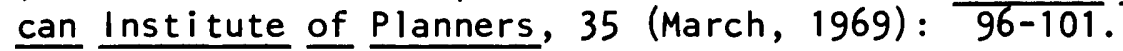

Kelman, Herbert C. 'Manipulation of Human Behavior: An Ethical Dilemma for the Social Scientist." Gerald Zaltman et al. (eds.). Creating Social Change. New York: Holt, Rinehart and Winston, Inc., 1972, pp. 574-84.

Kitsuse, John I. and Malcolm Spector. "Social Problems and Deviance: Some Parallel Issues." Social Problems, 22 (June, 1975): 584-94.

Problems: Social Conditions, Value-Judgments, and Social Problems." Social Problems, 20 (Spring, 1973): 407-19.

Knapp, Daniel and Kenneth Polk. Scouting the War on Poverty: Social Reform Policies in the Kennedy Administration. Lexington, Ma.: D. C. Heath and Company, 1971.

Kolko, Gabriel. Wealth and Power in America: An Analys is of Social Class and Income Distribution. New York: Praeger Publishers, 1962.

Kotler, Philip. "The Elements of Social Action.: Gerald Zaltman et al. (eds.). Creating Social Change. New York: Holt, Rinehart and Winston, Inc., 1972 .

Kramer, Ralph M. Participation of the Poor: Comparative Community Case Studies in the War on Poverty. Englewood Cliffs, N. J.: PrenticeHall, Inc., 1969. 
Kramer, Ralph M. and Harry Specht (eds.). Readings in Community Organization Practice. Englewood Cliffs, N. J.: Prentice-Hall, Inc., 1969.

Kravitz, Sanford. "The Community Action Program in Perspective." Warner Bloomberg, Jr. and Henry J. Schmandt (eds.). Power, Poverty, and Urban Policy. Beverly Hills, Ca.: Sage Publications, Inc., $1 \overline{968 .}$

Krieger, Martin H. "Some New Directions for Planning Theories." Journal of the American Institute of Planners, 40 (May, 1974): 156-63.

Krueckeberg, Donald A. and Arthur L. Silvers. Urban Planning Analys is: Methods and Models. New York: John Wiley \& Sons, Inc., 1974.

Krumholz, Norman, Janice M. Cogger, and John H. Linner. "The Cleveland Policy Planning Report." Journal of the American Institute of Planners, 41 (September, 1975): 298-304.

Kuhn, Thomas. The Structure of Scientific Revolutions. 2nd ed., enlarged. Chicago: The University of Chicago Press, 1970.

Lebowitz, Barry D. "Paradigms and Sociology." Portland, Or.: Portland State University, Department of Sociology. (Mimeographed, n.d.)

Lee, Douglass B., Jr. "Requiem for Large-Scale Models." Journal of the American Institute of Planners, 39 (May, 1973): 163-78.

Leiby, James. "Social Welfare: History of Basic Ideas." Encyclopedia of Social Work. Sixteenth Issue, Volume II. New York: National Association of Social Workers, 1971, pp. 1461-76.

Levine, Robert A. The Poor Ye Need Not Have with You: Lessons from the War on Poverty. Cambridge, Ma.: The MIT Press, 1970.

Levitan, Sar A. The Great Society's Poor Law: A New Approach to Poverty. Balt imore, Md.: The Johns Hopkins Press, T969.

Lewis, 0scar. "The Culture of Poverty." Scientific American, 4 (October, 1966): 19-25.

Lindblom, Charles E. The Intelligence of Democracy: Decision Making through Mutual Adjustment. New York: The Free Press, 1965.

The Policy-Making Process. Englewood Cliffs, N. J.: Prentice-Hall, Inc., 1968.

"The Science of 'Muddling Through"'. Public Administration Review, 19 (Spring, 1959): 79-88.

Lineberry, Robert L. and Ira Sharkansky. Urban Politics and Public Policy. New York: Harper \& Row, Publishers, 1971 . 
Lippitt, Ronald. "The Use of Social Research to Improve Social Practice." American Journal of Orthopsychiatry, 35 (July, 1965): 663-69.

Loewenstein, Louis K. and Cyril C. Herrman. "The San Francisco Community Renewal Program: A Summary." $H$. Wentworth Eldredge (ed.). Taming Megalopol is, Volume II. Garden City, N. Y.: Anchor Books, 1967 , pp. 798-817.

Long, Norton E. "Another View of Responsible Planning." Journal of the American Institute of Planners, 41 (September, 1975): $311-16$.

. "Citizenship or Consumership in Metropolitan Areas." Journal of the American Institute of Planners, 31 (February, 1965):

Lowi, Theodore J. The End of Liberalism. New York: W. W. Norton, 1969.

Lubove, Roy. The Professional Altruist: The Emergence of Social Work as a Career, $1880-1930$. Cambridge, Ma.: Harvard University Press, $\overline{1965}$.

Lynd, Robert S. "Power in the United States." G. William Domhoff and Hoyt B. Ballard (eds.). C. Wright Mills and the Power Elite.

Boston: Beacon Press, 1968, pp. 103-115.

Manis, Jerome G. "Assessing the Seriousness of Social Problems." Social Problems, 22 (October, 1974b): 1-15.

-The Concept of Social Problems: Vox Populi and Sociological Analysis." Social Problems, 21 (1974a): 305-15.

Manis, Jerome G. and Bernard N. Meltzer (eds.). Symbolic Interaction: A Reader in Social Psychology. Boston: Allyn and Bacon, 1967.

Mann, Lawrence D. "Social Science Advances and Planning Applications: 1900-1965." Journal of the American Institute of Planners, 38 (November, 1972): $346-58$.

March, James G. and Herbert A. Simon. Organizations. New York: John Wiley, 1958.

Marris, Peter and Martin Rein. Dilemmas of Social Reform. New York: Atherton Press, 1967.

Matson, Floyd $W$. The Broken Image: Man, Science and Society. Garden City, N. Y.: Anchor Books, 1966.

Matza, David. "The Disreputable Poor." Neil J. Smelser and Seymour Martin Lipset (eds.). Social Structure and Mobility in Economic Development. Chicago: Aldine Publishing Company, 1966, pp. 310-39. 
Mayer, Robert R. Social Planning and Social Change. Englewood Cliffs, N. J.: Prentice-Hall, Inc., 1972 .

- "Social System Models for Planners." Journal of the American Institute of Planners, 38 (May, 1972): 130-39.

Mazziotti, Donald F. "The Underlying Assumptions of Advocacy Planning: Pluralism and Reform." Journal of the American Institute of Planners, 40 (January, 1974): 40-47.

Mead, George H. Mind, Self, and Society. The University of Chicago Press, 1934.

Meltzer, Jack and Joyce Whitley. "Social and Physical Planning for the Urban Slum." Brian J. L. Berry and Jack Meltzer (eds.). Goals for Urban America. Englewood Cliffs, N. J.: Prentice-Hall, Inc., 1967 , pp. $\frac{133-52 \text {. }}{133}$

Merton, Robert K. "Social Problems and Sociological Theory." Robert K. Merton and Robert A. Nisbet (eds.). Contemporary Social Problems. 2nd ed. New York: Harcourt, Brace \& World, Inc., 1966, pp. 775823.

Meyerson, Martin and Edward C. Banfield. Politics, Planning, and the Public Interest: The Case of Public Housing in Chicago. Glencoe, 11.: Free Press, 1955 .

Michael, Donald N. On Learning to Plan--and Planning to Learn: The Social Psychology of Changing Toward Future-Responsive Societal Learning. San Francisco: Jossey-Bass Publishers, 1973.

. "Speculation on Future Process Theory." David R. Godschalk (ed.). Planning in America: Learning from Turbulence. Washington, D. C.: American Institute of Planners, 1974, pp. 3561 .

Miller, Walter B. "Lower Class Culture as a Generating Milieu of Gang Delinquency." Journal of Social Issues, 14 (1958): 5-19.

Mills, C. Wright. The Power Elite. New York: Galaxy, 1959.

"The Professional Ideology of Social Pathologists." Irving Louis Horowitz (ed.). Power, Politics, and People: The

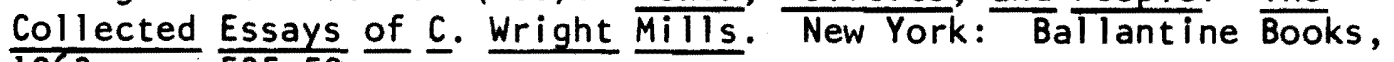
1963, pp. $\frac{525-52 .}{\text {. }}$ versity Press, 1959. 
Mogulof, Melvin B. "Coalition to Adversary: Citizen Participation in Three Federal Programs." Journal of the American Institute of Planners, 35 (July, 1969): $225-32$.

Morison, Samuel Eliot and Henry Steele Commager. The Growth of the Ameri-

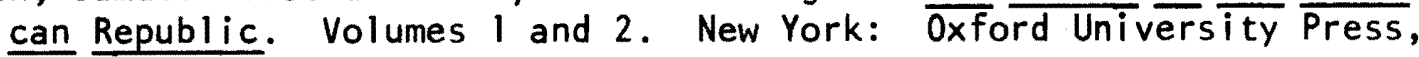
1957 .

Morris, Robert (ed.). Centrally Planned Change: Prospects and Concepts. New York: National Association of Social Workers, 1964.

Morris, Robert and Robert H. Binstock. Feasible Planning for Social Change. New York: Columbia University Press, 1966.

Morris, Robert and Martin Rein. "Emerging Patterns in Community Planning." Social Work Practice. New York: Columbia University Press, 1963, pp. 155-76.

Moynihan, Daniel P. Maximum Feasible Misunderstanding: Community Action in the War on Poverty. New York: The Free Press, 1969.

(ed.). On Understanding Poverty: Perspectives from the Social sciences. New York: Basic Books, Inc., 1969.

Myrdahl, Gunnar. Beyond the Welfare State: Economic Planning and Its International Implications. New Haven: Yale University Press, 1960 .

National Advisory Commission on Civil Disorders. Report. New York: Bantam Books, 1968.

National Commission on Urban Problems. Building the American City. Washington, D. C.: Government Printing Office, 1969.

Needleman, Martin L. and Carolyn Emerson Needleman. Guerrillas in the Bureaucracy: The Community Planning Experiment in the United States. New York: John Wiley \& Sons, 1974.

Nelson, Richard R. "Intellectualizing about the Moon-Ghet to Metaphor: A Study of the Current Malaise of Rational Analysis of Social Problems." Policy Sciences, 5 (December, 1974): 375-414.

0strom, Vincent. The Intellectual Crisis in American Public Administration. The University of Alabama Press, 1973.

Ozbekhan, Hasan. "Toward a General Theory of Planning." Erich Jantsch (ed.). Perspectives of Planning. Paris: Organization for Economic Cooperation and Development, 1969, pp. 47-155.

Pease, Otis (ed.). The Progressive Years: The Spirit and Achievement of American Reform. New York: George Braziller, Inc., 1962. 
Peattie, Lisa R. "Reflections on Advocacy Planning." Journal of the American Institute of Planners, 34 (March, 1968): 80-88.

Perlman, Robert. "Social Welfare Planning and Physical Planning." Journal of the American Institute of Planners, 32 (July, 1966): 297-304.

Perlman, Robert and Arnold Gurin. Community Organization and Social Planning. New York: John Wiley \& Sons, Inc., 1972.

Perloff, Harvey S. "Common Goals and the Linking of Physical and Social Planning." Bernard J. Frieden and Robert Morris (eds.). Urban Planning and Social Policy. New York: Basic Books, 1968, pp. 346-60.

. "New Directions in Social Planning." Journal of the American Institute of Planners, 31 (November, 1965): $\frac{297-304 .}{}$

. "Social Planning in the Metropolis." Leonard J. DuhI (ed.). The Urban Condition. New York: Basic Books, Inc., 1963, pp. $337-\overline{47}$.

Piven, Frances Fox. "Federal Intervention in the Cities: The New Urban Programs as a Political Strategy." Erwin 0. Smigel (ed.). Handbook on the Study of Social Problems. Chicago: Rand McNally and Company, $1 9 7 \overline { 1 , p p . } 5 9 \longdiv { 1 - 6 0 8 . }$

American Institute of Planners, 41 (September, 1975): $308-10$.

- "Social Planning or Politics: A Comment on the Dyckman Paper." Ernest Erber (ed.). Urban Planning in Transition. New York: Grossman Publishers, 1970, pp. 45-51.

(Whom Does the Advocate Planner Serve?" Social Policy, I (May-June, 1970): 34-41.

Piven, Frances Fox and Richard A. Cloward. Regulating the Poor: The Functions of Public Welfare. New York: Vintage Books, 1971.

Platt, John. "World Transformation: Changes in Belief Systems." The Futurist, 8 (June, 1974): 124-25.

Plotnick, Robert D. and Felicity Skidmore. Progress against Poverty: A Review of the 1964-1974 Decade. New York: Academic Press, 1975.

Polanyi, Karl. The Great Transformation. Boston: Beacon Press, 1957.

Powell, Elwin H. "The Evolution of the American City and the Emergence of Anomie: A Culture Case Study of Buffalo, New York: 1810-1910." Sylvia Fleis Fava (ed.). Urbanism in World Perspective: A Reader. New York: Thomas Y. Crowell Company, Inc., 1968, pp. 425-34. 
President's Commission on Income Maintenance Programs. Poverty Amid Plenty: The American Paradox. Washington, D. C.: U. S. Government Printing Office, 1969 .

Pumphrey, Ralph E. "Social Welfare in the United States." Harry L. Lurie (ed.). Encyclopedia of Social Work. Volume XV, 1965, pp. 19-36.

Rabinovitz, Francis. City Politics and Planning. New York: Atherton Press, 1969.

Rainwater, Lee (ed.). Social Problems and Public Policy: Deviance and Liberty. Chicago: Aldine Publishing Company, 1974.

Ranney, David C. Planning and Politics in the Metropolis. Columbus, Oh.: Charles E. Merrill Publishing Company, 1969.

Rein, Martin. "Social Planning: The Search for Legitimacy." Journal of the American Institute of Planners, 35 (July, 1969): $\frac{233-44 .}{2}$ liefs." Journal of the American Institute of Planners, 37 (September, 1971): $2 \overline{97}-\overline{310}$.

- Social Policy: Issues of Choice and Change. New York: Random House, Inc., 1970.

-1 "Social Science and the Elimination of Poverty." Journal of the American Institute of Planners, 33 (May, 1967): 146-63.

Rein, Martin and Peter Marris. 'Poverty and the Community Planner's Mandate." Bernard J. Frieden and Robert Morris (eds.). Urban Planning and Social Policy. New York: Basic Books, Inc., 1968, pp. $423-3 \overline{1}$.

Reiner, Janet S., Everett Reimer, and Thomas A. Reiner. "Client Analysis and the Planning of Public Programs." Journal of the Ameri can Institute of Planners, 29 (November, 1963): $27 \overline{0-8} \overline{2}$.

Reissman, Leonard. Inequality in American Society: Social Stratification. Glenview, 11.: Scott, Foresman and Company, 1973.

Riecken, Henry W. and Robert F. Boruch (eds.). Social Experimentation: A Method for Planning and Evaluating Social Intervention. New York: Academic Press, 1974.

Rist, Ray C. The Quest for Autonomy: A Socio-Historical Study of Black Revolt in Detroit. Los Angeles: The Center for Afro-Amer ican Studies, University of California, 1972.

Rittel, Horst W. J. and Melvin Webber. "Dilemmas in a General Theory of Planning." Policy Sciences, 4 (June, 1973): 155-69. 
Ritzer, George. "Sociology: A Multiple Paradigm Science." The American Sociologist, 10 (August, 1975): 156-67.

Rivlin, Alice M. New Approaches to Public Decision-Making. Prepared for the Economic Council of Canada, 1972.

- Systematic Thinking for Social Action. Washington, D. C.: The Brookings Institution, 1971 .

Robinson, Ira M. (ed.). Decision-Making in Urban Planning. Beverly Hills, Ca.: Sage Publications, 1972.

Rogers, Everett M. "Change Agents, Clients, and Change." Gerald Zaltman et al. (eds.). Creating Social Change. New York: Holt, Rinehart and Winston, Inc., 1972, pp. 193-213.

Rondinelli, Dennis A. "Adjunctive Planning and Urban Development Policy." Urban Affairs Quarterly, 7 (September, 1971): 13-39.

-Urban Planning as Policy Analysis: Management of Urban Change." Journal of the American Institute of Planners, 39 (January, 1973): $\frac{13-22}{13}$

Rose, Arnold M. (ed.). Human Behavior and Social Processes: An Interactionist Approach. Boston: Houghton Mifflin Co., 1962.

Ross, Robert and Graham L. Staines. "The Politics of Analyzing Social Problems." Social Problems, 20 (Summer, 1972): 18-40.

Rubington, Earl and Martin S. Weinberg (eds.). The Study of Social

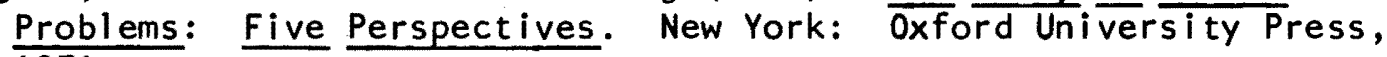
1971.

Rytina, Joan Huber, William H. Form, and John Pease. "Income and Strattification Ideology: Beliefs about the American Opportunity Structure." Journal of Sociology, 75 (January, 1970): 703-16.

Schattschneider E. E. The Semisovereign People. New York: Holt, Rinehart and Winston, 1960 .

Scheff, Thomas J. "Toward a Sociological Model of Consensus." American Sociological Review, 32 (February, 1967): 32-46.

Schein, Edgar H. Process Consultation: Its Role in Organization Development. Reading, Ma.: Addison-Westey Publishing Company, 1969.

Schnore, Leo F. "Social Problems in an Urban-Industrial Context." Social Problems, 9 (Winter, 1962): 228-40.

Schnore, Leo F. and Henry Fagin (eds.). Urban Research and Policy Planning. Beverly Hills, Ca.: Sage Publications, Inc., 1967. 
Schon, Donald A. Beyond the Stable State. New York: Random House, 1971 .

Schottland, Charles 1. (ed.). The Welfare State: Selected Essays. New York: Harper \& Row, Publishers, 1967.

Scott, Mel. American City Planning Since 1890. Berkeley: University of Cal i fornia Press, 1969 .

Schur, Edwin M. "Recent Social Problems Texts: An Essay-Review." Social Problems, 10 (Winter, 1963): 287-92.

Seashore, Stanley and Robert McNeill (eds.). The Management of Urban Crisis. New York: The Free Press, 1971.

Seaver, Robert C. "The Dilemma of Citizen Participation." Hans B. C. Spiegel (ed.). Citizen Participation in Urban Development. Volume 1. Concepts and Issues. Washington, D. C.: NTL Institute for Applied Behavioral Science, 1968, pp. 61-71.

Selznick, Philip. TVA and the Grass Roots: A Study in the Sociology of Formal Organization. Berkeley: University of California Press, 1949.

Simon, Herbert A. Models of Man: Social and Rational. New York: John Wiley, 1957.

Skinner, B. F. Beyond Freedom and Dignity. New York: A Bantam/Vintage Book, 1971 .

Skjei, Stephen S. "Urban Problems and the Theoretical Justification of Urban Planning." Urban Affairs Quarterly, 11 (March, 1976):

$323-44$.

Smigel, Erwin 0. (ed.). Handbook on the Study of Social Problems. Chicago: Rand McNally and Company, 1971.

Spiegel, Hans B. C. (ed.). Citizen Participation in Urban Development. Volumes $I$ and 11 . Washington, D. C.: NTL Institute for Applied Behavioral Science, 1968.

Spiege 1, Hans B. C. and Stephen D. Mittenthal. "The Many Faces of Citizen Participation: A Bibliographic Overview." Hans B. C. Spiegel (eds.). Citizen Participation in Urban Development. Volume I. Washington, D. C.: NTL Institute for Applied Behavioral Science, 1968, pp. 3-17.

Stagner, Ross. "Decision-Making and Conflict Resolution." Stanley E. Seashore and Robert J. McNeill (eds.). Management of the Urban Crisis. New York: The Free Press, 1971, pp. 192-233. 
Steger, Wilbur A. "Review of Analytic Techniques for the CPR." Journal of the American Institute of Planners, 31 (May, 1965): 166-72.

Suchman, Edward A. Evaluative Research: Principles and Practice in Public Service and Social Action Programs. New York: Russell Sage Foundation, 1967 .

Sundquist, James L. (ed.). On Fighting Poverty. New York: Basic Books, 1969.

Sweezy, Paul M. "Power Elite or Ruling Class?" G. William Domhoff and Hoyt B. Ballard (eds.). C. Wright Mills and the Power Elite.

Boston: Beacon Press, 1968, pp. 115-32.

Taylor, James B. "Introducing Social Innovation." The Journal of Applied Behavioral Science, 6 (1970): 69-77.

Timms, Noel. A Sociological Approach to Social Problems. New York: The Humanities Press, 1967.

Titmuss, Richard M. Commitment to Welfare. London: George Allen and Unwin Ltd., 1968.

University Press, 1959 .

Trattner, Walter 1. From Poor Law to Welfare State: A History of Social Welfare in America. New York: The Free Press, $19 \overline{74 .}$

Urban America and the Urban Coalition. One Year Later. New York: Praeger, 1969.

Valentine, Charles A. Culture and Poverty: Critique and Counter-Proposals. Chicago: The University of Chicago Press, 1968.

Van Til, Jon and Sally Bould Van Til. "Citizen Participation in Social Policy: The End of a Cycle?" Social Problems, 3 (Winter, 1970): 313-23.

Veblen, Thorstein. The Theory of the Leisure Class. New York: The New American Library, 1962 .

Vernon, Raymond. The Myth and Reality of Our Urban Problems. Cambridge, Ma.: Harvard University Press, $1 \overline{967}$.

Vollmer, Howard M. "Basic Roles for Applying Social Science to Urban and Social Problems." Urban Social Change Review, 3 (Spring, 1970): $32-33$. 
Walinsky, Adam. "Keeping the Poor in Their Place: Notes on the Importance of Being One-up." Arthur B. Shostak and William Gomberg (eds.). New Perspectives on Poverty. Englewood Cliffs, N. J.: Prentice- $\overline{\mathrm{Ha}} 1$, Inc., 1965, pp. 159-68.

Waller, Willard. "Social Problems and the Mores." American Sociological Review, 1 (December, 1936): 922-33.

Warner, W. Lloyd et al. "What Social Class Is in America." (1949) Melvin M. Tumin (ed.). Readings on Social Stratification. En-

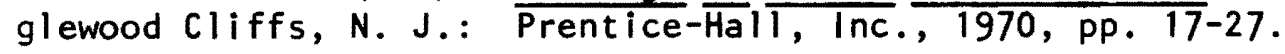

Warner, Sam Bass, Jr. (ed.). Planning for a Nation of Cities. Cambridge, Ma.: The MIT Press, 1966.

Warren, Roland L. "Model Cities First Round: Politics, Planning, and Participation." Journal of the American Institute of Planners, 35 (July, 1969): $\frac{\text { 245-52. }}{24}$

Warren, Roland L., Stephen M. Rose, and Ann F. Bergunder. The Structure of Urban Reform. Lexington, Ma.: Lexington Books, $\overline{D . C}$. Heath and Company, 1974.

Watson, Goodwin. "Resistance to Change." Gerald Zaltman et al. (eds.). Creating Social Change. New York: Holt, Rinehart and Winston, Inc., 1972, Pp. $610-18$.

Webber, Melvin M. "Comprehensive Planning and Social Responsibility." Journal of the American Institute of Planners, 29 (November, 1963): $\frac{132}{232-41}$.

-..-...- "The Prospects for Policies Planning." Leonard J. Duhl (ed.). The Urban Condition. New York: Basic Books, Inc., 1963, pp. $329-30$.

. "The Roles of Intelligence Systems in Urban Systems Planning." Journal of the American Institute of Planners, 31 (November, 1965): $289-\overline{96}$.

.Systems Planning for Social Policy." Ralph M. Kramer and Harry Specht (eds.). Readings in Community Organization Practice. Englewood Cliffs, N. J.: Prentice-Hall, Inc.,

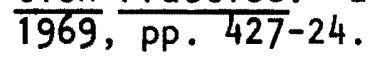

Wedge, Bryant. "A Psychiatric Model for Intercession in Intergroup Conflict." Journal of Applied Behavioral Science, 7 (November/December, $1 9 7 1 \longdiv { : 7 3 3 - 6 1 . }$

Weinberg, Martin S, and Earl Rubington. The Solution of Social Problems: Five Perspectives. New York: Oxford University Press, 1973. 
Weinberg, S. Kirson. Social Problems in Our Time: A Sociological Analysis. Englewood Cliffs, N. J.: Prentice-Hall, Inc., 1960.

Weiss, Carol H. (ed.). Evaluating Action Programs: Readings in Social Action and Education. Boston: Allyn and Bacon, Inc., 1972 .

Wholey, Joseph S. et al. Federal Evaluation Policy: Analyzing the Effects of Public Programs. Washington, $\bar{D}$. C.: The Urban Insti tute, $\frac{197}{1 .}$

Wildavsky, Aaron. "If Planning Is Everything, Maybe It's Nothing." Policy Sciences, 4 (June, 1973): 127-53.

- "The Self-Evaluating Organization." Public Administration Review, 32 (September/October, 1972): 509-20.

Wilensky, Harold L. Organizational Intelligence: Knowledge and Policy in Government and Industry. New York: Basic Books, Inc., 1967.

Wilensky, Harold L. and Charles N. Lebeaux. Industrial Society and Social Welfare. New York: The Free Press, 1965.

Will, Robert E. and Harold G. Vatter (eds.). Poverty in Affluence. New York: Harcourt, Brace \& World, Inc., 1970.

Wilson, James Q. Urban Renewal: The Record and the Controversy. Cambridge, Ma.: The MIT Press, 1966.

Wood, Elizabeth. Social Planning: A Primer for Urbanists. Brooklyn: Community Education Program, PTanning Department, Pratt Institute, 1965.

Wrong, Dennis H. "The Oversocialized Conception of Man in Modern Sociology." American Sociological Review, 26 (April, 1961): 183-93.

Wurster, Catherine Bauer. "The Dreary Deadlock of Public Housing." William L. C. Wheaton et al. (eds.). Urban Housing. New York: The Free Press, 1966, $\overline{\mathrm{pp}} . \overline{245-51 .}$

Young, Robert C. "Goals and Goal-Setting." Journal of the American Inst Itute of Planners, 32 (March, 1966): 76-85.

Zal tman, Gerald, Robert Duncan, and Jonny Holbek. Innovations and Organizations. New York: John Wiley, \& Sons, $197 \overline{3 .}$

Zaltman, Gerald, Philip Kotler, and Ira Kaufman (eds.). Creating Social Change. New York: Holt, Rinehart and Winston, Inc., $1 \overline{972}$.

Zurcher, Louis A., Jr. and Charles M. Bonjean (eds.). Planned Social Intervention: An Interdisciplinary Anthology. Scranton: ChandTer Publishing Company, 1970. 